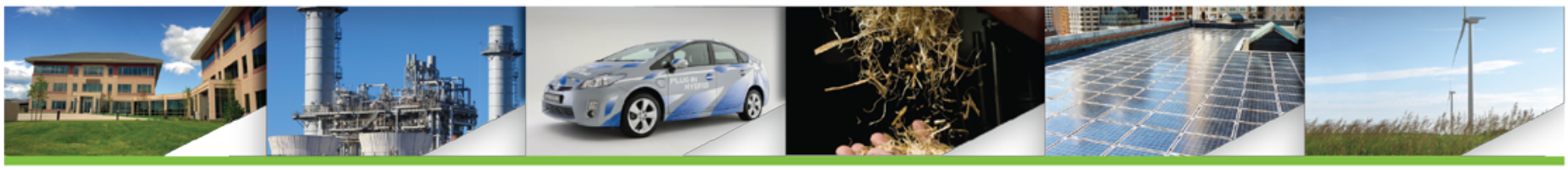

\title{
The Economic Potential of Three Nuclear-Renewable Hybrid Energy Systems Providing Thermal Energy to Industry
}

Mark Ruth, Dylan Cutler, Francisco Flores-Espino, Greg Stark, and Thomas Jenkin National Renewable Energy Laboratory

The Joint Institute for Strategic Energy Analysis is operated by the Alliance for Sustainable Energy, LLC, on behalf of the U.S. Department of Energy's National Renewable Energy Laboratory, the University of Colorado-Boulder, the Colorado School of Mines, the Colorado State University, the Massachusetts Institute of Technology, and Stanford University.

Technical Report

NREL/TP-6A50-66745

December 2016

Contract No. DE-AC36-08GO28308 


\section{The Economic Potential of Three Nuclear-Renewable Hybrid Energy Systems Providing Thermal Energy to Industry}

Mark Ruth, Dylan Cutler, Francisco Flores-Espino, Greg Stark, and Thomas Jenkin National Renewable Energy Laboratory

Prepared under Task No. SA15.1008

The Joint Institute for Strategic Energy Analysis is operated by the Alliance for Sustainable Energy, LLC, on behalf of the U.S. Department of Energy's National Renewable Energy Laboratory, the University of Colorado-Boulder, the Colorado School of Mines, Colorado State University, the Massachusetts Institute of Technology, and Stanford University.

JISEA $^{\circledR}$ and all JISEA-based marks are trademarks or registered trademarks of the Alliance for Sustainable Energy, LLC.

The Joint Institute for Strategic Energy Analysis 15013 Denver West Parkway Golden, CO 80401 303-275-3000 • www.jisea.org
Technical Report

NREL/TP-6A50-66745

December 2016

Contract No. DE-AC36-08GO28308 


\section{NOTICE}

This report was prepared as an account of work sponsored by an agency of the United States government. Neither the United States government nor any agency thereof, nor any of their employees, makes any warranty, express or implied, or assumes any legal liability or responsibility for the accuracy, completeness, or usefulness of any information, apparatus, product, or process disclosed, or represents that its use would not infringe privately owned rights. Reference herein to any specific commercial product, process, or service by trade name, trademark, manufacturer, or otherwise does not necessarily constitute or imply its endorsement, recommendation, or favoring by the United States government or any agency thereof. The views and opinions of authors expressed herein do not necessarily state or reflect those of the United States government or any agency thereof.

This report is available at no cost from the National Renewable Energy Laboratory (NREL) at www.nrel.gov/publications.

Available electronically at SciTech Connect http:/www.osti.gov/scitech

Available for a processing fee to U.S. Department of Energy and its contractors, in paper, from:

U.S. Department of Energy

Office of Scientific and Technical Information

P.O. Box 62

Oak Ridge, TN 37831-0062

OSTI http://www.osti.gov

Phone: 865.576.8401

Fax: 865.576.5728

Email: reports@osti.gov

Available for sale to the public, in paper, from:

U.S. Department of Commerce

National Technical Information Service

5301 Shawnee Road

Alexandria, VA 22312

NTIS http://www.ntis.gov

Phone: 800.553 .6847 or 703.605 .6000

Fax: 703.605.6900

Email: orders@ntis.gov

Cover Photos: (left to right) PIX 04135, iStock 22779761, PIX 16933., PIX 15648, PIX 08466, PIX 21205

NREL prints on paper that contains recycled content. 


\section{Preface}

Changes are occurring throughout the U.S. economy, especially in regards to how energy is generated and used in the electricity, buildings, industrial, and transportation sectors. These changes are being driven by environmental and energy security concerns and by economics. The electric-sector market share of natural gas and variable renewable generation, such as wind and solar photovoltaics (PV), continues to grow. The buildings sector is evolving to meet efficiency standards, the transportation sector is evolving to meet efficiency and renewable fuels standards, and the industrial sector is evolving to reduce emissions. Those changes are driving investment and utilization strategies for generation and other assets.

Nuclear and renewable energy sources are important to consider in the energy sector's evolution because both are considered to be clean and non-carbon-emitting energy sources. The Idaho National Laboratory (INL) and National Renewable Energy Laboratory (NREL) are jointly investigating potential synergies between technologies exploiting nuclear and renewable energy sources. The two laboratories have held several joint workshops since 2011. Those workshops brought together experts in both areas to identify synergies and potential opportunities to work together. Workshop participants identified nuclear-renewable hybrid energy systems (N-R HESs) as one of the opportunities and recommended investigating whether N-R HESs could both generate dispatchable electricity without carbon emissions and provide clean energy to industrial processes. The participants also recommended analyzing the potential for N-R HESs to provide dispatchable capacity to a grid with high penetrations of non-dispatchable resources and to investigate whether real inertia provided by thermal power cycles within N-R HESs provides value to the grid.

This report is one of a series of reports that INL and NREL are producing to investigate the technical and economic aspects of N-R HESs. Previous reports provided results of an analysis of two N-R HES scenarios. The first is a Texas-synthetic gasoline scenario that includes four subsystems comprising a nuclear reactor, thermal power cycle, wind power plant, and synthetic gasoline production technology. The second is an Arizona-desalination scenario with its four subsystems that include a nuclear reactor, thermal power cycle, PV, and a desalination plant. INL analyzed the technical performance of the same two N-R HESs in another report.

This report builds on that analysis. In this analysis, the Texas-synthetic gasoline scenario provides the basis; however, the industrial process is removed. Instead, the N-R HES sells heat directly to an industrial customer. We also included subsystems that convert electricity to heat, thus allowing the renewable energy subsystem to generate heat and benefit from that revenue stream.

Future analyses are planned for other N-R HES options including one where hydrogen is produced within an N-R HES. 


\section{Acknowledgments}

The authors thank the Office of Strategic Programs within the U.S. Department of Energy's (DOE's) office of Energy Efficiency and Renewable Energy (EERE) for their support of this analysis and report, and Gian Porro for his management of NREL's work for EERE's Office of Strategic Programs. The authors also thank those who originated and developed the concept of nuclear-renewable hybrid energy systems: Charles Forsberg of the Massachusetts Institute of Technology (MIT); Richard Boardman, Shannon Bragg-Sitton, Humberto Garcia, and Bob Cherry of Idaho National Laboratory (INL); and Owen Zinaman of NREL. And we acknowledge and thank the following individuals for their reviews and comments: Doug Arent of the Joint Institute for Strategic Energy Analysis (JISEA); Tom Williams of NREL; Paul Spitsen of EERE; Carl Sink of DOE's Office of Nuclear Energy (NE); and Richard Boardman and Shannon BraggSitton of INL.

This work was supported by the U.S. Department of Energy under Contract No. DE-AC3608GO28308 with the National Renewable Energy Laboratory. Funding was provided by DOE EERE's Office of Strategic Programs. 


\section{Acronyms}

\begin{tabular}{ll} 
AEO & Annual Energy Outlook \\
Btu & British thermal units \\
capex & capital expenditure \\
EPA & U.S. Environmental Protection Agency \\
FIRES & Firebrick Resistance Heated Energy Storage \\
GHG & greenhouse gas \\
HES & hybrid energy system \\
IRR & internal rate of return \\
kW & kilowatt \\
kWe & kilowatt electric \\
kWt & kilowatt thermal \\
kW-yr & kilowatt-year \\
LW-SMR & light water small modular reactor \\
mmBtu & million British thermal unit \\
MWe & megawatt electrical \\
MWh & megawatt-hour \\
MWt & megawatt thermal \\
NPV & net present value \\
N-R HES & nuclear-renewable hybrid energy system \\
NREL & National Renewable Energy Laboratory \\
O\&M & operations and maintenance \\
psig & pounds per square inch - gauge \\
PV & photovoltaics \\
REopt & Renewable Energy Optimization (planning \\
TCI & platform) \\
& total capital investment \\
& \\
\hline &
\end{tabular}




\section{Executive Summary}

The U.S. economy is evolving, especially in regard to how energy is generated and used in the electricity, buildings, industrial, and transportation sectors. Changes are being motivated by economics as well as environmental and energy security concerns. In the electric sector, market share of natural gas and variable renewable generation, such as wind and solar photovoltaic (PV), continues to grow. In the industrial sector, policy and regulatory requirements to reduce greenhouse gas (GHG) and other emissions are motivating advanced technologies. For these reasons, analysts are working to understand implications of near-term goals and identify pathways that achieve deep decarbonization. Analysts are also working to identify opportunities to provide flexibility to the grid.

Tightly coupled nuclear-renewable hybrid energy systems (N-R HESs) are a technology that can generate very low-carbon, dispatchable electricity and provide very low-carbon thermal energy for industrial processes at a lower cost than alternatives. N-R HESs are defined as systems that are managed by a single entity and link a nuclear reactor that generates heat, a thermal power cycle for heat-to-electricity conversion, at least one renewable energy source, and an industrial process that uses thermal and/or electrical energy. These hybrid configurations differ from traditional technologies that produce a single product and use a minimal number of energy sources. Because of that flexibility, N-R HESs are potentially advantageous over traditional technologies that produce a single product and use a minimal number of energy sources.

In this report, we explore a derivative of the N-R HES that does not directly support an industrial process producing a product but rather sells a thermal product (steam or a high-temperature heat transfer fluid) to one or more industrial customers, such as those found in an industrial park. We report on our analysis of the economics of three different N-R HES scenarios that could begin operations in 2035. This analysis builds upon our previous analysis of two N-R HES scenarios: one with a nuclear reactor, thermal power cycle, wind power plant, and synthetic gasoline production technology in Texas and a second with a nuclear reactor, thermal power cycle, PV, and a desalination plant in Arizona. In this analysis, the N-R HES sells heat directly to an industrial customer, including via subsystems that convert electricity to heat, thus allowing the renewable energy subsystem to generate heat and benefit from that revenue stream. In the first scenario reported here, an electric boiler that converts wind-generated electricity to heat when the price of electricity is low is evaluated. In the second scenario, the electric boiler from scenario one is replaced with an electric thermal storage unit that both converts electricity to heat and stores that heat. In the third scenario, both an electric boiler and a thermal storage unit, which is charged with heat either from the electric boiler or from the nuclear reactor, are included. The heat flow is allowed to vary from hour to hour in the first scenario to analyze a system that does not include storage but that held constant in the second and third scenarios because most customers are likely to require a consistent heat source.

We tested five hypotheses regarding the potential benefits of the N-R HES in each of the three scenarios:

1. The N-R HES configurations analyzed have the potential to be profitable to investors and are likely to be more profitable than uncoupled configurations. 
2. Using nuclear-generated heat in an N-R HES can economically reduce GHG emissions from industry. If the cost of carbon is included in economic analyses, the N-R HES would have a lower cost than competing, uncoupled, natural gas configurations.

3. N-R HESs can support resource adequacy for the electricity grid while maximizing production of an alternative product (thermal energy) if the market structures incentivize that option.

4. N-R HESs would be more profitable than uncoupled configurations because they can produce electricity when its value is high and the thermal energy product when the value of electricity is low.

5. By enabling electricity conversion to heat within N-R HESs, additional wind generation is profitable because the electricity they generate can be converted to valuable heat when the electricity price is low.

We used REopt, an energy planning platform developed by the National Renewable Energy Laboratory (NREL), to optimize the design (i.e., identify the optimal subsystem configurations) and operation of each N-R HES to maximize its net present value (NPV) over the analysis period. To optimize the design, REopt identifies the optimal configuration as the one with the most profitable set of subsystems. Under some conditions, the optimal configuration only includes one or two subsystems (e.g., the nuclear reactor) of the full N-R HES. For the base case analyses, the financial assumptions include 100\% equity, a 10\% nominal discount rate, a 3\% inflation rate, and startup in 2035. Capital and operating cost estimates come from other published analyses as described in Section 2. We generated electricity market prices using the PLEXOS production cost model with a high penetration of renewable generators (wind generators produce $21 \%$ and solar PV produce $20 \%$ of the annual electricity generation) using 2035 fuel costs. We set the thermal product price equivalent to the cost of heat from a natural gas boiler with the same financial assumptions. We varied electricity and thermal product prices to analyze their impacts on the optimal configurations and how those configurations would be operated.

Our analysis partially supports hypothesis \#1. The full N-R HES configurations for all three scenarios are projected to have positive NPVs at a $10 \%$ nominal discount rate under the base case parameters; however, the configuration with the nuclear reactor generating and selling heat exclusively is more profitable than any other configuration at the base case parameters. Table ES - 1 compares the NPV, the internal rate of return (IRR), total capital investment (TCI), and profitability ratio (NPV/TCI) of all three full N-R HES configurations. The table also shows those financial results for a nuclear reactor generating heat for sale and a nuclear reactor with a thermal power cycle that can generate electricity when the value of electricity is greater than that of heat.

Both the IRR and the NPV/TCI profitability ratios of the nuclear reactor alone $-5.8 \%$ and 0.51 , respectively - are much higher than those of the three N-R HES scenarios because the TCI of the nuclear reactor alone is much lower due to the simplicity of the configuration. In the systems analyzed here, the nuclear reactor alone receives most of the potentially available income because the value of the thermal product is higher than that of the electricity product during most of the year. The reason is that the price of electricity is set by the marginal cost of either natural gas combined-cycle generators or combustion turbines during most of the year and the value of 
electricity at those prices is lower than that of the thermal product. The IRR and NPV/TCI ratios for Scenario \#1 are higher than those for the other two scenarios because Scenario \#1 does not include additional costs necessary for the storage required to generate a constant thermal product. The flexibility to switch between heat and electricity without that requirement allows the configuration to maximize income without being constrained by the cost of additional storage. The NPV/TCI ratio of Scenario \#2 is greater than that for Scenario \#3 because the electric thermal storage unit is less expensive than the combined electric boiler and thermal storage unit.

\section{Table ES - 1. Financial Results of Three Full N-R HES Scenarios Compared to Nuclear Heat Only} Configuration and Flexible Nuclear Power Configuration

\begin{tabular}{|c|c|c|c|c|c|}
\hline Scenario & $\begin{array}{c}\text { Nuclear } \\
\text { Reactor Only }\end{array}$ & $\begin{array}{l}\text { Nuclear } \\
\text { Reactor with } \\
\text { Thermal } \\
\text { Power Cycle }\end{array}$ & $\begin{array}{c}\text { \#1 } \\
\text { Electric Boiler }\end{array}$ & $\begin{array}{c}\text { \#2 } \\
\text { Electric } \\
\text { Thermal } \\
\text { Storage }\end{array}$ & $\begin{array}{c}\text { \#3 } \\
\text { Electric } \\
\text { Boiler- } \\
\text { Thermal } \\
\text { Storage }\end{array}$ \\
\hline $\begin{array}{l}\text { Thermal } \\
\text { Production }\end{array}$ & Constant & Variable & Variable & Constant & Constant \\
\hline \multirow[t]{9}{*}{ Configuration } & $\begin{array}{l}\text { Nuclear } \\
\text { Reactor } \\
\text { (167 MWt) }\end{array}$ & $\begin{array}{l}\text { Nuclear } \\
\text { Reactor } \\
\text { (167 MWt) }\end{array}$ & $\begin{array}{l}\text { Nuclear } \\
\text { Reactor } \\
\text { (167 MWt) }\end{array}$ & $\begin{array}{l}\text { Nuclear } \\
\text { Reactor } \\
\text { (167 MWt) }\end{array}$ & $\begin{array}{l}\text { Nuclear } \\
\text { Reactor } \\
\text { (167 MWt) }\end{array}$ \\
\hline & & + & + & + & + \\
\hline & & $\begin{array}{c}\text { Thermal } \\
\text { Power Cycle } \\
\text { (50 MWe) }\end{array}$ & $\begin{array}{l}\text { Thermal } \\
\text { Power Cycle } \\
\text { (50 MWe) }\end{array}$ & $\begin{array}{c}\text { Thermal } \\
\text { Power Cycle } \\
\text { (50 MWe) }\end{array}$ & $\begin{array}{l}\text { Thermal } \\
\text { Power Cycle } \\
\text { (50 MWe) }\end{array}$ \\
\hline & & & + & + & + \\
\hline & & & $\begin{array}{c}\text { Wind Power } \\
\text { Plant } \\
\text { (50 MWe) }\end{array}$ & $\begin{array}{c}\text { Wind Power } \\
\text { Plant } \\
\text { (50 MWe) }\end{array}$ & $\begin{array}{c}\text { Wind Power } \\
\text { Plant } \\
\text { (50 MWe) }\end{array}$ \\
\hline & & & + & + & + \\
\hline & & & $\begin{array}{c}\text { Electric Boiler } \\
(50 \mathrm{MWe})\end{array}$ & Electric & $\begin{array}{l}\text { Electric Boiler } \\
\text { (100 MWe) }\end{array}$ \\
\hline & & & & Storage & + \\
\hline & & & & (50 MWe) & $\begin{array}{c}\text { Thermal } \\
\text { Storage ( } 250 \\
\text { MWh) }\end{array}$ \\
\hline NPV (\$million) & $\$ 94.4$ & $\$ 61.3$ & $\$ 43.3$ & $\$ 30.1$ & $\$ 22.2$ \\
\hline IRR & $5.8 \%$ & $2.9 \%$ & $1.6 \%$ & $1.1 \%$ & $0.8 \%$ \\
\hline TCI (\$million) & $\$ 186$ & $\$ 251$ & $\$ 340$ & $\$ 339$ & $\$ 347$ \\
\hline NPV/TCI Ratio & 0.51 & 0.24 & 0.13 & 0.09 & 0.06 \\
\hline
\end{tabular}

Our analysis partially supports hypothesis \#2. For all three scenarios, the optimal configuration is the nuclear reactor generating the thermal product exclusively. Using the nuclear reactor to produce that thermal energy would avoid the 281,000 metric tons of $\mathrm{CO}_{2}$ annually that a natural gas boiler generating the same heat would emit. We set the thermal product price at \$7.55 per million British thermal unit (MMBtu), which is the price of a competing thermal product that could be produced by a natural gas boiler that pays the 2015 Annual Energy Outlook 
reference case natural gas prices; ${ }^{1}$ however, it does not pay a cost of carbon that would have an $\mathrm{NPV}$ of $\$ 0$. At that thermal product price, the nuclear reactor has an NPV of \$94.4 million, so we project that the nuclear reactor would be more profitable than a natural gas boiler even without a cost of carbon. With a $\$ 20 /$ metric ton carbon dioxide-equivalent $\left(\mathrm{CO}_{2} \mathrm{e}\right)$ cost of carbon, the NPV for the natural gas boiler is negative at $-\$ 82$ million. With NPVs of $\$ 43.3$ million, $\$ 30.1$ million, and \$22.2 million for the three full N-R HES configurations respectively, all of the N-R HES scenarios are found to have a higher rate of return than a natural gas boiler at the base case prices.

Our analysis partially supports hypothesis \#3. N-R HESs can support resource adequacy for the electricity grid while maximizing production of the thermal energy product if the market structures incentivize that option. Unlike the configurations with only a nuclear reactor, the optimal configurations of each N-R HES could receive a capacity payment at high electricity prices and low thermal product prices. Scenarios \#2 and \#3 could receive capacity payments in a price range with a higher thermal product price because the combination of capacity payments and the value of electrical energy are sufficient for the thermal power cycle but the value of the thermal product is not so high that electricity would optimally be converted to heat.

Our analysis partially supports hypothesis \#4. N-R HESs would have a higher rate of return than uncoupled configurations because they can produce electricity when its price is high and the thermal product when the price of electricity is low. The optimal configurations are capable of providing that flexibility when the electricity price is high and/or the thermal product price is high but do not include it with the base case electricity and thermal prices.

Our analysis partially supports hypothesis \#5. Additional wind generation would be profitable because the wind-generated electricity can be converted to heat during hours when the electricity price is low as long as the thermal product price is high and the annual average electricity price is not too low. In all three scenarios, the thermal product price had to be at least $\$ 15.00$ \$19.00/MMBtu before the optimal configurations included additional wind power plants at electricity costs below the costs when wind power was profitable based solely on electric generation. Wind power appeared in the optimal configuration whenever the annual average electric price was more than $\sim 1.25$ times the projected annual average electricity price, yet under the high thermal product price referenced above; wind power would appear in the optimal solution at electricity prices such that the annual average electricity price is as low as $0.95-1.0$ of the projected annual average electricity price. Thus, the hypothesis is supported in those ranges, but not when prices are closer to the reference prices for the thermal product.

This analysis shows that N-R HES configurations could be profitable, primarily due to the fact that the projected cost of nuclear generation of heat is less than natural gas generation cost projections under the analysis assumptions. Nuclear generation of heat does not emit carbon dioxide so, with a cost of carbon, it would be more economical than natural gas generation. Even though nuclear generation of the thermal product exclusively is the optimal configuration at the base case electricity and thermal product prices, the benefits of the N-R HES's flexibility are apparent at higher electricity and thermal product prices. That flexibility allows the conceptual N-R HES to support resource adequacy on the grid if capacity payments are sufficient. Flexibility also allows the N-R HES to maximize profitability by switching between products depending upon the value of each product. 


\section{Table of Contents}

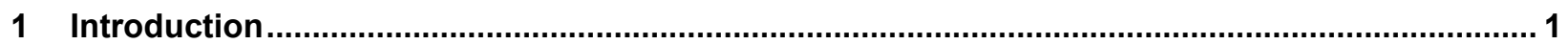

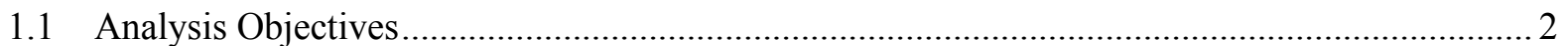

1.2 Nuclear-Renewable Hybrid Energy Systems Analyzed ........................................................... 3

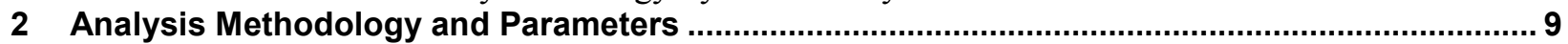

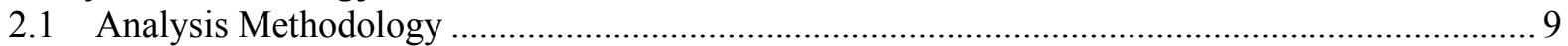

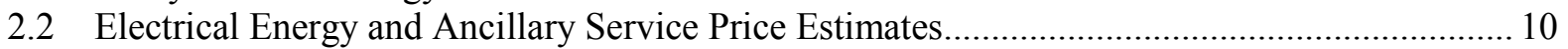

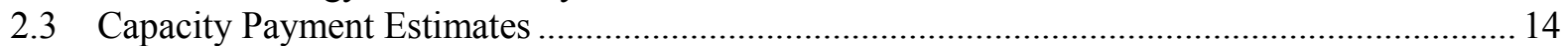

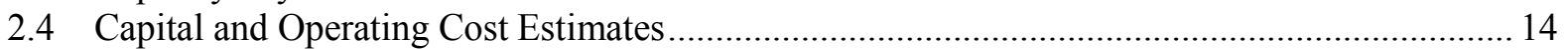

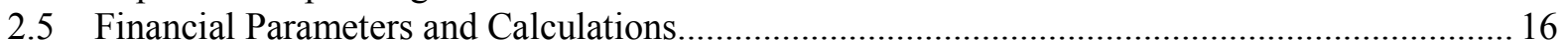

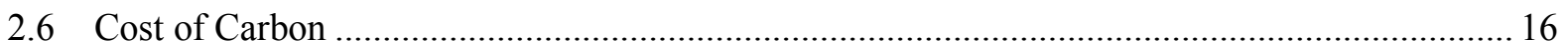

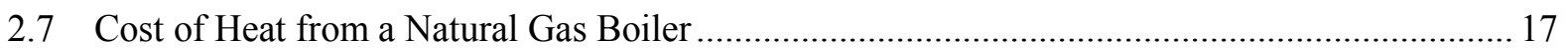

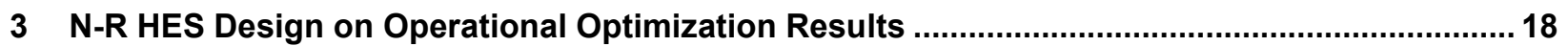

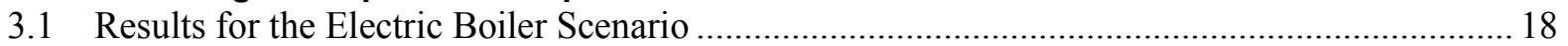

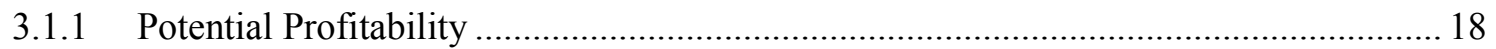

3.1.2 Potential to Reduce GHG Emissions and their Associated Costs ................................. 27

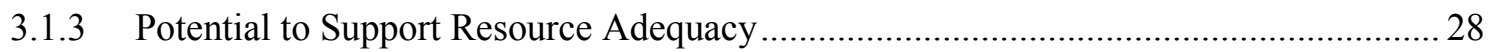

3.1.4 Potential for Flexibility to Increase Profitability ....................................................... 31

3.1.5 Potential for Electricity-to-Heat Conversion to Increase Wind Capacity ...................... 31

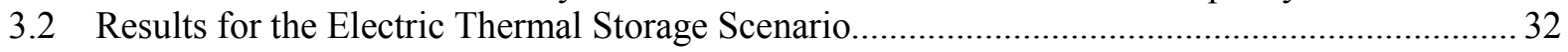

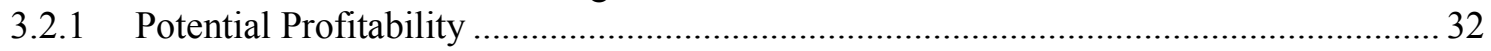

3.2.2 Potential to Reduce GHG Emissions and their Associated Costs ................................... 45

3.2.3 Potential to Support Resource Adequacy ............................................................. 45

3.2.4 Potential for Flexibility to Increase Profitability .......................................................... 48

3.2.5 Potential for Electricity-to-Heat Conversion to Increase Wind Capacity ...................... 48

3.3 Results for the Electric Boiler-Thermal Storage Scenario .................................................... 49

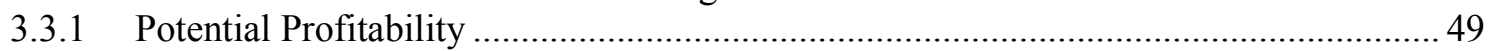

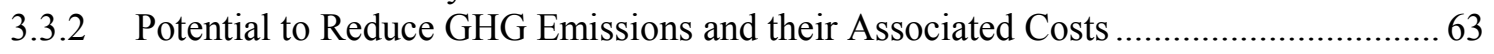

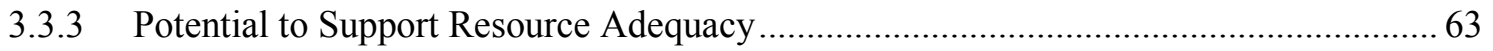

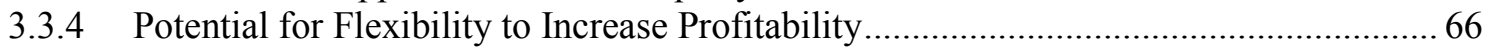

3.3.5 Potential for Electricity-to-Heat Conversion to Increase Wind Capacity ....................... 66

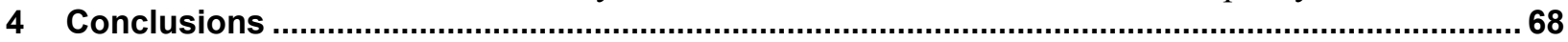

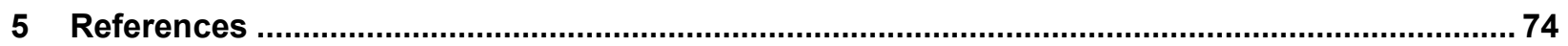

\section{List of Figures}

Figure 1. N-R HES Scenario \#1: The electric boiler converts wind-generated electricity to thermal energy

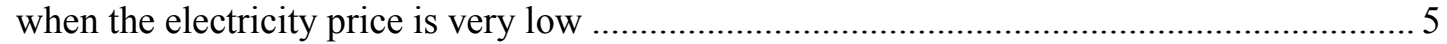

Figure 2. N-R HES Scenario \#2: The electric thermal storage unit both converts wind-generated electricity to thermal energy when the electricity price is very low and stores that energy so

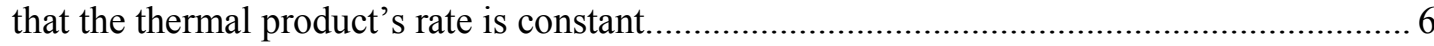

Figure 3. N-R HES Scenario \#3: The electric boiler converts electricity to thermal energy when the electricity price is very low. The thermal storage unit stores thermal energy from both the nuclear reactor and the electric boiler. The thermal product's rate is constant...................... 8

Figure 4. Optimal configurations for the Electric Boiler Scenario with a capacity payment of $\$ 50 / \mathrm{kW}-\mathrm{yr} 20$ Figure 5. Optimal annual product generation for the Electric Boiler Scenario at various heat prices and

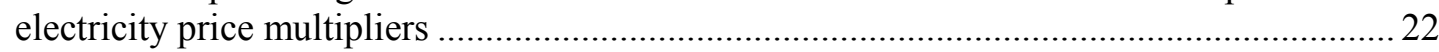

Figure 6. Optimal capacity payments awarded for the Electric Boiler Scenario at various heat prices and

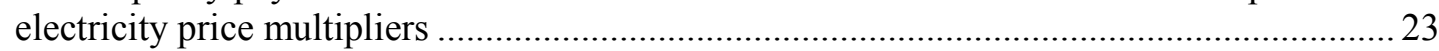

Figure 7. Electric Boiler Scenario NPVs at various heat prices and electricity price multipliers.............. 24 
Figure 8. Optimal configurations for the Electric Boiler Scenario at various heat prices and electricity price multipliers at three levels of capacity payments ..................................................... 29

Figure 9. Optimal capacity payments awarded for the Electric Boiler Scenario at various heat prices and electricity price multipliers at three levels of capacity payments ........................................ 30

Figure 10. Optimal annual electricity production for Electric Boiler Scenario at various heat prices and electricity price multipliers at three levels of capacity payments ......................................... 31

Figure 11. Optimal configurations for the Electric Thermal Storage Scenario at various heat prices and

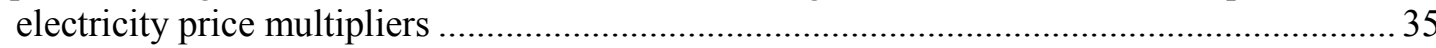

Figure 12. Optimal constant thermal product generation rate for the Electric Thermal Storage Scenario at various heat prices and electricity price multipliers ............................................................. 36

Figure 13. Optimal thermal storage capacity for the Electric Thermal Storage Scenario at various heat

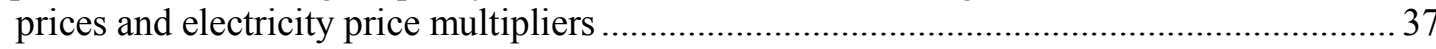

Figure 14. Optimal capacity of wind power plants for the Electric Thermal Storage Scenario at various heat prices and electricity price multipliers ................................................................... 38

Figure 15. Optimal annual product generation for the Electric Thermal Storage Scenario at various heat prices and electricity price multipliers ................................................................................ 39

Figure 16. Optimal capacity payments awarded for the Electric Thermal Storage Scenario at various heat

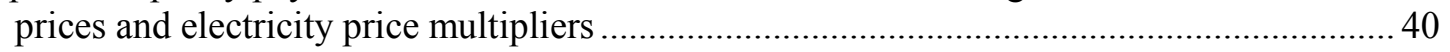

Figure 17. Electric Thermal Storage Scenario NPVs at various heat prices and electricity price multipliers41

Figure 18. Optimal configurations for the Electric Thermal Storage Scenario at various heat prices and electricity price multipliers at three levels of capacity payments ........................................ 46

Figure 19. Optimal capacity payments awarded for the Electric Thermal Storage Scenario at various heat prices and electricity price multipliers at three levels of capacity payments ......................... 47

Figure 20. Optimal annual electricity production for Electric Thermal Storage Scenario at various heat prices and electricity price multipliers at three levels of capacity payments .......................... 48

Figure 21. Optimal configurations for the Electric Boiler-Thermal Storage Scenario at various heat prices

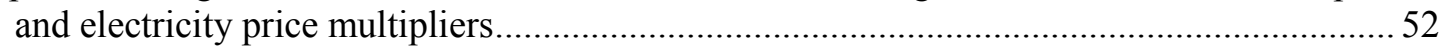

Figure 22. Optimal constant thermal product generation rate for the Electric Boiler-Thermal Storage Scenario at various heat prices and electricity price multipliers ........................................ 53

Figure 23. Optimal thermal storage capacity for the Electric Boiler-Thermal Storage Scenario at various heat prices and electricity price multipliers ................................................................. 54

Figure 24. Optimal capacity of wind power plants for the Electric Boiler-Thermal Storage Scenario at various heat prices and electricity price multipliers ....................................................... 55

Figure 25. Optimal annual product generation for the Electric Boiler-Thermal Storage Scenario at various

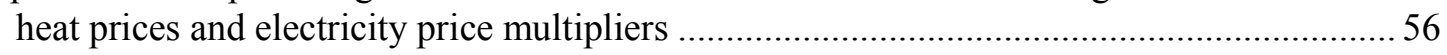

Figure 26. Optimal capacity payments awarded for the Electric Boiler-Thermal Storage Scenario at various heat prices and electricity price multipliers......................................................... 57

Figure 27. Electric Boiler-Thermal Storage Scenario NPVs at various heat prices and electricity price

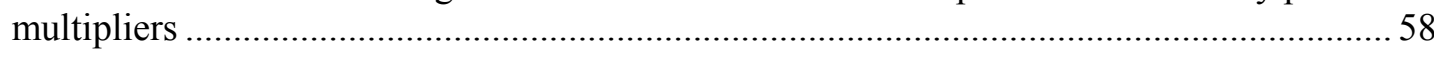

Figure 28. Optimal configurations for the Electric Boiler-Thermal Storage Scenario at various heat prices and electricity price multipliers at three levels of capacity payments.................................. 64

Figure 29. Optimal capacity payments awarded for the Electric Boiler-Thermal Storage Scenario at various heat prices and electricity price multipliers at three levels of capacity payments.... 65

Figure 30. Optimal annual electricity production for Electric Boiler-Thermal Storage Scenario at various heat prices and electricity price multipliers at three levels of capacity payments .................. 66

Figure 31. Optimal capacity payments awarded for the three scenarios at various heat prices and electricity price multipliers at $\$ 50 / \mathrm{kW}$-yr capacity payments

Figure 32. Optimal annual electricity production for the three scenarios at various heat prices and electricity price multipliers at $\$ 50 / \mathrm{kW}$-yr capacity payments 


\section{List of Tables}

Table ES - 1. Financial Results of Three Full N-R HES Scenarios Compared to Nuclear Heat Only

Configuration and Flexible Nuclear Power Configuration .....................................................viii

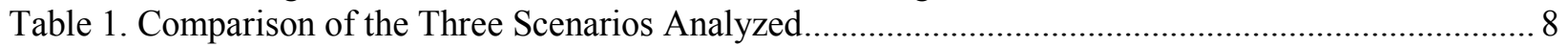

Table 2. Breakdown of Electrical Energy Costs in PJM...................................................................... 12

Table 3. Capital and Operating Costs for Subsystems in Previous Analysis ............................................ 15

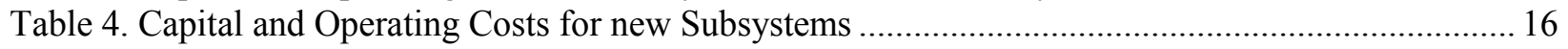

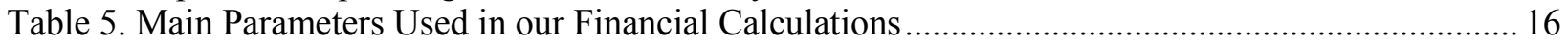

Table 6. Social Costs of Carbon Emissions in 2035 (\$/metric ton $\left.\mathrm{CO}_{2} \mathrm{e}\right)$............................................. 17

Table 7. Electric Boiler Scenario Present Values at Base Case Conditions for Four Configurations ........ 25

Table 8. Electric Boiler Scenario Output Summary at Base Case Conditions for Four Configurations..... 26

Table 9. Financial Comparison Between Nuclear-Only Configuration and Natural Gas Boiler ............... 27

Table 10. Financial Comparison between Nuclear-Generated Heat and Heat Generated Using Natural Gas Including Costs of Carbon ......................................................................................... 28

Table 11. Electric Thermal Storage Scenario Present Values at Base Case Conditions for Four Configurations

Table 12. Electric Thermal Storage Scenario Output Summary at Base Case Conditions for Four Configurations

Table 13. Electric Boiler-Thermal Storage Scenario Present Values at Base Case Conditions for Four Configurations.

Table 14. Electric Boiler-Thermal Storage Scenario Output Summary at Base Case Conditions for Four Configurations.

Table 15. Financial Results of Three Full N-R HES Scenarios Compared to Nuclear-Heat Only Configuration and Flexible Nuclear Power Configuration 70 


\section{Introduction}

Nuclear-renewable hybrid energy systems (N-R HESs) are a potential technology that can generate very low-carbon, dispatchable electricity and provide very low-carbon thermal energy to industry and may be able to do so at a lower cost than alternatives. ${ }^{2} \mathrm{~N}-\mathrm{R}$ HESs are defined as co-managed systems that link a nuclear reactor that generates heat, a thermal power cycle for heat-to-electricity conversion, at least one renewable energy source, and an industrial process that uses thermal and/or electrical energy. As co-managed systems, they are operated as if they are owned by a single entity; thus, they have a common objective that is usually overall profit. These hybrid configurations differ from traditional technologies that produce a single product and use a minimal number of energy sources. In this report, we alter the definition of the N-R HES so that it does not directly include an industrial process but rather sells a thermal product (steam or a high-temperature heat transfer fluid) to one or more industrial customers such as those found in an industrial park. N-R HESs can provide a number of potential societal benefits: ${ }^{3}$

1. Dispatchable, flexible, very low-carbon electricity generation that can support adequate resources on the grid

2. Reduced greenhouse gas (GHG) emissions in the industrial sector

3. Synchronous electro-mechanical (real) inertia that supports the grid

4. Alleviation of the impacts of electricity price suppression at high penetration of low marginal cost generation (e.g., nuclear and renewables).

In tightly coupled N-R HESs, all subsystems are directly coupled (i.e., linked to one another without regularly operated connections to outside entities such as the grid or thermal customers) behind a single bus to the grid. Investment and operational decisions of a tightly coupled N-R HESs are made by a single financial entity.

In previous work, we analyzed the potential financial performance of two tightly coupled N-R HESs: one with a nuclear reactor, thermal power cycle, wind power plant, and synthetic gasoline production technology in Texas and a second with a nuclear reactor, thermal power cycle, photovoltaic (PV) solar power plant, and a desalination plant in Arizona. ${ }^{4}$ In that analysis, we focused on the economics of the two N-R HESs - how they compare to other options, including configurations without all the subsystems in each N-R HES and alternatives in which natural gas combustion provides the thermal energy.

In this analysis, we adapted the Texas N-R HES by removing the natural-gas-to-syntheticgasoline subsystem. Instead, an independent customer or set of customers (as may be found in an industrial park) purchases the thermal energy. We also included the option to convert wind power to thermal energy so electrical energy from the wind power plant and energy from the nuclear reactor can be sold in both thermal and electrical forms. In addition, we included the option to store thermal energy generated by the nuclear reactor, from electricity generated by the wind power plant, or grid electricity. Including thermal energy storage provides a constant flow of thermal energy, enabling the consumer(s) to operate at steady state.

In this report, we discuss our analysis of three different N-R HES scenarios. Each provides thermal energy. In the first scenario, the heat flow varies from hour to hour because we did not include thermal storage in that scenario. In the second and third scenarios, the heat flow remains 
constant to allow the heat consumers to operate at steady state as we envision most consumers would prefer. The first scenario includes an electric boiler so that wind-generated electricity can produce heat when the price of electricity is low. The second scenario also allows heat to be produced using electricity but it differs from the first scenario because the thermal energy can be stored and used as needed. The third scenario adds to the first scenario by allowing thermal storage from both the nuclear-generated thermal heat and wind-generated electricity.

Because none of the N-R HES scenarios analyzed here includes an industrial process, its capital cost is much lower than the synthetic gasoline N-R HES analyzed in Ruth et al. (2016). ${ }^{5}$ Without that capital cost, the N-R HES has more financial flexibility, which may result in optimal N-R HES configurations that are more flexible than in the scenarios analyzed previously.

This section describes the analysis objectives and the three N-R HESs that we examined.

\subsection{Analysis Objectives}

This analysis focuses on determining whether the benefits of N-R HESs are likely to overcome their increased cost and complexity relative to independent configurations. We focused the analysis on value to the investors but considered the value of N-R HESs to society as a secondary objective. We did not evaluate N-R HES market impacts (such as ability to support greater penetrations of variable renewable electricity generation) or evolution (i.e., investment drivers and decision timing). Those issues are outside the scope of this analysis.

We tested five hypotheses regarding the potential benefits of the N-R HES in each of the three scenarios:

1. The N-R HES configurations analyzed have the potential to be profitable to investors and are likely to be more profitable than uncoupled configurations.

2. Using nuclear-generated heat in an N-R HES can economically reduce GHG emissions from industry. If a cost of carbon is included in economic analyses, the N-R HES would have a lower cost than competing uncoupled natural gas configurations.

3. N-R HESs can support resource adequacy for the electricity grid while maximizing production of an alternative product (thermal energy) if the market structures incentivize that option.

4. N-R HESs would be more profitable than uncoupled configurations because they can produce electricity when its value is high and the thermal energy product when the value of electricity is low.

5. By enabling electricity conversion to heat within N-R HESs, additional wind generation is profitable because the electricity they generate can be converted to valuable heat when the electricity price is low.

We chose to consider value to investors as the primary objective for several reasons. The key reason is that, if there is no value for investors under projected futures, the technology is unlikely to be built and would not affect the grid or benefit society. Second, if there is value, especially if that value is great, many N-R HESs are likely to be built and competition between the N-R HESs is likely to drive down the price of electricity and/or the thermal energy provided to industry while still providing sufficient profits to incentivize these generation resources. Reducing those 
prices would benefit society by providing lower-cost resources. Third, we decided not to attempt to create a pricing strategy that allocates costs between multiple products because of the uncertainty of such a strategy.

The second and third hypotheses listed above are intended to provide some information on potential societal impacts. We compared the N-R HESs to uncoupled configurations that use natural gas to provide heat to determine impacts on GHG emissions and monetized those impacts using a cost of carbon. Even though we did not explicitly model resource adequacy in our optimizations, we addressed the issue by including a capacity payment and the flexibility to meet capacity while primarily producing thermal energy.

The fourth hypothesis focuses on investor motivation. It explores whether the N-R HESs' flexibility to shift between products based on the variability in electricity prices results in increased profitability.

The fifth hypothesis focuses on the ability of additional products (heat within this analysis) to increase the penetration of variable renewable generation (wind power here). It is one aspect of the potential ability of N-R HESs to alleviate the impacts of electricity price suppression at high penetration of low marginal cost generation.

\subsection{Nuclear-Renewable Hybrid Energy Systems Analyzed}

N-R HESs are systems managed by a single entity that link a nuclear reactor that generates heat, a thermal power cycle for heat-to-electricity conversion, at least one renewable energy source, and an industrial process that uses thermal and/or electrical energy. For this effort, we alter the definition of the N-R HES so that it does not directly include an industrial process but rather sells a thermal product (steam or a high-temperature heat transfer fluid) to one or more industrial customers such as those found in an industrial park. To perform the analysis, we adapted the Texas N-R HES that we analyzed previously. ${ }^{6}$ We removed the natural-gas-to-synthetic-gasoline subsystem and replaced it with sales of the thermal energy to an independent customer or set of customers as might be in an industrial park. We also added the option to convert wind power to thermal energy so that energy from both the wind power plant and the nuclear reactor can be sold in both thermal and electrical forms. In addition, we added an option to store thermal energy from any source: nuclear-generated, electricity generated by the wind power plant, or grid electricity. Including thermal energy storage enables the N-R HES to provide a constant flow of thermal energy, enabling the customer or customers to operate at steady state.

We chose three scenarios for this analysis. Each includes a light water small modular nuclear reactor (LW-SMR), a thermal power cycle that converts nuclear-generated thermal energy to electricity, a wind power plant, and equipment to convert electricity to thermal energy (e.g., an electric boiler). The scenarios differ in whether they include thermal energy storage and whether the storage unit can store thermal energy from both the nuclear subsystem and electricity or only electricity-generated thermal energy. The scenarios also differ in whether the system provides the thermal product at a constant rate or if it varies over time, forcing the user of that thermal energy to either ramp or have a backup thermal generation system. Many industries such as chemical plants, metallurgical plants, and petroleum refineries run continuous flow systems and thus require a constant heat source. Other industrial users such as food processors may be able to operate when heat is available. 
Figure 1 shows the first scenario's full configuration. This N-R HES includes an electrical boiler that converts the wind electricity to thermal energy. We assume that the thermal product's generation does not need to be constant.

For this scenario, we identified the optimal configuration from eight options under various electricity price vectors and thermal energy prices:

- The nuclear reactor produces only thermal energy.

- The nuclear reactor and thermal power cycle produce electricity, possibly in conjunction with thermal energy.

- The wind power plant produces only electricity.

- The wind power plant and electric boiler produce thermal energy, possibly in conjunction with electricity sold to the grid.

- The nuclear reactor produces only thermal energy and the wind power plant produces only electricity.

- The nuclear reactor and thermal power cycle (balance of plant) produce electricity, possibly in conjunction with thermal energy, and the wind power plant produces electricity.

- The nuclear reactor produces only thermal energy and the wind power plant and electric boiler produce thermal energy, possibly in conjunction with electricity sold to the grid.

- The nuclear reactor and thermal power cycle (balance of plant) produce electricity, possibly in conjunction with thermal energy, and the wind power plant and electric boiler produce thermal energy, possibly in conjunction with electricity sold to the grid. This configuration is the full N-R HES. 


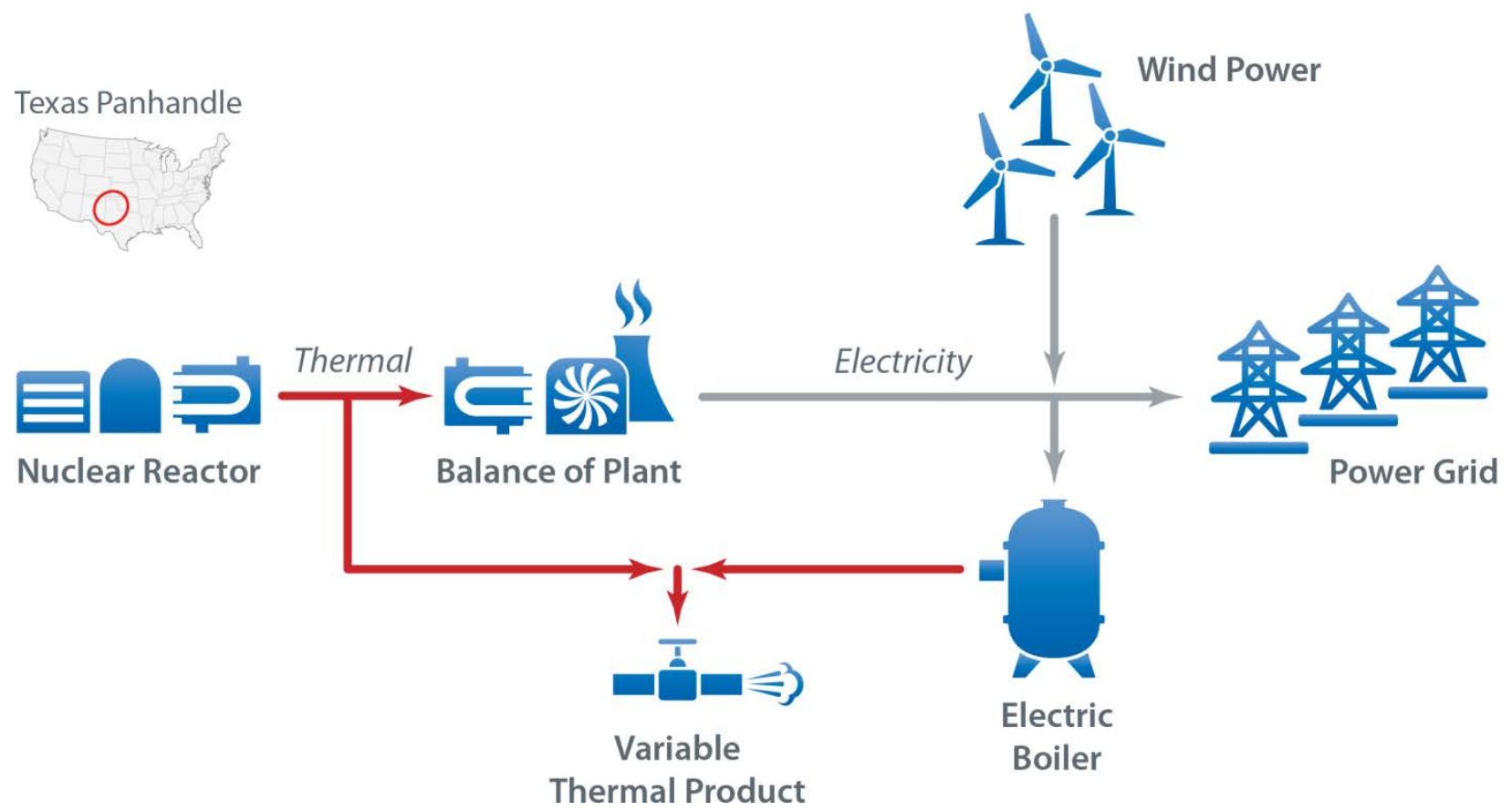

Figure 1. N-R HES Scenario \#1: The electric boiler converts wind-generated electricity to thermal energy when the electricity price is very low

Red arrows indicate flow of thermal energy and gray arrows indicate electricity

Figure 2 shows the second scenario's full configuration. In Scenario 2, we replaced the electric boiler in Scenario 1 with an electric thermal storage unit - a unit operation that both converts electricity to thermal energy and stores that thermal energy. Because the electric thermal storage unit can store thermal energy, we allowed it to use grid electricity in addition to wind-generated electricity so that the storage unit is not sized to provide a constant flow during the longest periods without wind. The thermal product is constant instead of ramping as in the first scenario because the storage can absorb the variability of generation.

We based the electric thermal storage unit on Firebrick Resistance Heated Energy Storage (FIRES) as proposed by Charles Forsberg and his colleagues. ${ }^{7}$ The FIRES concept consists of a ceramic firebrick storage medium of relatively high heat capacity and density and a maximum operating temperature of approximately $1,800^{\circ} \mathrm{C}$. We chose ceramic firebrick because of its low estimated cost, high durability, and large sensible heat storage capacities. The firebrick is "charged" using resistance heating when the price of electricity is low. Multi-layer insulation surrounds the firebrick and allows for thermal expansion. The system is expected to be similar to high-temperature firebrick industrial recuperators. Some parts of the world use a similar technology for home heating, although they are much smaller units. Alternatively, the firebrick could be heated directly by thermal energy from the nuclear reactor. Evaluation of that alternative is outside the scope of this analysis.

For Scenario 2, we identified the optimal configuration from eight options under various electricity price vectors and thermal energy prices:

- The nuclear reactor produces only thermal energy. 
- The nuclear reactor and thermal power cycle (balance of plant) produce electricity, possibly in conjunction with thermal energy.

- The wind power plant produces only electricity.

- The wind power plant and electric thermal storage device produce thermal energy, possibly in conjunction with electricity sold to the grid.

- The nuclear reactor produces only thermal energy and the wind power plant produces only electricity.

- The nuclear reactor and thermal power cycle (balance of plant) produce electricity, possibly in conjunction with thermal energy, and the wind power plant produces electricity.

- The nuclear reactor produces only thermal energy and the wind power plant and electric thermal storage produces thermal energy, possibly in conjunction with electricity sold to the grid.

- The nuclear reactor and thermal power cycle (balance of plant) produce electricity, possibly in conjunction with thermal energy, and the wind power plant and electric thermal storage unit produce thermal energy, possibly in conjunction with electricity sold to the grid. This configuration is the full N-R HES.

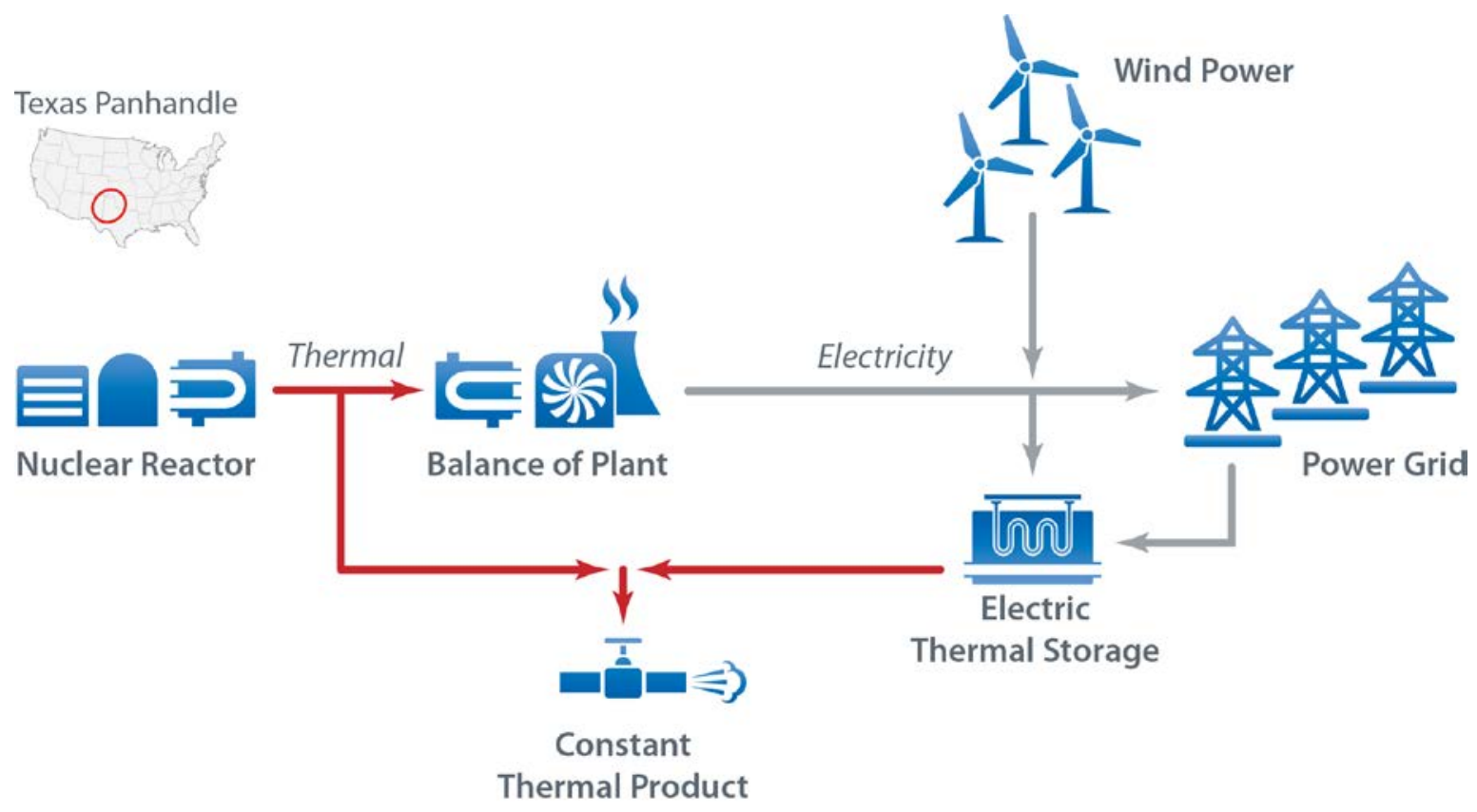

Figure 2. N-R HES Scenario \#2: The electric thermal storage unit both converts wind-generated electricity to thermal energy when the electricity price is very low and stores that energy so that the thermal product's rate is constant.

Red arrows indicate flow of thermal energy and gray arrows indicate electricity 
Figure 3 shows the third scenario's full configuration. The third scenario builds upon both the first and second scenarios. In Scenario 3, we used the boiler from the first scenario to convert both wind-generated and grid electricity to thermal energy. A molten salt thermal storage unit is also included. Unlike the second scenario, we used a thermal storage unit that can store thermal energy from either the electric boiler or the nuclear reactor. Like the second scenario, we held the thermal product constant.

For Scenario 3, we identified the optimal configuration from eight options under various electricity price vectors and thermal energy prices:

- The nuclear reactor produces only thermal energy.

- The nuclear reactor and thermal power cycle (balance of plant) produce electricity, possibly in conjunction with thermal energy.

- The wind power plant produces only electricity.

- The wind power plant and electric thermal storage device produce thermal energy, possibly in conjunction with electricity sold to the grid.

- The nuclear reactor produces only thermal energy and the wind power plant produces only electricity.

- The nuclear reactor and thermal power cycle (balance of plant) produce electricity, possibly in conjunction with thermal energy, and the wind power plant produces electricity.

- The nuclear reactor produces only thermal energy and the wind power plant and electric thermal storage device produce thermal energy, possibly in conjunction with electricity sold to the grid.

- The nuclear reactor and thermal power cycle (balance of plant) produce electricity, possibly in conjunction with thermal energy, and the wind power plant and electric thermal storage unit produce thermal energy, possibly in conjunction with electricity sold to the grid. This configuration is the full N-R HES. 


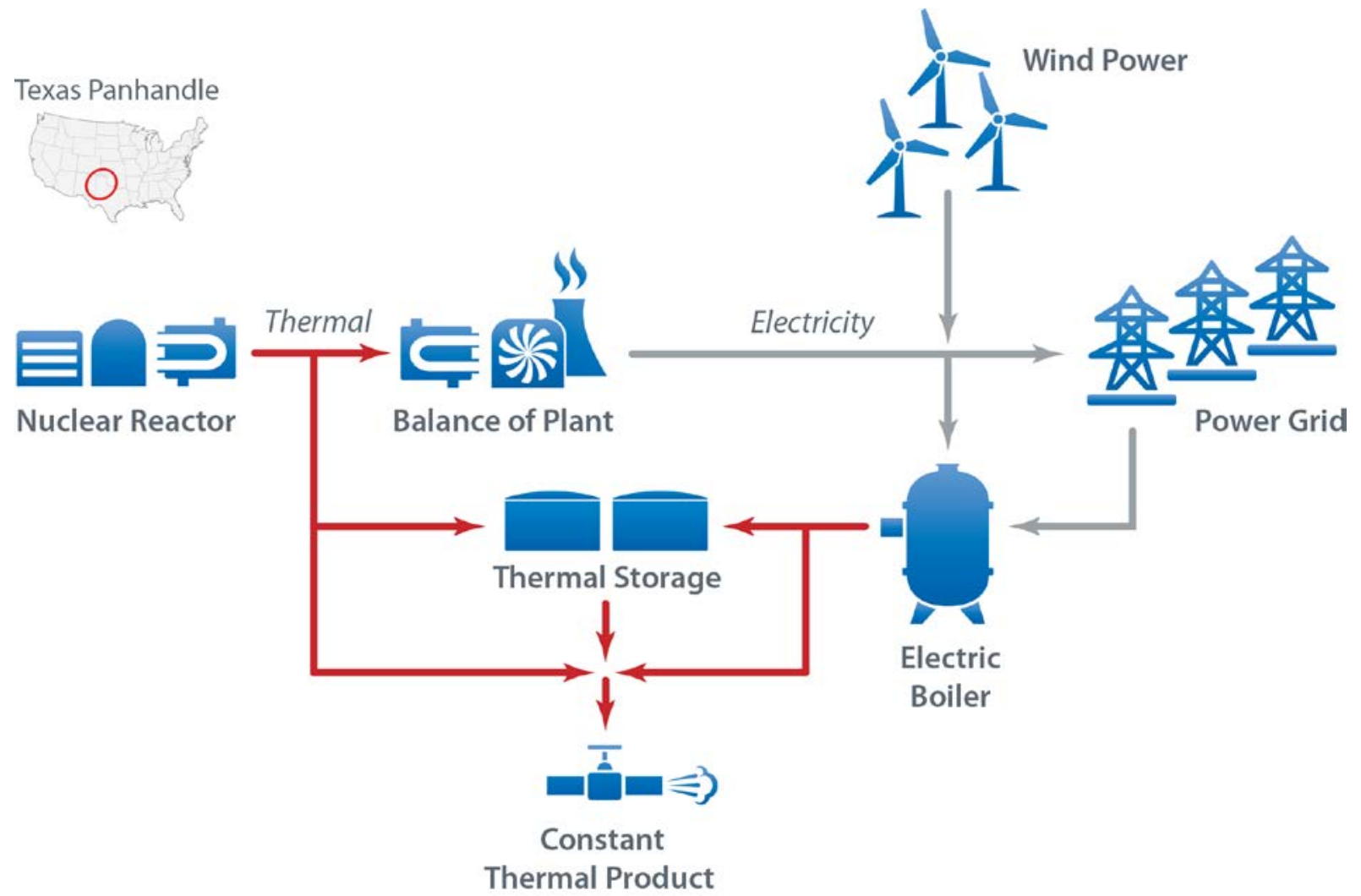

Figure 3. N-R HES Scenario \#3: The electric boiler converts electricity to thermal energy when the electricity price is very low. The thermal storage unit stores thermal energy from both the nuclear reactor and the electric boiler. The thermal product's rate is constant.

Red arrows indicate flow of thermal energy and gray arrows indicate electricity

Table 1 compares the three scenarios we analyzed and report here. The first scenario is titled "Electric Boiler" and is not forced to provide the thermal product at a constant rate (the amount of heat provided can vary from hour to hour). The second scenario is titled "Electric Thermal Storage" and is required to provide the thermal product at a constant rate. In that scenario, stored thermal energy can be generated only by electricity. The third scenario is titled "Electric BoilerThermal Storage" and also is required to provide the thermal product at a constant rate. Stored thermal energy can be generated by either electricity or the nuclear reactor.

Table 1. Comparison of the Three Scenarios Analyzed

\begin{tabular}{|lll|} 
Scenario & $\begin{array}{l}\text { Thermal } \\
\text { Product }\end{array}$ & Storage \\
\hline \#2 - Electric Boiler & Variable & None \\
\hline \#3 - Electric Boiler-Thermal Storage & Constant & Thermal storage from electricity \\
\hline
\end{tabular}




\section{Analysis Methodology and Parameters}

This section discusses the methodology used to perform the analysis and provides details and references for key parameters. The information provided in this section is intended for others performing similar analyses or comparing results from this analysis to their own.

Most of the key parameters in this analysis are identical to those used in Ruth et al. (2016). ${ }^{8}$ We do not discuss those parameters in detail. Instead, the reader can find the details in Ruth et al. (2016).

This section consists of seven subsections. The first subsection outlines the methodology used to perform the analysis. The second subsection discusses the electrical energy and ancillary service prices used. The third subsection discusses the capacity payments used for the electricity market. The fourth subsection reports the capital and operating cost estimates used in this analysis. The fifth subsection states the financial assumptions. The sixth subsection discusses the costs of carbon used in this analysis. The final subsection reports a cost of natural gas-generated heat that is used as a comparison in this analysis.

\subsection{Analysis Methodology}

The key feature of this analysis is optimization of subsystem sizes and operational decisions (internal dispatch strategy) to maximize the profitability of each of the three N-R HES scenarios defined in Section 1. We optimized each N-R HES under a variety of electricity price vectors and thermal energy prices to determine the most profitable configuration under each so that we could understand the drivers that impact configuration selection and operational decisions. Profit is expressed as net present value (NPV).

We used the National Renewable Energy Laboratory's (NREL's) Renewable Energy Optimization (REopt) tool for the optimization. REopt is an energy-planning platform that offers concurrent, multiple technology integration and optimization capabilities. Formulated as a mixed integer linear program, REopt identifies optimal subsystem sizes and dispatch strategies for the selected technologies. It takes into account subsystem costs (capital, fixed, and variable), fuel costs, financial parameters (discount rate, inflation, utility price escalation rates, incentives), utility prices, and other variables that contribute to a techno-economic analysis of the proposed system. REopt also has the capability to optimize a system for objectives other than those used in this analysis, such as minimum fuel consumption or minimum GHG emissions. ${ }^{9}$

To optimize profitability, REopt calculates an annual cash flow for each option. REopt requires a number of inputs to perform the optimization on subsystem size and hourly operations. The key inputs are:

- Electricity energy and ancillary service prices for both sales and purchasing

- Electricity capacity payments

- Capital and operating costs for each subsystem (the subsystems are the nuclear reactor, the thermal power cycle, the wind power plant, the electric boiler, the electric thermal storage unit, and the thermal storage unit). 
The subsections within this section discuss the basis and methodology used to estimate each of the REopt inputs and the annual cash flow calculation. The subsections discuss the parameters used to calculate comparisons of heat generated using natural gas. Natural gas prices and costs of carbon are not used directly for the REopt optimization; however, they are key parameters in preprocessing and post-processing, so they are also discussed in this section.

Using those inputs, REopt determined the subsystem capacities and hourly dispatch to maximize the NPV of the N-R HES for the scenario. All subsystems were allowed to vary in size from no capacity (i.e., not present) to a maximum capacity of 50 megawatt electrical (MWe) (167 megawatt thermal $[\mathrm{MWt}]$ in the case of the nuclear reactor). The maximum sizes were set to the same value because the purpose of the analysis is to understand the benefits of coupled subsystems with full flexibility. If the subsystem capacities were overly constrained (i.e., minimum capacity of one or more is greater than zero, thus requiring its presence in the optimal configuration, or the maximum of one is less than another so that the first may produce more energy than the second can use), the decision between subsystems and whether to include specific subsystems could be obfuscated.

We performed post-processing outside REopt to estimate the potential impacts of various costs of carbon and to develop comparisons to natural gas boilers that provide thermal energy instead of the N-R HES.

To address the ability of the N-R HESs analyzed to support the grid's resource adequacy requirements, we determined the economic incentive for the N-R HES to accept capacity payments. If the optimal configuration included capacity payments as income and could provide the power required to receive those payments, we identified that configuration as one that supports the grid's resource adequacy requirements. If the optimal configuration did not include capacity payments as income, we identified that configuration as one that does not support the grid's resource adequacy requirements.

We employed the same set of fundamental assumptions as in the previous analysis. ${ }^{10}$ First, we based the analysis on a green-field (all-new) plant - we assumed all subsystems are new so that we would analyze a more general case instead of being constrained to a specific set of conditions. Second, we performed the analysis using and reporting all results in 2013 dollars, although we used price projections to 2035 . Third, we performed the analysis with only one type of nuclear reactor-LW-SMR - because that design is most likely to be available by 2035 .

\subsection{Electrical Energy and Ancillary Service Price Estimates}

We used the same electricity prices as in the previous analysis; details regarding our methodology can be found in Ruth et al. (2016). ${ }^{11}$ This section describes the process in general and discusses the one difference between that analysis and this one: the N-R HES can purchase electricity at a price slightly higher than the marginal cost.

We designed this analysis such that electricity revenue can come from three main sources (note that the N-R HES can also receive revenue by selling the thermal product): 
1. Electrical energy revenue (dollars per megawatt-hour [\$/MWh])

2. Ancillary service revenue from contingency reserves, regulation, and flexibility reserves

3. Capacity payments (dollars per kilowatt-year $[\$ / \mathrm{kW}-\mathrm{yr}]$ ).

We estimated generation mixes based on three regions from standard-scenario national results developed at NREL. ${ }^{12}$ Most of the results presented here are based on the 2036 generation mix in NREL's National Renewable Portfolio Standard (RPS) scenario, which leads to $80 \%$ renewably generated electricity in 2050. Because the standard-scenario modeling results are calculated only for even-numbered years, results for the year 2035 are not available. Hence, 2036 results are considered sufficient for this effort as the generator mix for the year 2035 and are used in this analysis. Throughout this report, results based on this case are reported as "RPS80." In the RPS 80 case, wind generators produce $21 \%$ and solar photovoltaics (PV) produce $20 \%$ of the annual electricity generation. These penetrations are likely near the maximum renewable penetration in 2035 .

Once we had those generation mixes, we used the PLEXOS model to estimate the annual electrical energy production and hourly electrical energy and ancillary service prices using a PLEXOS production cost model. We estimated hourly electrical energy and ancillary reserve prices as those paid by the load during the period of study. For 2035 prices of coal, natural gas, and oil, we use reference case prices reported in the 2015 Annual Energy Outlook (AEO) to be consistent with our previous analysis. ${ }^{13}$ Electrical energy and ancillary service prices were derived from the short-run marginal costs of the marginal generator and do not include markups or any sort of scarcity pricing scheme. Prices at the price cap of $\$ 100 / \mathrm{MW}$ occurred primarily due to reserves violations - situations in which optimization software found it less expensive on the grid to short the reserves slightly rather than start or shutdown a generator.

For configurations that purchase electricity to produce thermal energy, we set the purchase price at the electrical energy price plus $\$ 15 / \mathrm{MWh}$. The addition of $\$ 15 / \mathrm{MWh}$ is intended to cover costs that regional transmission organizations or independent system operators incur but are not paid for as electrical energy (e.g., capacity, reserves, administration). As a basis of comparison, Table 2 shows the breakdown of costs incurred by PJM during 2013 and 2014. ${ }^{14}$ 
Table 2. Breakdown of Electrical Energy Costs in PJM ${ }^{15}$

\begin{tabular}{|c|c|c|c|c|c|c|c|c|c|}
\hline Category & $\begin{array}{l}2013 \\
\text { \$/MWh }\end{array}$ & $\begin{array}{l}2014 \\
\text { \$/MWh }\end{array}$ & $\begin{array}{l}\text { Q1 } 2014 \\
\text { \$/MWh }\end{array}$ & $\begin{array}{l}\text { Q2 } 2014 \\
\text { \$/MWh }\end{array}$ & $\begin{array}{l}\text { Q3 } 2014 \\
\text { \$/MWh }\end{array}$ & $\begin{array}{l}\text { Q4 } 2014 \\
\text { \$/MWh }\end{array}$ & $\begin{array}{l}2013 \text { to } 2014 \\
\text { Percent } \\
\text { Change } \\
\text { Totals }\end{array}$ & $\begin{array}{l}2013 \\
\text { Percent of } \\
\text { Total }\end{array}$ & $\begin{array}{l}2014 \\
\text { Percent of } \\
\text { Total }\end{array}$ \\
\hline $\begin{array}{l}\text { Load Weighted } \\
\text { Energy }\end{array}$ & $\$ 38.66$ & $\$ 53.14$ & $\$ 92.98$ & $\$ 42.85$ & $\$ 36.38$ & $\$ 35.47$ & $37.4 \%$ & $71.6 \%$ & $74.2 \%$ \\
\hline Capacity & $\$ 7.13$ & $\$ 9.01$ & $\$ 7.77$ & $\$ 9.48$ & $\$ 9.16$ & $\$ 14.11$ & $26.3 \%$ & $13.2 \%$ & $12.6 \%$ \\
\hline $\begin{array}{l}\text { Transmission } \\
\text { Service Charges }\end{array}$ & $\$ 5.20$ & $\$ 5.95$ & $\$ 5.19$ & $\$ 6.22$ & $\$ 6.05$ & $\$ 9.31$ & $14.5 \%$ & $9.6 \%$ & $8.3 \%$ \\
\hline $\begin{array}{l}\text { Energy Uplift } \\
\text { (Operating } \\
\text { Reserves) }\end{array}$ & $\$ 0.59$ & $\$ 1.18$ & $\$ 3.55$ & $\$ 0.34$ & $\$ 0.27$ & $\$ 0.41$ & $99.4 \%$ & $1.1 \%$ & $1.6 \%$ \\
\hline $\begin{array}{l}\text { Transmission } \\
\text { Enhancement Cost } \\
\text { Recovery }\end{array}$ & $\$ 0.39$ & $\$ 0.42$ & $\$ 0.36$ & $\$ 0.86$ & $\$ 1.22$ & $\$ 2.55$ & $8.9 \%$ & $0.7 \%$ & $0.6 \%$ \\
\hline $\begin{array}{l}\text { PJM Administrative } \\
\text { Fees }\end{array}$ & $\$ 0.43$ & $\$ 0.44$ & $\$ 0.43$ & $\$ 0.47$ & $\$ 0.45$ & $\$ 0.59$ & $1.5 \%$ & $0.8 \%$ & $0.6 \%$ \\
\hline Reactive & $\$ 0.80$ & $\$ 0.40$ & $\$ 0.37$ & $\$ 0.47$ & $\$ 0.38$ & $\$ 0.55$ & $(50.4 \%)$ & $1.5 \%$ & $0.6 \%$ \\
\hline Regulation & $\$ 0.24$ & $\$ 0.33$ & $\$ 0.63$ & $\$ 0.26$ & $\$ 0.18$ & $\$ 0.29$ & $33.1 \%$ & $0.5 \%$ & $0.5 \%$ \\
\hline $\begin{array}{l}\text { Synchronized } \\
\text { Reserves }\end{array}$ & $\$ 0.04$ & $\$ 0.21$ & $\$ 0.56$ & $\$ 0.12$ & $\$ 0.03$ & $\$ 0.10$ & $382.5 \%$ & $0.1 \%$ & $0.3 \%$ \\
\hline Capacity (FRR) & $\$ 0.11$ & $\$ 0.20$ & $\$ 0.06$ & $\$ 0.16$ & $\$ 0.30$ & $\$ 0.46$ & $90.2 \%$ & $0.2 \%$ & $0.3 \%$ \\
\hline $\begin{array}{l}\text { Transmission } \\
\text { Owner (Schedule } \\
\text { 1A) }\end{array}$ & $\$ 0.08$ & $\$ 0.09$ & $\$ 0.09$ & $\$ 0.09$ & $\$ 0.09$ & $\$ 0.13$ & $7.4 \%$ & $0.2 \%$ & $0.1 \%$ \\
\hline Black Start & $\$ 0.14$ & $\$ 0.08$ & $\$ 0.06$ & $\$ 0.07$ & $\$ 0.10$ & $\$ 0.11$ & $(45.9 \%)$ & $0.3 \%$ & $0.1 \%$ \\
\hline $\begin{array}{l}\text { Emergency Load } \\
\text { Response }\end{array}$ & $\$ 0.06$ & $\$ 0.06$ & $\$ 0.18$ & $\$ 0.03$ & $\$ 0.00$ & $\$ 0.00$ & $(14.9 \%)$ & $0.1 \%$ & $0.1 \%$ \\
\hline $\begin{array}{l}\text { Day Ahead } \\
\text { Scheduling Reserve } \\
\text { (DASR) }\end{array}$ & $\$ 0.06$ & $\$ 0.05$ & $\$ 0.17$ & $\$ 0.00$ & $\$ 0.00$ & $\$ 0.00$ & $(19.5 \%)$ & $0.1 \%$ & $0.1 \%$ \\
\hline
\end{tabular}




\begin{tabular}{|c|c|c|c|c|c|c|c|c|c|}
\hline Category & $\begin{array}{l}2013 \\
\text { \$/MWh }\end{array}$ & $\begin{array}{l}2014 \\
\text { \$/MWh }\end{array}$ & $\begin{array}{l}\text { Q1 } 2014 \\
\text { \$/MWh }\end{array}$ & $\begin{array}{l}\text { Q2 } 2014 \\
\text { \$/MWh }\end{array}$ & $\begin{array}{l}\text { Q3 } 2014 \\
\text { \$/MWh }\end{array}$ & $\begin{array}{l}\text { Q4 } 2014 \\
\text { \$/MWh }\end{array}$ & $\begin{array}{l}2013 \text { to } 2014 \\
\text { Percent } \\
\text { Change } \\
\text { Totals }\end{array}$ & $\begin{array}{l}2013 \\
\text { Percent of } \\
\text { Total }\end{array}$ & $\begin{array}{l}2014 \\
\text { Percent of } \\
\text { Total }\end{array}$ \\
\hline NERC/RFC & $\$ 0.02$ & $\$ 0.02$ & $\$ 0.02$ & $\$ 0.02$ & $\$ 0.02$ & $\$ 0.03$ & $5.6 \%$ & $0.0 \%$ & $0.0 \%$ \\
\hline Load Response & $\$ 0.01$ & $\$ 0.02$ & $\$ 0.04$ & $\$ 0.02$ & $\$ 0.01$ & $\$ 0.02$ & $69.8 \%$ & $0.0 \%$ & $0.0 \%$ \\
\hline $\begin{array}{l}\text { Non-Synchronized } \\
\text { Reserves }\end{array}$ & $\$ 0.00$ & $\$ 0.02$ & $\$ 0.04$ & $\$ 0.01$ & $\$ 0.00$ & $\$ 0.01$ & $625.0 \%$ & $0.0 \%$ & $0.0 \%$ \\
\hline $\begin{array}{l}\text { RTO Startup and } \\
\text { Expansion }\end{array}$ & $\$ 0.01$ & $\$ 0.01$ & $\$ 0.01$ & $\$ 0.01$ & $\$ 0.01$ & $\$ 0.01$ & $(11.9 \%)$ & $0.0 \%$ & $0.0 \%$ \\
\hline Emergency Energy & $\$ 0.00$ & $\$ 0.01$ & $\$ 0.13$ & $\$ 0.00$ & $\$ 0.00$ & $\$ 0.00$ & NA & $0.0 \%$ & $0.0 \%$ \\
\hline $\begin{array}{l}\text { Transmission } \\
\text { Facility Charges }\end{array}$ & $\$ 0.00$ & $\$ 0.00$ & $\$ 0.00$ & $\$ 0.00$ & $\$ 0.00$ & $\$ 0.00$ & $(8.7 \%)$ & $0.0 \%$ & $0.0 \%$ \\
\hline Total & $\$ 54.00$ & $\$ 71.62$ & $\$ 112.62$ & $\$ 61.48$ & $\$ 54.63$ & $\$ 64.15$ & $32.6 \%$ & $100.0 \%$ & $100.0 \%$ \\
\hline
\end{tabular}




\subsection{Capacity Payment Estimates}

We estimated a base case capacity payment of $\$ 50 / \mathrm{kW}$-yr based on observed variation of capacity payments in restructured markets over the last decade, as described in the previous report. In addition, we performed sensitivity analyses at two higher-capacity payment levels: $\$ 100 / \mathrm{kW}$-yr and \$150/kW-yr.

Capacity payments are intended to compensate generators necessary to meet a small number of "super-peak" demand hours each year when the available capacity may be fully utilized and other reliability mechanisms, including use of operating reserves or rolling blackouts, are needed to maintain reliability. Such events are quite rare (e.g., 10-50 hours annually) and are identified as hours where the electrical energy prices are extremely high. ${ }^{16}$ For example, energy prices in PJM exceeded $\$ 1000 / \mathrm{kWh}$ during 50 hours in 2015 but exceeded that threshold more hours in 2014 due to the polar vortex. ${ }^{17}$ Based on this information, we designed the analysis such that the N-R HES must provide electrical power to the grid for the 50 hours during the year, with the highest load to receive a capacity payment. (Note that these are the hours of gross load, not net load.)

Joskow (2006) notes that such events are quite rare (e.g., 10-50 hours), and the lack of available supply may lead to corresponding high prices that may be capped. Examples of this type of behavior are seen in PJM (see figure below), where only a few hours are over $\$ 1000 / \mathrm{MWh}$; occurrences above $\$ 200 / \mathrm{MWh}$ are also relatively rare. These occurrences were less than 50 hours in 2015, though somewhat higher in 2014 due to effects in January associated with the Polar Vortex (PJM 2016). For this reason, in this study we used 50 hours as the required number of hours for the N-R HES to receive the capacity payment. We allowed REopt to select configurations where the N-R HES does not provide full capacity during those hours, but the NR HES only receives a capacity payment for the minimum quantity of power provided during all those hours.

\subsection{Capital and Operating Cost Estimates}

For equipment that is the same as in the previous analysis, we used the same capital and operating costs. Table 3 reports those capital and operating costs. Costs for electricity generation equipment are from NREL's Annual Technology Baseline ${ }^{18}$ and other NREL references, as listed in the tables, and include all costs for a new facility (e.g., equipment, engineering, construction, financing, and land). Economies of scale were not included because scaling factors were not readily available. In order to optimize the utilization of the thermal energy between the industrial process and electricity generation, we modeled the thermal power cycle as an independent subsystem in REopt. 
Table 3. Capital and Operating Costs for Subsystems in Previous Analysis

\begin{tabular}{|llll|}
\hline Unit & Capital Cost & Fixed O\&M Cost & $\begin{array}{l}\text { Reference } \\
\text { Nuclear Reactor }\end{array}$ \\
Thermal Power Cycle & $\$ 3,716 / \mathrm{kWe}$ & $\$ 95 / \mathrm{kWe}-\mathrm{yr}$ & $\begin{array}{l}\text { Annual Technology } \\
\text { Baseline }^{*}\end{array}$ \\
\hline Wind Turbines & $\$ 1689 / \mathrm{kWe}^{19}$ & $\$ 46.75 / \mathrm{kWe}^{19} \mathrm{yr}^{20}$ & See endnotes \\
\hline
\end{tabular}

kWe: kilowatt electric

O\&M: operations and maintenance

Table 4 reports the capital and operating costs we used for equipment new in this analysis: the electric boiler, the electric thermal storage unit, and the thermal storage unit. We based the electric boiler cost on a quote from the Thomas B. Mansfield Co. of $\$ 1,265,000$ for a 50-MW boiler that produces saturated steam at a nominal operating pressure of 210 pounds per square inch - gauge (psig). Because installation costs were not included in the quote, we used a Lang factor of 3.2 for installation (Lang factor is defined as the ratio of the fixed capital investment to the delivered equipment cost). ${ }^{21}$ The resulting cost estimate is $\$ 81 / \mathrm{kW}$. We assume that the fixed operations and maintenance (O\&M) costs for the boiler are negligible.

We assumed the electric thermal storage unit's cost at $\$ 25 / \mathrm{kWht}$ and set the charge-discharge rate at $1 \mathrm{kWt}: 5 \mathrm{kWht}$ of stored energy based on a published estimate of the costs of FIRES technology. ${ }^{22}$ Based on conversations with the FIRES technology developers, we understand that the estimate includes installation costs; hence, we used the estimate directly. At the chargedischarge rate of $1 \mathrm{kWt}: 5 \mathrm{kWht}$, the capital cost of $\$ 25 / \mathrm{kWht}$ is equivalent to a capital cost of $\$ 125 / \mathrm{kW}$. (Since the efficiency of the electric thermal storage unit is $100 \%$ efficient, the electrical and thermal power units are equivalent). We estimated a thermal decay rate of $0.5 \% / \mathrm{hr}$ when heat from storage is not being used because we did not have any additional information on degradation. Like the electric boiler, we assume that the fixed O\&M costs are negligible to simplify the analysis. Fixed O\&M costs may not be negligible, however, and further investigation would be warranted as part of a more complete analysis.

We estimated the costs of the thermal storage unit based on costs for a two-tank molten salt storage system. The cost of $\$ 15$ per kilowatt thermal $(\mathrm{kWt})$ for the storage unit is a target set by the SunShot Initiative. ${ }^{23}$ The target cost was chosen assuming that it will be achieved by 2035 . The charge-discharge rates of the thermal storage unit were set to be the same as the electric thermal storage unit $1 \mathrm{kWt}: 5 \mathrm{kWht}$ of storage (equivalent to $0.2 \mathrm{MMBtu} / \mathrm{hr}$ per MMBtu thermal storage). We assumed a thermal decay rate of $0.05 \% / \mathrm{hr}$. We assume that the fixed O\&M costs are negligible.

We did not include fixed O\&M costs for any of the thermal conversion or storage units because they are likely to be small. Further investigation into those costs would be warranted if a more detailed analysis is performed.

\footnotetext{
${ }^{*}$ The Annual Technology Baseline includes a \$2/MWh electricity variable O\&M cost for nuclear power generation. That variable cost was not used in this report.
} 
Note that the electric thermal storage unit is more expensive than either the electric boiler or the thermal storage unit separately; however, it is less expensive than a combined boiler and thermal storage unit.

Table 4. Capital and Operating Costs for new Subsystems

\begin{tabular}{|llll|}
\hline Unit & Capital Cost & Fixed O\&M Costs & Reference \\
\hline Electric Boiler & $\$ 81 / \mathrm{kWe}$ & - & Equipment quote \\
\hline $\begin{array}{l}\text { Electric Thermal Storage } \\
\text { Unit }\end{array}$ & $\$ 25 / \mathrm{kWht}=$ & - & Published estimate \\
\hline Thermal Storage Unit & $\$ 125 / \mathrm{kW}$ & - & SunShot target \\
\hline
\end{tabular}

\subsection{Financial Parameters and Calculations}

We performed an analysis of the annual cash flows for the 25 -year economic life for each N-R HES. We used the same financial parameters as in the previous analysis. They are shown in Table 5. We recognize that the debt-to-equity ratio, cost of equity, and other parameters are dependent upon the industry, risk profile, and other factors. Investors should use their own financial parameters to analyze the financial viability of these systems under their specific circumstances.

\begin{tabular}{ll} 
Table 5. Main Parameters Used in our Financial Calculations \\
\hline Start of operations (year) & 2035 \\
\hline Analysis period (years) & 25 \\
\hline Tax rate & $35 \%$ \\
\hline Cost of equity & $10 \%$ \\
\hline Debt percentage & $0.00 \%$ \\
\hline $\begin{array}{l}\text { Discount rate (nominal) } \\
\text { Inflation rate } \\
\text { (electricity/water/gasoline/natural } \\
\text { gas) }\end{array}$ & $10 \%$ \\
\hline
\end{tabular}

\subsection{Cost of Carbon}

To add a cost of carbon emissions in sensitivities, we used the range of social costs of carbon developed by the U.S. Environmental Protection Agency (EPA). Social costs of carbon estimate the economic damages associated with small increases in $\mathrm{CO}_{2}$ emissions. Because the damage estimates are future-looking, EPA uses three different discount rates to convert the values to current year dollars: $5 \%, 3 \%$, and $2.5 \%$. In addition, because the extent of damages is uncertain, EPA provides a second value with a $3 \%$ discount rate that uses the $95^{\text {th }}$ percentile of the range of 
damage estimates instead of the mean. ${ }^{\dagger}$ Table 6 reports the estimated social cost of carbon in 2035 in 2014 dollars. These values were used because we considered the difference between 2013 dollars and 2014 dollars negligible.

Table 6. Social Costs of Carbon Emissions in 2035 (\$/metric ton $\left.\mathrm{CO}_{2} \mathrm{e}\right)$

\begin{tabular}{|c|c|c|c|c|}
\hline $\begin{array}{l}\text { Discount Rate } \\
\text { and Statistic }\end{array}$ & $5 \%$ & $3 \%$ & $2.5 \%$ & $\begin{array}{l}3 \% \\
95 \text { th percentile }\end{array}$ \\
\hline 2035 Cost & $\$ 20$ & $\$ 61$ & $\$ 86$ & $\$ 186$ \\
\hline
\end{tabular}

\subsection{Cost of Heat from a Natural Gas Boiler}

For comparative purposes, we estimated the cost of heat from a natural gas boiler based on natural gas prices and estimated the capital and operating costs of a natural gas boiler and its efficiency. We used natural gas prices from the reference case in the $2015 \mathrm{AEO}^{24}$ to be consistent with our previous analysis of two N-R HESs. ${ }^{25}$ We used capital and operating cost estimates for a super-high efficiency boiler from a study on the future of natural gas. ${ }^{26}$ The capital cost of a $167 \mathrm{MWt}$ boiler is $\$ 7.1$ million. Using the financial parameters in Table 5 above, we estimated that the price of heat necessary to achieve the $10 \%$ nominal discount rate is \$7.55/MMBtu. We estimated the emissions at $117 \mathrm{lb} \mathrm{CO}_{2} / \mathrm{MMBtu}$ of natural gas consumption based on Energy Information Administration data. ${ }^{27}$

\footnotetext{
${ }^{\dagger}$ http://www3.epa.gov/climatechange/EPAactivities/economics/scc.html and updated from $2007 \$$ to $2014 \$$ in the printout of the EPA website available at http://denverclimatestudygroup.com/wp-content/uploads/2015/10/2015The-Social-Cost-of-Carbon-study-summary.pdf.
} 


\section{N-R HES Design on Operational Optimization Results}

\subsection{Results for the Electric Boiler Scenario}

Scenario 1, the Electric Boiler Scenario, consists of four primary subsystems: (1) a nuclear reactor, (2) a thermal power cycle that can be associated with the nuclear reactor, (3) a wind power plant, and (4) an electric boiler that uses electricity to produce steam. We set the same maximum size for the nuclear reactor, the thermal power cycle, the wind power plant, and the electric boiler- $50 \mathrm{MWe}$ - to clearly show the impacts of each subsystem. The thermal power cycle efficiency of 30\% implies a thermal capacity of $167 \mathrm{MWt}$ for the nuclear reactor.

In this scenario, the thermal product can be generated at variable rates. In other words, the customer(s) do not need a consistent source of heat. Instead, they require a total quantity of heat over the year but can adapt to varying rates by adjusting their process. We included this flexibility to give the N-R HES the potential to maximize profitability by generating electricity when its value is high and thermal product when it is low. The number of potential customers that can utilize a variable source of thermal energy (e.g., the amount of heat can go up or down somewhat in exchange for a lower price thermal energy source) is likely to be limited; however, some are to be expected.

We used REopt to determine the optimal size of each subsystem and the energy flow on an hourly basis. It allows for energy to be split (i.e., some of the thermal energy from the nuclear reactor can be used for the industrial process and the remainder for electricity) during any hour if that provides the cost-optimal solution.

\subsubsection{Potential Profitability}

We analyzed the potential profitability of the N-R HES with an electric boiler but not thermal storage by varying the prices of the electricity and thermal products and using REopt to calculate the optimal subsystem combinations and internal dispatch, as discussed in Section 2.1. We varied the price of the thermal product from $\$ 0 / \mathrm{MMBtu}$ to $\$ 35.00 / \mathrm{MMBtu}$. The range was chosen to demonstrate the impacts of various prices. We varied the price of electricity using a multiplier that affected the electrical energy price for all 8,760 hours in the year. ${ }^{\ddagger}$ In each case, the multiplier was randomly assigned a value between 0 and 2; thus, the electrical energy price in that case could be $\$ 0 / \mathrm{MWh}$ for every hour of the year, twice the electrical energy price developed for the reference case, or any other multiplied value between 0 and 2 . The electricity multiplier could be considered a combination of (1) the difference between marginal generation costs and market prices (due to bidding strategies and market settlement) and (2) uncertainty in the natural gas price because natural gas is on the operating cost margin for the vast majority of the year. Unless stated otherwise, all other parameters remain at the reference values. Note that this analysis assumes perfect foresight of all expenses, renewable resource, and product prices throughout the project life.

\footnotetext{
\$ Prices of ancillary services (reserves, flex reserves, and regulation up and down) were not multiplied because a change in price has little effect on the operational selection and optimization.
} 
Figure 4 shows the optimal configuration selections for $\approx 2,000$ combinations of thermal product prices and electricity multipliers. These values were independently and randomly sampled from a uniform distribution across the ranges described above. The results of this analysis indicate that:

- If the electricity price multiplier is below 1.22 and the thermal product's price is below $\$ 5.00 / \mathrm{MMBtu}$, no configurations exceed the required cost of capital (i.e., the NPV is less than zero for all combinations).

- If the electricity price multiplier is between $1.22-1.25$ and the price of the thermal product is below $\$ 5.00 / \mathrm{MMBtu}$ (as shown by the red dots), projected income of the LWSMR with a thermal power cycle exceeds the required cost of capital and the configuration produces electricity when its price is above zero. During hours when the electricity price is $\$ 0 / \mathrm{kWh}$, the configuration produces and sells heat.

- If the electricity price multiplier is below 1.25 and thermal product's price is between $\$ 5.00 /$ MMBtu-\$19.00/MMBtu (as shown by the yellow dots), the nuclear reactor generates and sells thermal energy exclusively (i.e., it does not generate any electricity).

- If the thermal product's price is above $\$ 9.00 / \mathrm{MMBtu}$ and the electricity price multiplier is above 1.25 , or the thermal product's price is above $\$ 19.00 / \mathrm{MMBtu}$ at all electricity prices (as shown by the dark blue dots), the nuclear reactor generates and sells thermal energy exclusively (i.e., it does not generate any electricity), a wind power plant generates electricity, and an electric boiler converts that electricity to heat during some hours of the year.

- If the electricity multiplier is above 1.25 , the thermal product's price is below $\$ 9.00 / \mathrm{MMBtu}$, and the prices of the thermal product and electricity are in the range indicated by the light blue dots, the nuclear reactor generates and sells thermal energy exclusively (i.e., it does not generate any electricity) and a wind power plant generates and sells electricity exclusively.

- If the electricity multiplier is above 1.25 , the thermal product's price is below $\$ 8.70 / \mathrm{MMBtu}$, and the prices of the thermal product and electricity are in the range indicated by the orange dots, the LW-SMR with a thermal power cycle has a projected income that exceeds the required cost of capital; the configuration produces electricity when its price is above zero; and a wind power plant generates and sells electricity exclusively.

The solid black dot in Figure 4 indicates the reference case thermal energy product price (\$7.55/MMBtu) and the electricity price vector developed for this analysis (the multiplier is 1.0 ). To estimate the reference case thermal product price, we estimated the cost of a natural gas boiler to produce the thermal energy without a cost of carbon as discussed in Section 2.7.

The separation between the configurations with light blue dots and the orange dots is a function of both the electricity price and the thermal product's price because, as the electricity price multiplier is held constant and the thermal product price increases (horizontal on Figure 4), the nuclear reactor is incentivized to produce heat. Likewise, as the thermal product price is held constant and the electricity price increases, the nuclear reactor is incentivized to produce electricity. 
Note that in all price ranges where the wind power plant is identified within the optimal configuration, it is built at its maximum size (50 MWe). Likewise, in all price ranges that identify the electric boiler in the optimal configuration, the electric boiler is built at its maximum size (50 MWe).

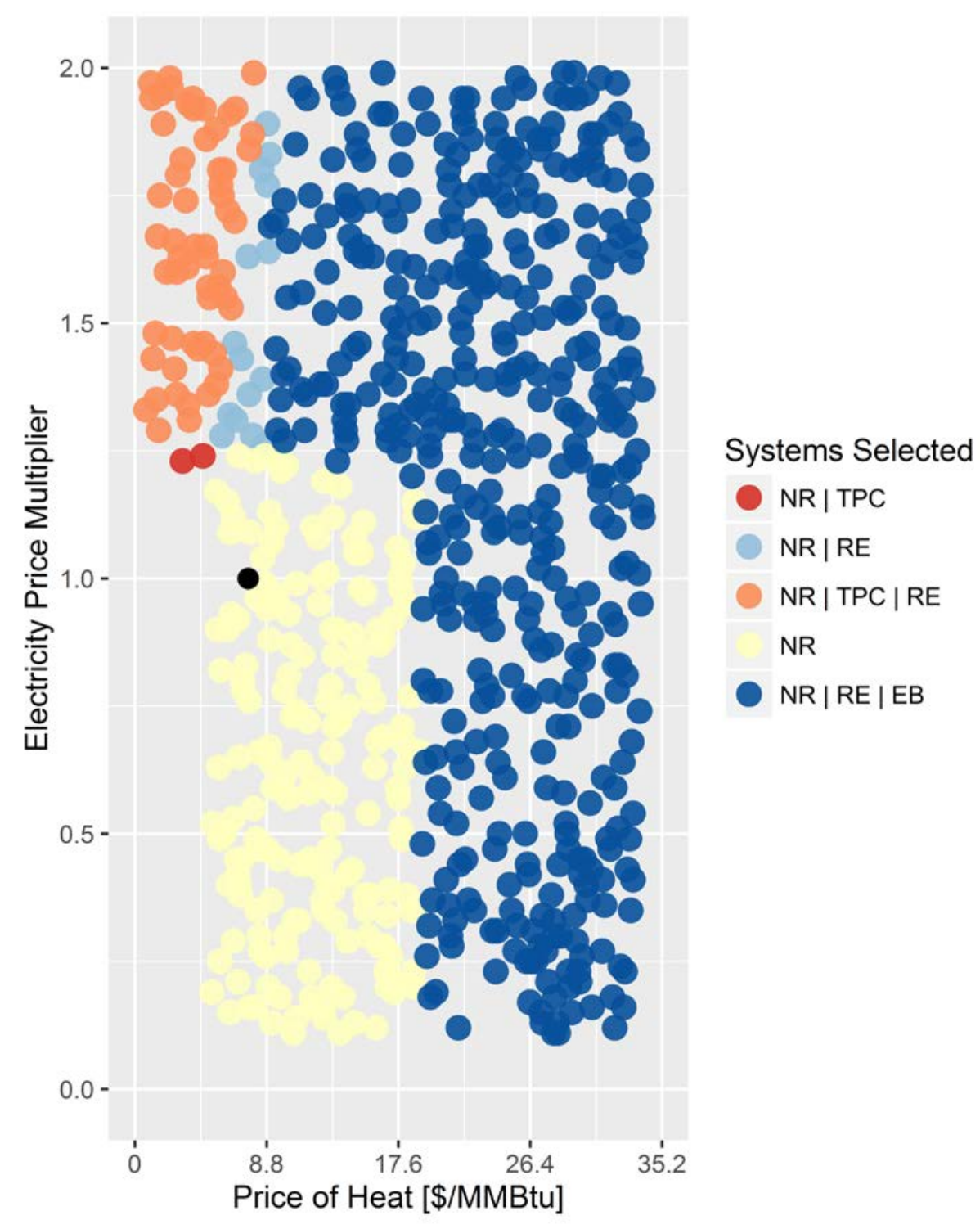

Figure 4. Optimal configurations for the Electric Boiler Scenario with a capacity payment of $\$ 50 / k W-y r$

EB: Electric boiler

NR: Nuclear reactor

RE: Renewable electricity generation

TPC: Thermal power cycle

Solid black dot at $\$ 7.70 / \mathrm{MMBtu}$ and 1.0 indicates reference case prices of heat and electricity.

Figure 5 shows the optimal product mix based on each optimal configuration shown in Figure 4, and Figure 6 indicates the capacity payment awarded. As in Figure 4, if the electricity price multiplier is above 1.25 , the wind power plant produces electricity. That electricity is usually 
sold to the grid. However, when the price of heat is greater than $\$ 9.00 / \mathrm{MMBtu}$, wind-generated electricity is used to produce thermal energy during hours when the price of electricity is $\$ 0 / \mathrm{MWh}$, and when the price of heat is greater than $\$ 19.00 / \mathrm{MMBtu}$, wind-generated electricity is used to produce thermal energy during additional hours. The use of wind-generated electricity at thermal energy prices between $\$ 9.00 / \mathrm{MMBtu}-\$ 19 / \mathrm{MMBtu}$ reduces the annual electricity sales from the wind power plant from $\sim 154,000 \mathrm{MWh} / \mathrm{yr}$ to $\sim 151,000 \mathrm{MWh} / \mathrm{yr}$ (too small a difference to be apparent in Figure 5). If the price of heat is above \$5.00/MMBtu, the thermal energy is almost always a more valuable product than the electricity it can be used to produce (as shown by the black dots on the right side of Figure 5). When the electricity price multiplier is above 1.25 , the nuclear reactor would sometimes produce thermal energy. At lower thermal energy prices (below $\$ 5.00 / \mathrm{MMBtu}$ ), the nuclear reactor would primarily produce electricity but would produce thermal energy during hours when the price of electricity is $\$ 0 / \mathrm{MWh}$. At higher thermal energy prices (above $\$ 9.00 / \mathrm{MMBtu}$ ), the nuclear reactor only produces thermal energy, but the wind power plant produces electricity when the multiplier is above 1.25 . At intermediate thermal energy prices ( $\$ 5.00 / \mathrm{MMBtu}$ to $\$ 9.00 / \mathrm{MMBtu})$, some thermal energy generated by the nuclear reactor would be converted to electricity to receive the capacity payment as long as the price of the thermal energy is not too high. That intermediate range is most easily seen in Figure 4, where the light blue dots indicate the range where nuclear-electricity is not generated and the red dots above $\$ 5.00 / \mathrm{MMBtu}$ indicate a range where electricity is produced to receive the capacity payment.

As shown by the blue dots on Figure 6, the N-R HES in Scenario 1 only receives a capacity payment when the electricity generation equipment is selected (i.e., at higher electricity prices) and the thermal product's price is relatively low. At higher thermal product prices, all the nuclear energy is used for the thermal product. At lower electricity prices, the value of the capacity payment is insufficient to incentivize inclusion of the thermal power cycle in the optimal configuration. 

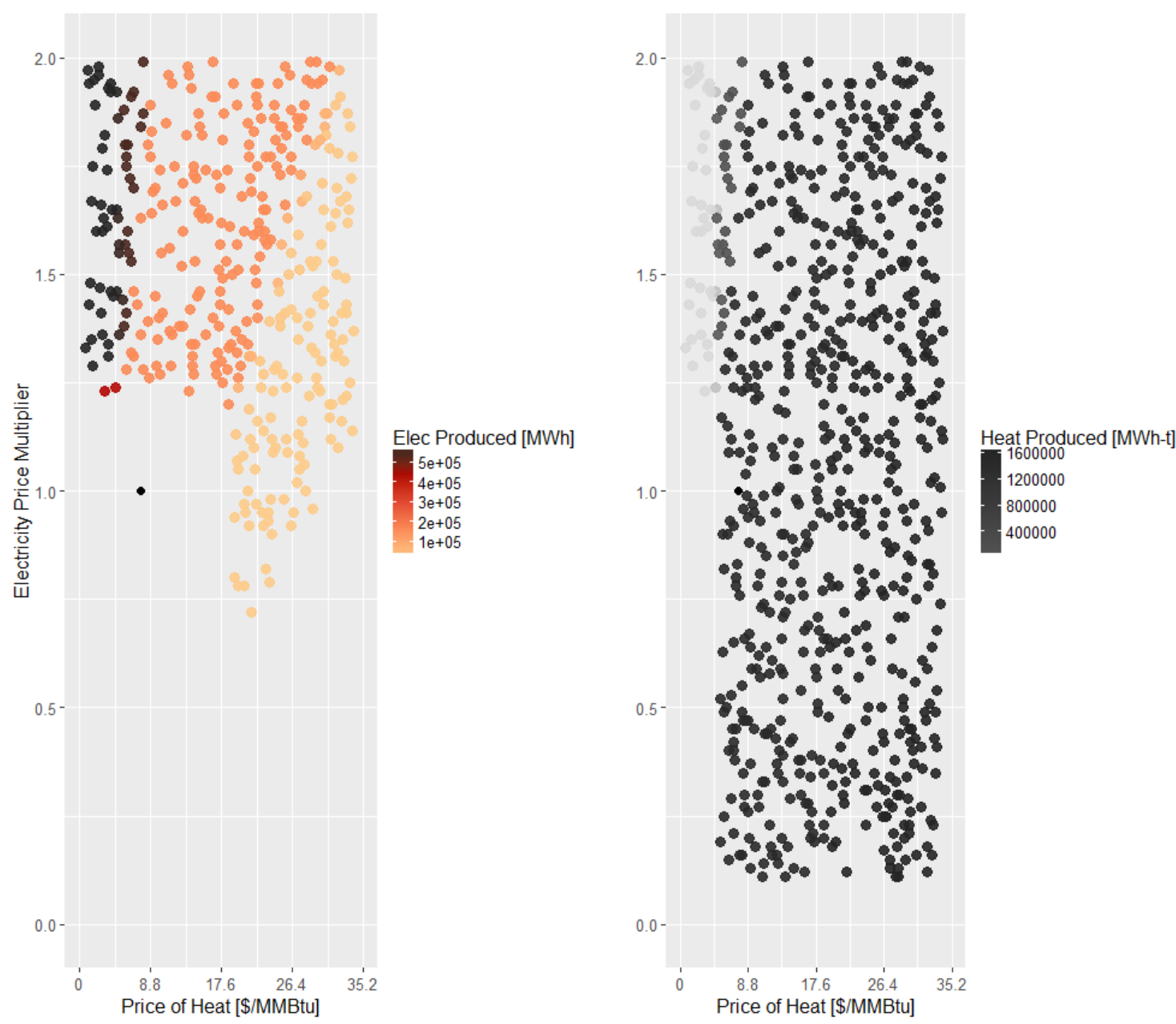

Figure 5. Optimal annual product generation for the Electric Boiler Scenario at various heat prices and electricity price multipliers

Electricity is on the left; darker colors indicate greater generation. The thermal product is on the right. Electricity pricing based on AEO reference case and \$50/kW-yr capacity payments.

Solid black dot at $\$ 7.70 / \mathrm{MMBtu}$ and 1.0 indicates reference case prices of heat and electricity. 


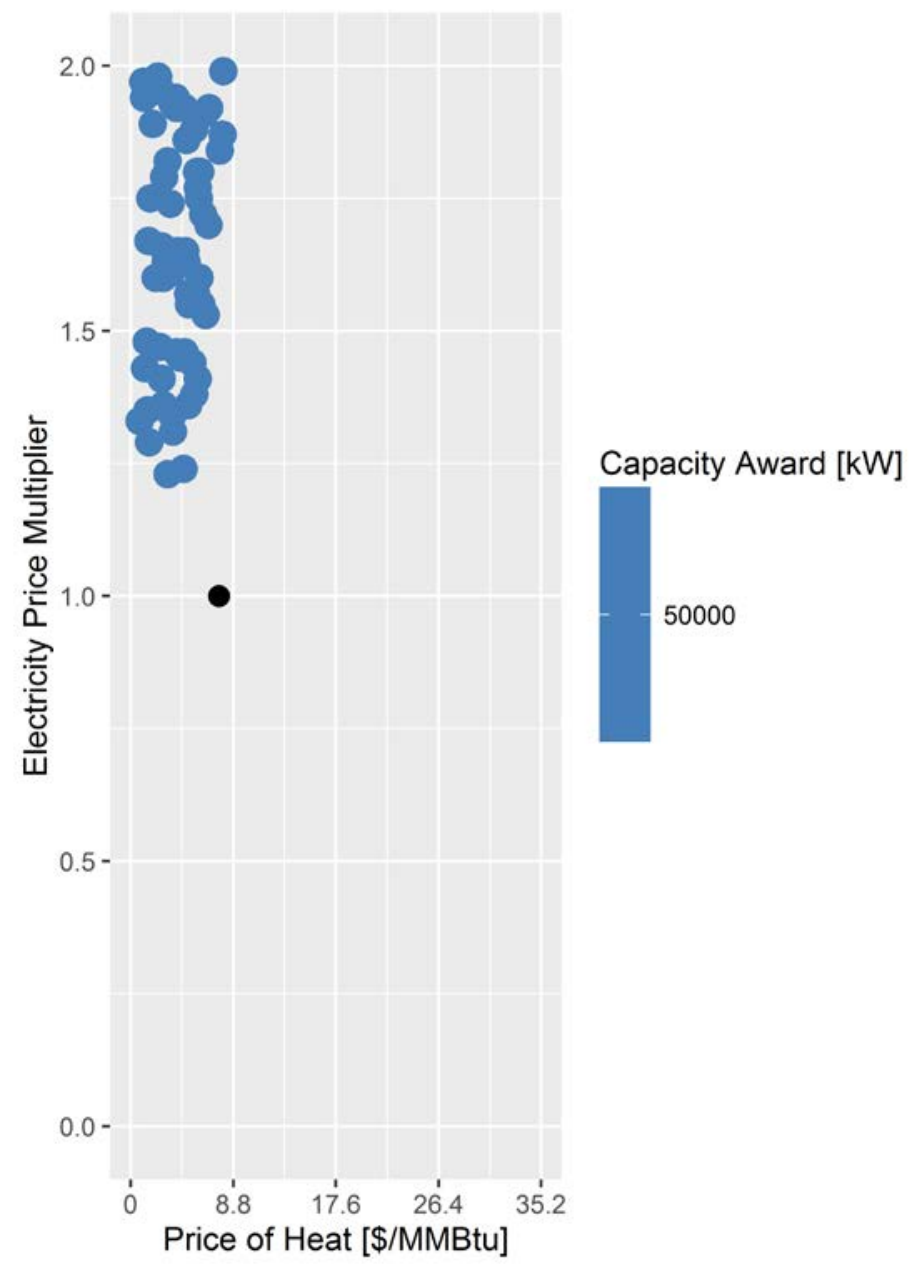

Figure 6. Optimal capacity payments awarded for the Electric Boiler Scenario at various heat prices and electricity price multipliers

Solid black dot at $\$ 7.70 / \mathrm{MMBtu}$ and 1.0 indicates reference case prices of heat and electricity.

Figure 7 shows the NPVs for the optimal configurations shown in Figure 4. Note that profitability increases more dramatically with rising thermal product prices than with rising electricity prices. 


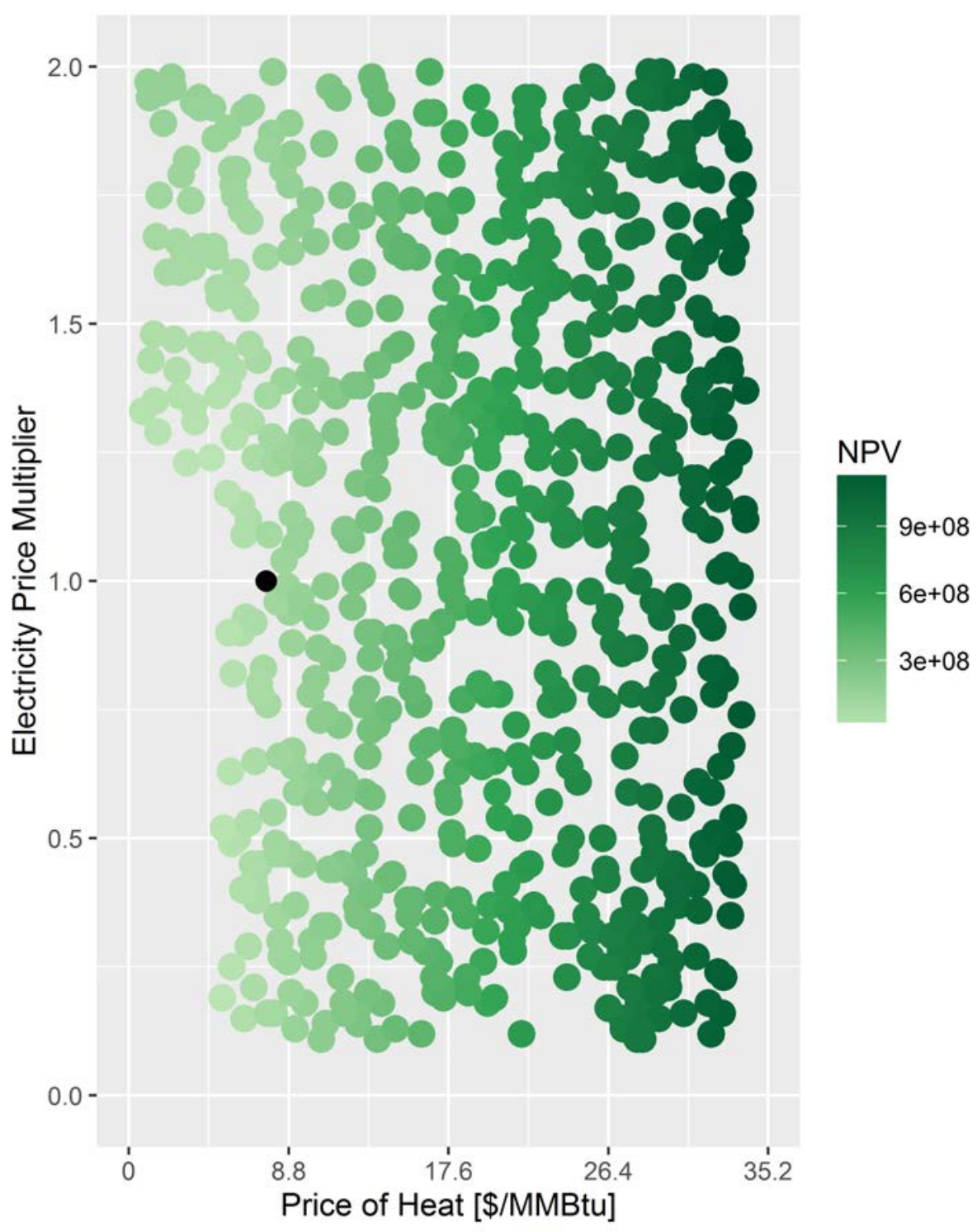

Figure 7. Electric Boiler Scenario NPVs at various heat prices and electricity price multipliers

Electricity pricing based on AEO reference case and $\$ 50 / \mathrm{kW}$-yr capacity payments.

Darker shades indicate higher NPVs.

Solid black dot at $\$ 7.70 / \mathrm{MMBtu}$ and 1.0 indicates reference case prices of heat and electricity.

Table 7 provides the present values of all the annual revenues and expenses under the base case parameters for the optimal configuration (a nuclear reactor providing heat as a thermal product). For comparison, present values for three alternative configurations are also provided. In the first of those configurations, a thermal power cycle is added where electricity is only produced during hours when the net income for electricity is greater than the net income for heat (i.e., when the price of electricity is high). The second alternative configuration adds a wind power plant to the subsystems in the first alternative configuration. The wind power plant produces electricity that is sold to the grid. The third alternative configuration adds an electric boiler that converts electricity from the wind power plant to heat during hours when the price of electricity is low enough that net income from electricity would be less than net income from the thermal product. 
Table 7. Electric Boiler Scenario Present Values at Base Case Conditions for Four Configurations

(Negative values indicate expenses and positive indicate income)

\begin{tabular}{|c|c|c|c|c|}
\hline \multirow[t]{8}{*}{ Configuration } & $\begin{array}{l}\text { Nuclear } \\
\text { Reactor } \\
\text { (167 MWt) }\end{array}$ & $\begin{array}{l}\text { Nuclear } \\
\text { Reactor } \\
\text { (167 MWt) }\end{array}$ & $\begin{array}{l}\text { Nuclear } \\
\text { Reactor } \\
\text { (167 MWt) }\end{array}$ & $\begin{array}{l}\text { Nuclear } \\
\text { Reactor } \\
\text { (167 MWt) }\end{array}$ \\
\hline & & + & + & + \\
\hline & & $\begin{array}{l}\text { Thermal Power } \\
\text { Cycle (50 MWe) }\end{array}$ & $\begin{array}{l}\text { Thermal Power } \\
\text { Cycle (50 MWe) }\end{array}$ & $\begin{array}{l}\text { Thermal Power } \\
\text { Cycle (50 MWe) }\end{array}$ \\
\hline & & & + & + \\
\hline & & & $\begin{array}{l}\text { Wind Power } \\
\text { Plant } \\
\text { (50 MWe) }\end{array}$ & $\begin{array}{l}\text { Wind Power } \\
\text { Plant } \\
\text { (50 MWe) }\end{array}$ \\
\hline & & & & + \\
\hline & & & & $\begin{array}{l}\text { Electric Boiler } \\
(50 \mathrm{MWe}) \\
\end{array}$ \\
\hline & $\begin{array}{l}\text { Present Value } \\
\text { (\$million) }\end{array}$ & $\begin{array}{l}\text { Present Value } \\
\text { (\$million) }\end{array}$ & $\begin{array}{l}\text { Present Value } \\
\text { (\$million) }\end{array}$ & $\begin{array}{l}\text { Present Value } \\
\text { (\$million) }\end{array}$ \\
\hline \multicolumn{5}{|l|}{ Nuclear Plant } \\
\hline $\begin{array}{l}\text { Reactor Capital } \\
\text { Expenditure (Capex) }\end{array}$ & $-\$ 186$ & $-\$ 186$ & $-\$ 186$ & $-\$ 186$ \\
\hline Nuclear Fixed O\&M & $-\$ 55$ & $-\$ 55$ & $-\$ 55$ & $-\$ 55$ \\
\hline \multicolumn{5}{|l|}{ Thermal Power Cycle } \\
\hline $\begin{array}{l}\text { Thermal Power Cycle } \\
\text { Capex }\end{array}$ & $\$ 0$ & $-\$ 65$ & $-\$ 65$ & $-\$ 65$ \\
\hline \multicolumn{5}{|l|}{ Wind Power Plant } \\
\hline Capex & $\$ 0$ & $\$ 0$ & $-\$ 84$ & $-\$ 84$ \\
\hline Fixed O\&M & $\$ 0$ & $\$ 0$ & $-\$ 27$ & $-\$ 27$ \\
\hline \multicolumn{5}{|l|}{ Electric Boiler } \\
\hline Capex & $\$ 0$ & $\$ 0$ & $\$ 0$ & $-\$ 4$ \\
\hline \multicolumn{5}{|l|}{ Revenue } \\
\hline Purchased Electricity & $\$ 0$ & $\$ 0$ & $\$ 0$ & $\$ 0$ \\
\hline Thermal Product Revenue & $\$ 434$ & $\$ 430$ & $\$ 431$ & $\$ 437$ \\
\hline Capacity Payments & $\$ 0$ & $\$ 29$ & $\$ 29$ & $\$ 29$ \\
\hline Electricity Revenue & $\$ 0$ & $\$ 2$ & $\$ 97$ & $\$ 96$ \\
\hline Ancillary Services & $\$ 0$ & $\$ 4$ & $\$ 4$ & $\$ 4$ \\
\hline Taxes & $-\$ 99$ & $-\$ 98$ & $-\$ 99$ & $-\$ 101$ \\
\hline NPV & $\$ 94$ & $\$ 61$ & $\$ 44$ & $\$ 43$ \\
\hline
\end{tabular}

Capex: capital expenditure

Table 8 compares other financial parameters of the nuclear-only configuration and the alternatives identified in Table 7. At $\$ 94$ million, the NPV for the simplest configuration is much 
higher than the options with additional subsystems. Adding the thermal power cycle increases the total capital investment (TCI) by $\$ 65$ million, from $\$ 186$ million to $\$ 251$ million. Most of the increased income with the thermal power cycle comes from capacity payments, with a small amount from the ability to sell electrical energy and ancillary services. The net impact is a \$33million-dollar reduction in the NPV, from $\$ 94$ million to $\$ 61$ million.

Adding wind generation increases the capital expenditure by $\$ 84$ million and requires an additional operating cost. Because of the high penetration of wind generation on the grid used for this simulation, the impact on the NPV is a further reduction to $\$ 44$ million. Because the wind power plant generates electricity during some hours when its price is zero, adding an electric boiler could increase the thermal product sales and improve the economics of the plant. However, the increased sales also increase taxes, and the net between them does not cover the cost of the boiler.

Each additional subsystem not only decreases the NPV but also increases the TCI; therefore, the profitability metric (NPV/TCI) decreases with each additional subsystem.

Table 8. Electric Boiler Scenario Output Summary at Base Case Conditions for Four Configurations

\begin{tabular}{|c|c|c|c|c|}
\hline Configuration & $\begin{array}{l}\text { Nuclear Reactor } \\
\text { (167 MWt) }\end{array}$ & $\begin{array}{c}\text { Nuclear Reactor } \\
\text { (167 MWt) } \\
+ \\
\text { Thermal Power } \\
\text { Cycle (50 MWe) }\end{array}$ & 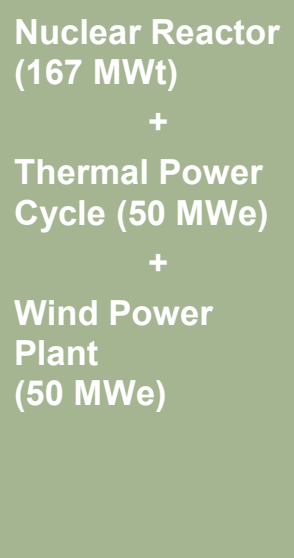 & 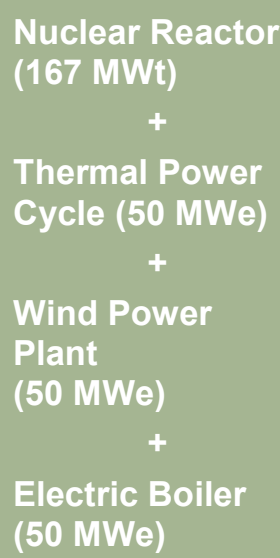 \\
\hline $\begin{array}{l}\text { Annual Electricity } \\
\text { Output (GWh) }\end{array}$ & 0 & 4.1 & 157 & 155 \\
\hline $\begin{array}{l}\text { Annual Thermal } \\
\text { Energy Produced } \\
\text { (mmBtu) }\end{array}$ & $4,980,000$ & $4,930,000$ & $4,940,000$ & $5,010,000$ \\
\hline TCI (\$million) & $-\$ 186$ & $-\$ 251$ & $-\$ 336$ & $-\$ 340$ \\
\hline $\begin{array}{l}\text { NPV at } 10 \% \text { Discount } \\
\text { Rate (\$million) }\end{array}$ & $\$ 94.4$ & $\$ 61.3$ & $\$ 44.0$ & $\$ 43.3$ \\
\hline $\begin{array}{l}\text { Payback Period } \\
\text { (years) }\end{array}$ & 10.5 & 14.8 & 18.0 & 18.1 \\
\hline $\begin{array}{l}\text { IRR after } 25 \text { years of } \\
\text { operation }\end{array}$ & $5.8 \%$ & $2.9 \%$ & $1.6 \%$ & $1.6 \%$ \\
\hline NPV/TCI Ratio & 0.51 & 0.24 & 0.13 & 0.13 \\
\hline
\end{tabular}

IRR: internal rate of return 
Table 9 compares nuclear-generated heat to natural gas-generated heat, providing the same amount of thermal energy over the course of the year with the heat price of \$7.55/MMBtu. Note that the natural gas boiler has an NPV of $\$ 0$ because we set the heat price such that it covers the capital and operating costs of a natural gas boiler with a $10 \%$ discount rate. Table 9 shows that, using our capital and operating cost assumptions, nuclear-generated heat is less expensive than natural gas.

Table 9. Financial Comparison Between Nuclear-Only Configuration and Natural Gas Boiler

\begin{tabular}{|llllll|} 
& $\begin{array}{l}\text { NPV @ 10\% } \\
\text { Discount } \\
\text { Rate }\end{array}$ & TCI & $\begin{array}{l}\text { NPV/TCI } \\
\text { Ratio }\end{array}$ & IRR & $\begin{array}{l}\text { Annual } \\
\text { Electricity } \\
\text { Output } \\
\text { (GWh) }\end{array}$ \\
\hline $\begin{array}{l}\text { Nuclear reactor (167 MWt) } \\
\text { Natural gas boiler (167 } \\
\text { MWt) }\end{array}$ & $\$ 0$ & $\$ 7.4$ million million & 0.00 & $0 \%$ & 0 \\
\hline
\end{tabular}

For Scenario 1, the full N-R HES (LW-SMR nuclear reactor-thermal power cycle-wind power plant-electric boiler) is not the economically optimal solution under the base case electricity and heat prices. Instead, the most profitable configuration is one that includes only a nuclear reactor providing heat. This option has an NPV that is $\$ 51.1$ million greater than that of the full N-R HES and a $0.51 \mathrm{NPV} / \mathrm{TCI}$ ratio, compared to the 0.13 of the full N-R HES.

From these results, we conclude that income from the full N-R HES configuration for this scenario exceeds the required cost of capital but it is not as profitable as the alternative configuration that produces the thermal product alone.

\subsubsection{Potential to Reduce GHG Emissions and their Associated Costs}

One of the key potential benefits of N-R HESs is the potential to reduce carbon emissions and, if a cost of carbon is applied, the associated costs of those emissions. Table 10 compares the potential impacts of using nuclear-generated thermal energy to natural gas-generated thermal energy under several costs of carbon. The configurations reported are the thermal-energy-only figures because the Electric Boiler Scenario's optimal solution under the base case pricing is simply production of thermal energy by the nuclear reactor. The annual cost of carbon and potential impacts of a cost of carbon on the NPV and NPV/TCI ratio at all four costs of carbon are reported in Section 2.6. The natural gas boilers emit $117 \mathrm{lb} \mathrm{CO} / \mathrm{MMBtu}$ due to combustion.

With the base case parameters, using natural gas heat instead of nuclear heat increases $\mathrm{CO}_{2}$ emissions by 281,000 metric tons annually and, at all costs of carbon, results in negative NPVs and NPV/TCI ratios. 
Table 10. Financial Comparison between Nuclear-Generated Heat and Heat Generated Using Natural Gas Including Costs of Carbon

\begin{tabular}{|c|c|c|c|c|c|}
\hline & $\begin{array}{l}\mathrm{CO}_{2} \\
\text { Emissions } \\
\text { (metric ton } \\
\mathrm{CO}_{2} / \mathrm{yr} \text { ) }\end{array}$ & $\begin{array}{l}\text { Cost of } \\
\text { Carbon } \\
\text { (levelized) }\end{array}$ & $\begin{array}{l}\text { NPV with Cost } \\
\text { of Carbon }\end{array}$ & $\mathrm{TCl}$ & $\begin{array}{l}\text { NPV/TCI } \\
\text { Ratio with } \\
\text { Cost of } \\
\text { Carbon }\end{array}$ \\
\hline Nuclear heat & 0 & $\$ 0$ & $\$ 94.4$ million & $\begin{array}{l}\$ 186 \\
\text { million }\end{array}$ & 0.51 \\
\hline \multirow{4}{*}{ Natural gas heat } & \multirow{4}{*}{281,000} & $\$ 82$ million & -\$82 million & \multirow{4}{*}{$\$ 7$ million } & -11.5 \\
\hline & & $\$ 228$ million & $-\$ 228$ million & & -32.1 \\
\hline & & \$318 million & -\$318 million & & -44.7 \\
\hline & & $\$ 700$ million & -\$700 million & & -98.5 \\
\hline
\end{tabular}

Using nuclear heat for this industrial process reduces the $\mathrm{CO}_{2}$ emissions when compared to natural gas-generated heat. For natural gas-generated heat at a thermal product price of \$7.55/MMBtu, any cost of carbon results in a negative NPV. Any cost of carbon makes the financial benefits of nuclear-generated heat greater and decreases the probability of investment in natural gas boilers.

\subsubsection{Potential to Support Resource Adequacy}

We tested the hypothesis that N-R HESs can support electricity resource adequacy while maximizing production of a more profitable industrial product with sufficient incentives (i.e., a capacity payment that is sufficiently high). In this analysis, the Electric Boiler Scenario did not select a configuration that includes the thermal power cycle at a capacity payment of $\$ 50 / \mathrm{kW}-\mathrm{yr}$ and base case prices. The thermal power cycle's cost combined with the opportunity cost of not making heat during the hours necessary to receive the capacity payment was greater than the potential income. Figure 9 shows the price ranges where capacity payments are received at three different capacity payment levels: $\$ 50 / \mathrm{kW}-\mathrm{yr}, \$ 100 / \mathrm{kW}-\mathrm{yr}$, and $\$ 150 / \mathrm{kW}-\mathrm{yr}$.

Increased capacity payments increase the incentive to build electricity generation. As shown in Figure 8 , increased capacity payments result in lower hourly electricity prices necessary for optimal configurations to include thermal power cycles. Increasing the capacity payment from $\$ 50 / \mathrm{kW}$-yr to $\$ 100 / \mathrm{kW}$-yr has little effect unless the price of the thermal product is below $\$ 5.00 / \mathrm{MMBtu}$. In that case, a slightly lower electricity multiplier is necessary to build any configuration with an income that exceeds the required cost of capital. The configuration with the lowest required electricity multiplier sells both thermal energy and enough electricity to receive the capacity payment.

The higher capacity payment of $\$ 150 / \mathrm{kW}$-yr results in an optimal configuration that sells both thermal energy and enough electricity to receive the capacity payment at all profitable combinations with electricity multipliers below 1.0. The higher capacity payment also incentivizes including a thermal power cycle at all thermal product prices because the capacity payment's value overcomes the increased capital cost and reduction in thermal production. That difference is shown by the pink dots in the $\$ 150 / \mathrm{kW}$-yr capacity payment figure in place of the blue dots in the other two figures. 
Higher capacity payments lead to increased electricity generation during peak hours (i.e., those required to receive the capacity payment). Figure 10 shows the optimal annual electricity production under the three capacity payments. It shows that at higher capacity payments, electricity is generated up to the highest heat prices considered in the analysis. The result indicates that this N-R HES can support grid resource adequacy as long as the capacity payment is sufficient.

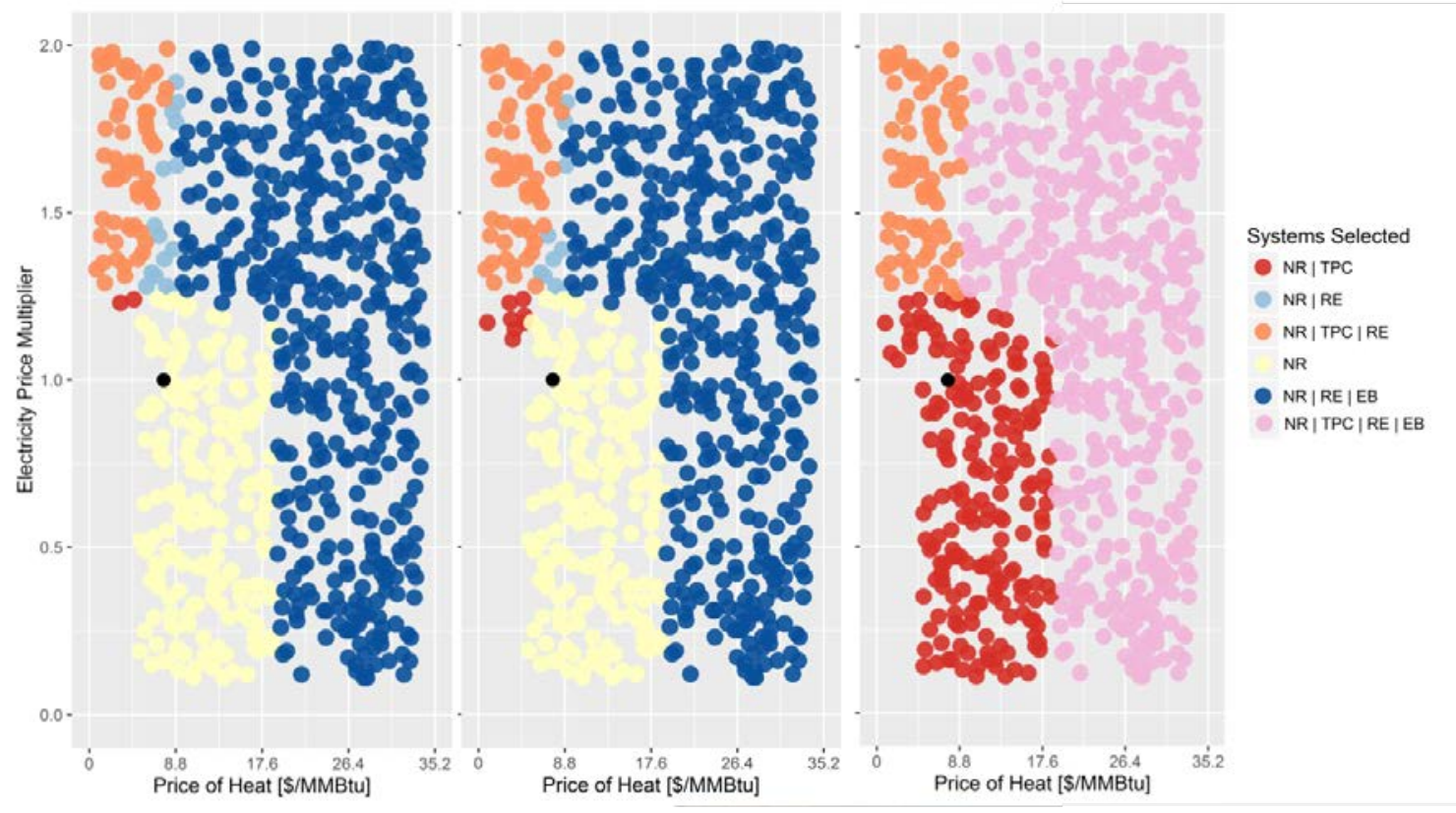

Figure 8. Optimal configurations for the Electric Boiler Scenario at various heat prices and electricity price multipliers at three levels of capacity payments

\$50/kW-yr (left); \$100/kW-yr (middle); \$150/kW-yr (right)

EB: Electric boiler

NR: Nuclear reactor

RE: Renewable electricity generation

TPC: Thermal power cycle

Solid black dot at $\$ 7.70 / \mathrm{MMBtu}$ and 1.0 indicates reference case prices of heat and electricity 


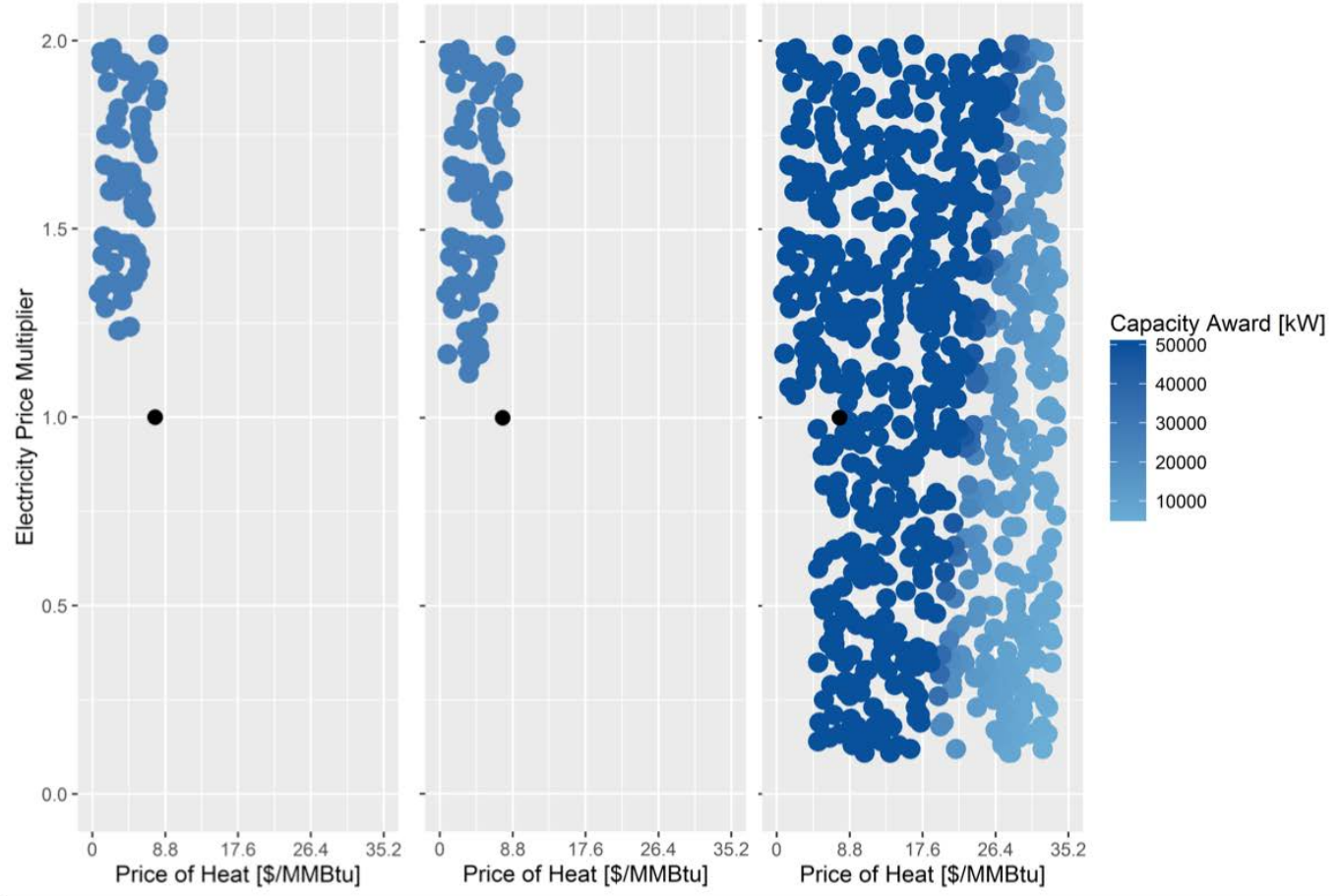

Figure 9. Optimal capacity payments awarded for the Electric Boiler Scenario at various heat prices and electricity price multipliers at three levels of capacity payments

\$50/kW-yr (left); \$100/kW-yr (middle); \$150/kW-yr (right)

Solid black dot at $\$ 7.70 / \mathrm{MMBtu}$ and 1.0 indicates reference case prices of heat and electricity 

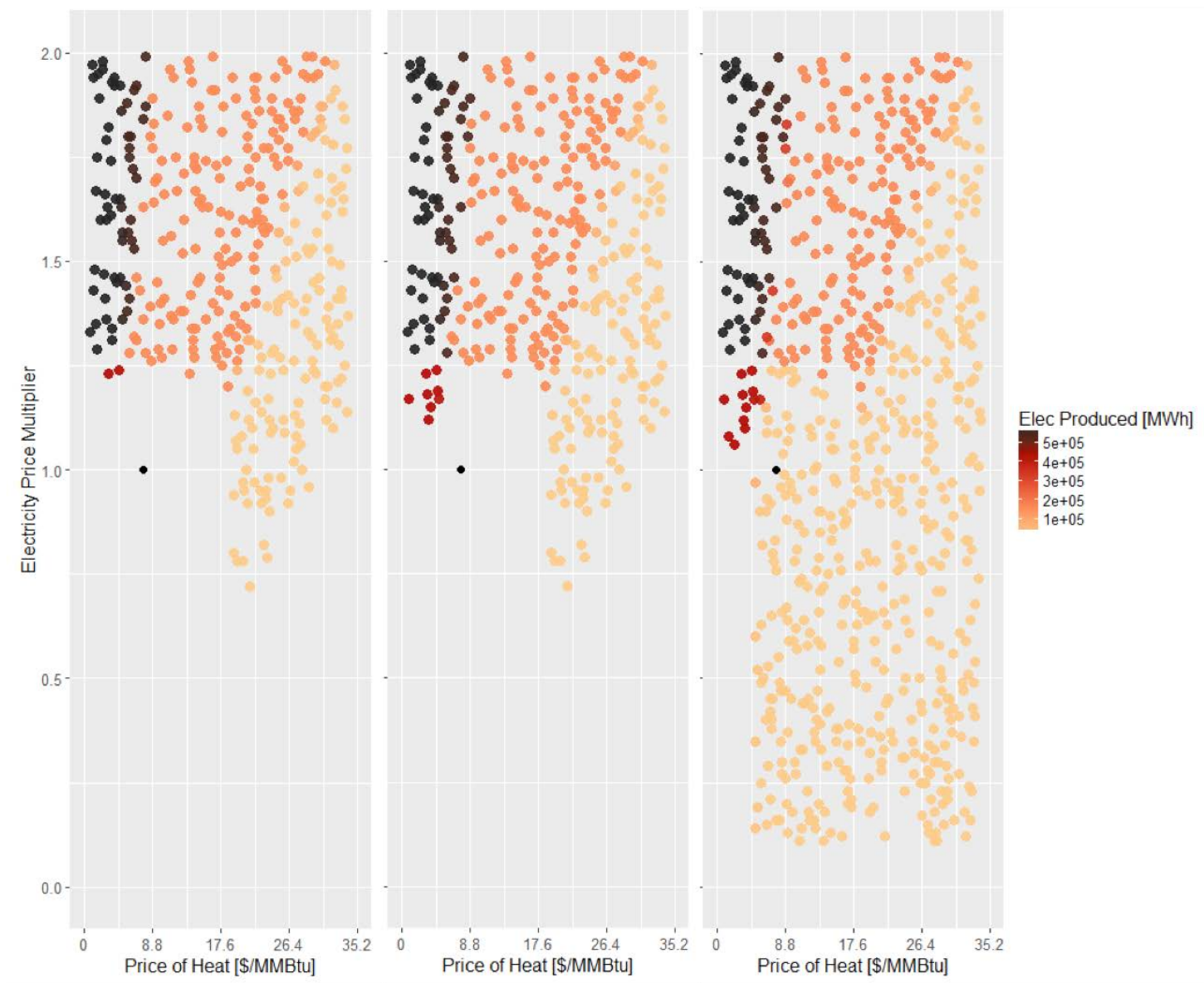

Figure 10. Optimal annual electricity production for Electric Boiler Scenario at various heat prices and electricity price multipliers at three levels of capacity payments

\$50/kW-yr (left); \$100/kW-yr (middle); \$150/kW-yr (right)

Solid black dot at $\$ 7.70 / \mathrm{MMBtu}$ and 1.0 indicates reference case prices of heat and electricity

\subsubsection{Potential for Flexibility to Increase Profitability}

We tested the hypothesis that, at some combinations of electricity and product prices, N-R HESs would be more profitable than uncoupled configurations because they can produce electricity when its price is high and the industrial product when the price of electricity is low.

Based on this analysis, some configurations are more profitable because they can adjust their product to follow market prices. In Figure 10, that situation is most noticeable at the highest electricity and thermal product prices, when heat is sold during some hours (orange dots) because it still has value even though the price of electricity is $\$ 0 / \mathrm{MWh}$ during those hours.

\subsubsection{Potential for Electricity-to-Heat Conversion to Increase Wind Capacity}

We tested the hypothesis that, at some combinations of electricity and thermal product prices, optimally configured N-R HESs include wind generation only because the wind-generated electricity is converted to heat. Thus, wind generation would be profitably built where otherwise it would not be. 
Figure 4 shows that at thermal product prices below $\$ 19.00 / \mathrm{MMBtu}$, the wind power plant is only included in the optimal configuration if the electricity price multiplier is above 1.25 . When the thermal product price is above $\$ 19.00 / \mathrm{MMBtu}$, the wind power plant is included in all profitable configurations. Those results indicate that the hypothesis is true as long as the price of the thermal product is high. Note that the breakpoint of $\$ 19.00 / \mathrm{MMBtu}$ is much higher than the thermal product's reference case price of $\$ 7.55 / \mathrm{MMBtu}$.

\subsection{Results for the Electric Thermal Storage Scenario}

Scenario 2, the Electric Thermal Storage Scenario, consists of four primary subsystems: (1) a nuclear reactor, (2) a thermal power cycle that can be associated with the nuclear reactor, (3) a wind power plant, and (4) an electric thermal storage unit-a unit operation that both converts electricity to thermal energy and stores that thermal energy. We set the same maximum size for the nuclear reactor, the thermal power cycle, and the wind power plant to the same value -50 MWe. The thermal power cycle efficiency of 30\% implies a thermal capacity of $167 \mathrm{MWt}$ for the nuclear reactor.

In Scenario 2, the electric thermal storage subsystem can generate heat from electricity. The thermal product can be sold immediately or stored and sold at a later hour. We set the maximum size of the electric thermal storage unit to $100 \mathrm{MWe}$ so that it can simultaneously generate heat for storage and heat to be sold as the thermal product. The total thermal product is held constant over all hours of the year. In other words, the customer(s) receive a consistent source of heat. Unlike the Electric Boiler Scenario, the customers do not need to adapt to varying rates of thermal energy availability. We set the maximum rate of the thermal product to $217 \mathrm{MWt}$. The electric thermal storage unit has a constant charge and discharge rate of $1 \mathrm{kWt}: 5 \mathrm{kWht}$ of storage.

As with the other scenarios, we used REopt to determine the optimal size of each subsystem and the energy flow on an hourly basis. It allows for energy to be split (i.e., some of the thermal energy from the nuclear reactor can be used for the industrial process and the remainder for electricity) during any hour if that provides the optimal solution.

\subsubsection{Potential Profitability}

We analyzed the potential profitability of the N-R HES with an electric boiler and thermal storage by varying the prices of the electricity and thermal products and using REopt to calculate the optimal subsystem combinations and internal dispatch, as discussed in Section 2.1. We varied the price of the thermal product from $\$ 0 / \mathrm{MMBtu}$ to $\$ 35.00 / \mathrm{MMBtu}$. The range was chosen to show the impacts of various prices. We varied the price of electricity using a multiplier that affected the electrical energy price for all 8,760 hours in the year. ${ }^{\S}$ In each case, the multiplier was randomly assigned a value between 0 and 2; thus, the electrical energy price in that case could be $\$ 0 / \mathrm{MWh}$ for every hour of the year, twice the electrical energy price developed for the reference case, or any other multiplied value between 0 and 2 . The electricity multiplier could be considered a combination of (1) the difference between marginal generation costs and market prices (due to bidding strategies) and (2) uncertainty in the natural gas price because natural gas

\footnotetext{
$\S$ Prices of ancillary services (reserves, flex reserves, and regulation up and down) were not multiplied because a change in price has little effect on the operational selection and optimization.
} 
is on the operating cost margin for the vast majority of the year. Unless stated otherwise, all other parameters remain at the reference values. Note that this analysis assumes perfect foresight of all expenses and product prices throughout the project life.

Figure 11 shows the optimal configuration selections for $\approx 500$ combinations of thermal product prices and electricity multipliers. These values were independently, randomly sampled from a uniform distribution across the ranges described above. The results of this analysis indicate that:

- If the electricity price multiplier is below 1.22 and the thermal product's price is below $\$ 5.00 / \mathrm{MMBtu}$, no configurations have incomes that exceed the required cost of capital (i.e., the NPV is less than zero for all combinations).

- If the electricity price multiplier is between 1.22 and 1.25 and the price of the thermal product is below $\$ 5.00 / \mathrm{MMBtu}$ (as shown by the red dots), the LW-SMR with a thermal power cycle has sufficient income to meet the required cost of capital and the configuration produces electricity when its price is above zero. During hours when the electricity price is $\$ 0 / \mathrm{kWh}$, the configuration produces and sells heat.

- If the electricity price multiplier is below 1.25 and thermal product's price is between $\$ 5.00 /$ MMBtu and $\$ 18.00 / \mathrm{MMBtu}$ at an electricity multiplier of 1.25 , just above $\$ 5.00 /$ MMBtu at an electricity multiplier of 0.2 , or to the left of the line between those two values (as shown by the yellow dots), the nuclear reactor generates and sells thermal energy exclusively (i.e., it does not generate any electricity).

- If the electricity price multiplier is below 0.95 and thermal product's price is above the line between $\$ 5.00 / \mathrm{MMBtu}$ with an electricity multiplier of 0.2 and \$19.00/MMBtu with an electricity multiplier of 0.95 (as shown by the green dots), both the nuclear reactor and the electric thermal storage unit produce heat. The electric thermal storage unit uses grid electricity to generate the heat but it does not charge the storage system during all hours out of the year. Instead, the optimal configuration includes the thermal storage unit and charges that storage unit during periods with low cost electricity while discharging at a constant rate

- If the electricity price multiplier is above 0.95 and the thermal product's price is above $\$ 18.00 / \mathrm{MMBtu}$ with that price increasing as the electricity price multiplier increases (as shown by the dark blue dots), the nuclear reactor generates and sells thermal energy exclusively (i.e., it does not generate any electricity), the wind power plant generates electricity, and an electric thermal storage unit converts both wind and grid electricity to heat.

- A few cases near the left of the dark blue dots are indicated by pink dots. In those cases, the wind power plant generates electricity, an electric thermal storage unit converts both wind and grid electricity to heat, and the nuclear reactor primarily sells heat but can use a thermal power cycle to produce enough electricity to receive the capacity payments.

- If the electricity multiplier is above 1.25 , the thermal product's price is above $\$ 5.00 / \mathrm{MMBtu}$, and the prices of the thermal product and electricity are in the range indicated by the light blue dots, the nuclear reactor generates and sells thermal energy exclusively (i.e., it does not generate any electricity) and a wind power plant generates and sells electricity to the grid exclusively. The value of electricity is too high for wind or 
grid electricity to be used to produce the thermal product but is not high enough for the nuclear-generated thermal energy to be used to generate electricity.

- If the electricity multiplier is above 1.25 , the thermal product's price is below \$5.00/MMBtu (as indicated by the orange dots), income for the LW-SMR with a thermal power cycle exceeds the required cost of capital, and the configuration produces electricity when its price is above zero and a wind power plant generates and sells electricity exclusively.

The solid black dot indicates the reference case thermal energy product price (\$7.70/MMBtu) and the electricity price vector developed for this analysis (the multiplier is 1.0). To estimate the reference case thermal product price, we estimated the cost of a natural gas boiler to produce the thermal energy without a cost of carbon, as discussed in Section 2.7 above. 


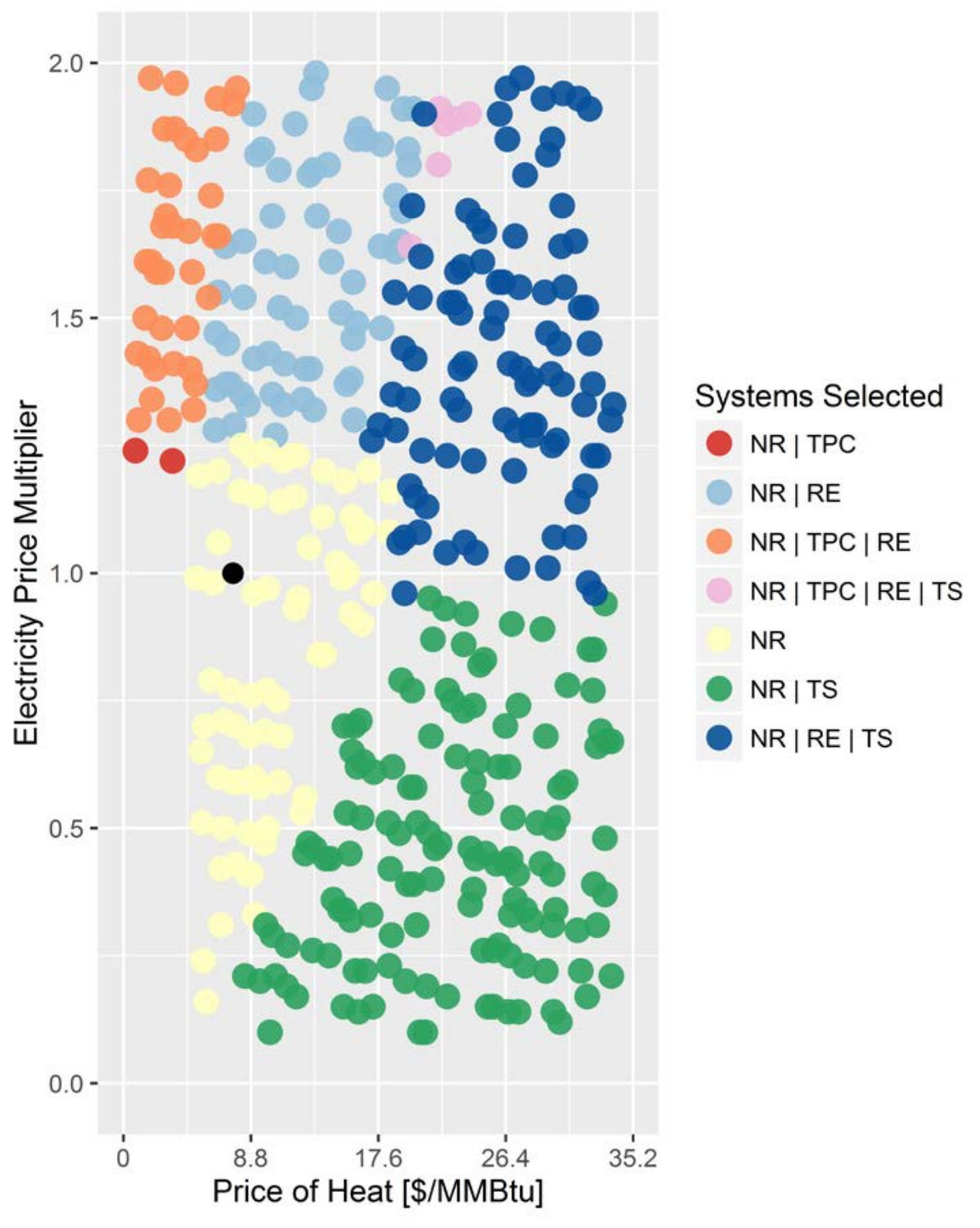

Figure 11. Optimal configurations for the Electric Thermal Storage Scenario at various heat prices and electricity price multipliers

NR: Nuclear reactor

RE: Renewable electricity generation

TPC: Thermal power cycle

TS: Thermal storage (the electric thermal storage unit)

Solid black dot at $\$ 7.70 / \mathrm{MMBtu}$ and 1.0 indicates reference case prices of heat and electricity.

Figure 12 shows the optimal constant thermal product production rate from the N-R HES at various heat prices and electricity price multipliers. Note that the lower thermal energy production rate is the maximum generation from the nuclear reactor $(167 \mathrm{MWt})$ and the higher heat rate is that generation plus the maximum thermal rate available from the electric boiler (217 MWt). In most cases, the heat generation is at one value or the other for all hours during the year depending upon the ratio of the average electricity price and thermal product price. At some points near the top of the interface, some thermal production is sacrificed (i.e., the thermal 
product generation rate is lower than $217 \mathrm{MWt}$ ) to receive capacity payments. Other points in those price ranges indicate conditions where the optimal operational conditions require differing amounts of electricity purchased and sold to enable constant heat generation.

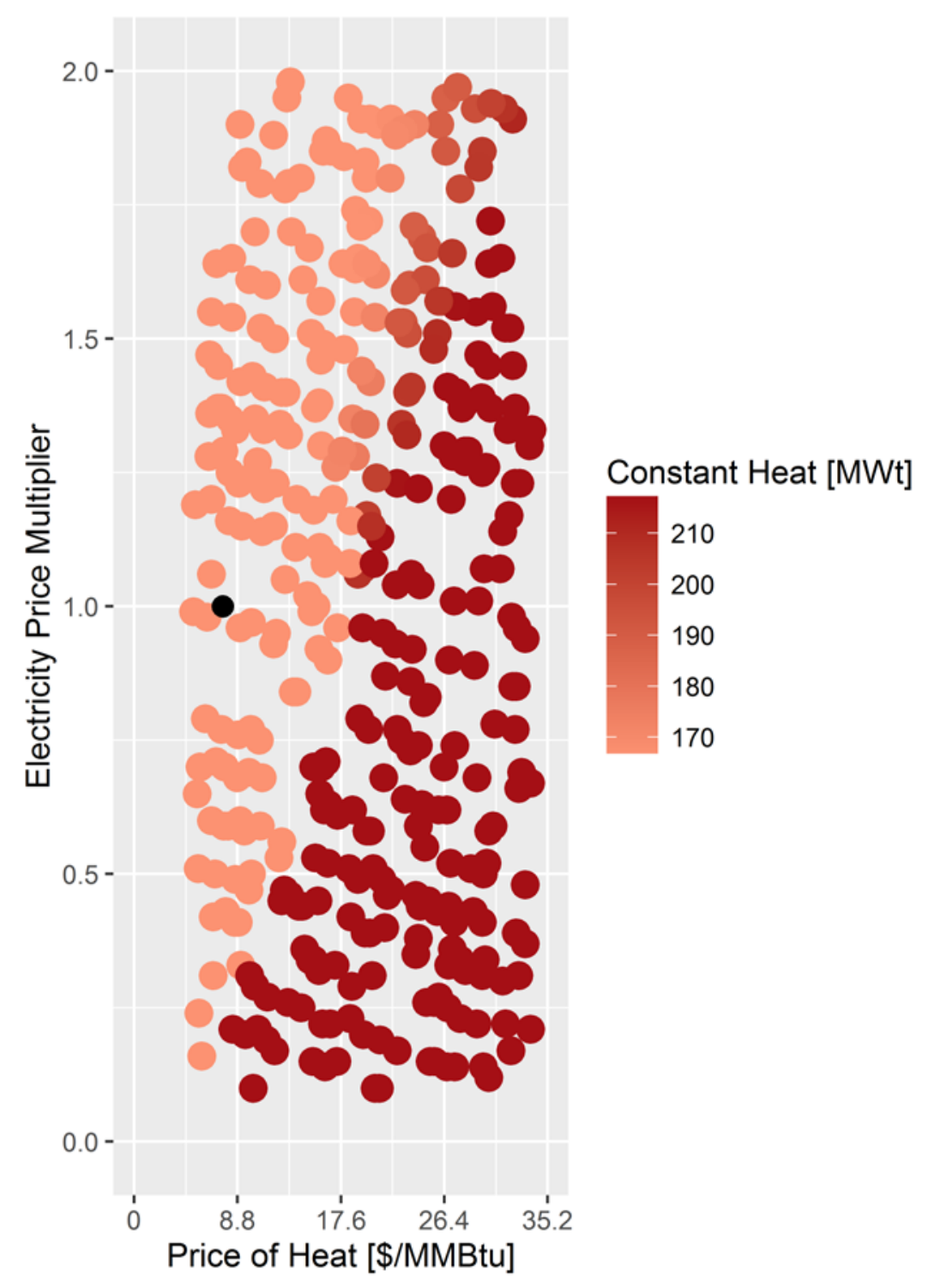

Figure 12. Optimal constant thermal product generation rate for the Electric Thermal Storage Scenario at various heat prices and electricity price multipliers

Solid black dot at $\$ 7.70 / \mathrm{MMBtu}$ and 1.0 indicates reference case prices of heat and electricity.

Figure 13 shows the optimal thermal storage capacity in the N-R HES at various heat prices and electricity price multipliers. Note that thermal storage is only selected as a subsystem in the ideal systems in the green, dark blue, and pink dots in Figure 11. For low electricity prices, the storage is sized such that it can always charge and discharge 50MWt (to reach the maximum constant thermal demand of $217 \mathrm{MWt}$; additional storage is not necessary because of the low cost of electricity. In most cases, the thermal storage unit's capacity is $\sim 1000 \mathrm{MWh}-\mathrm{t}$ because the 
storage unit is sized to charge with low-cost electricity and discharge to maintain the constant rate of $217 \mathrm{MWt}$.

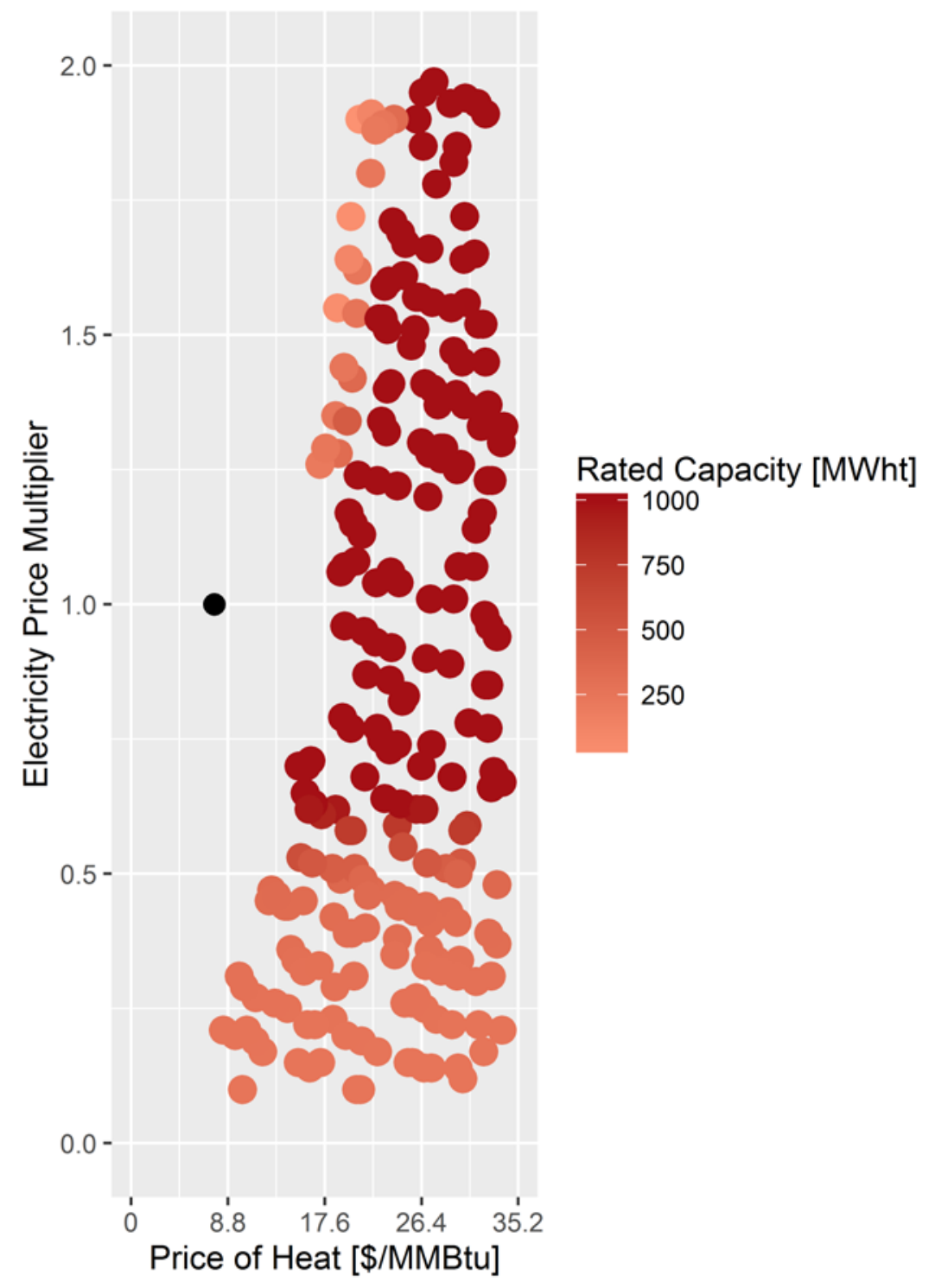

Figure 13. Optimal thermal storage capacity for the Electric Thermal Storage Scenario at various heat prices and electricity price multipliers

Solid black dot at $\$ 7.70 / \mathrm{MMBtu}$ and 1.0 indicates reference case prices of heat and electricity

Figure 14 shows the optimal capacity of the wind power plant for the configurations with wind power plants as shown in Figure 11 (the orange, light blue, pink, and dark blue dots). Note that in almost all cases, the wind power plant is at maximum capacity $(50 \mathrm{MW})$. The exception is the interface where low electricity prices do not warrant the full system size, with wind entering the solution at the lowest size (and electricity multiplier) at the highest thermal energy price. 


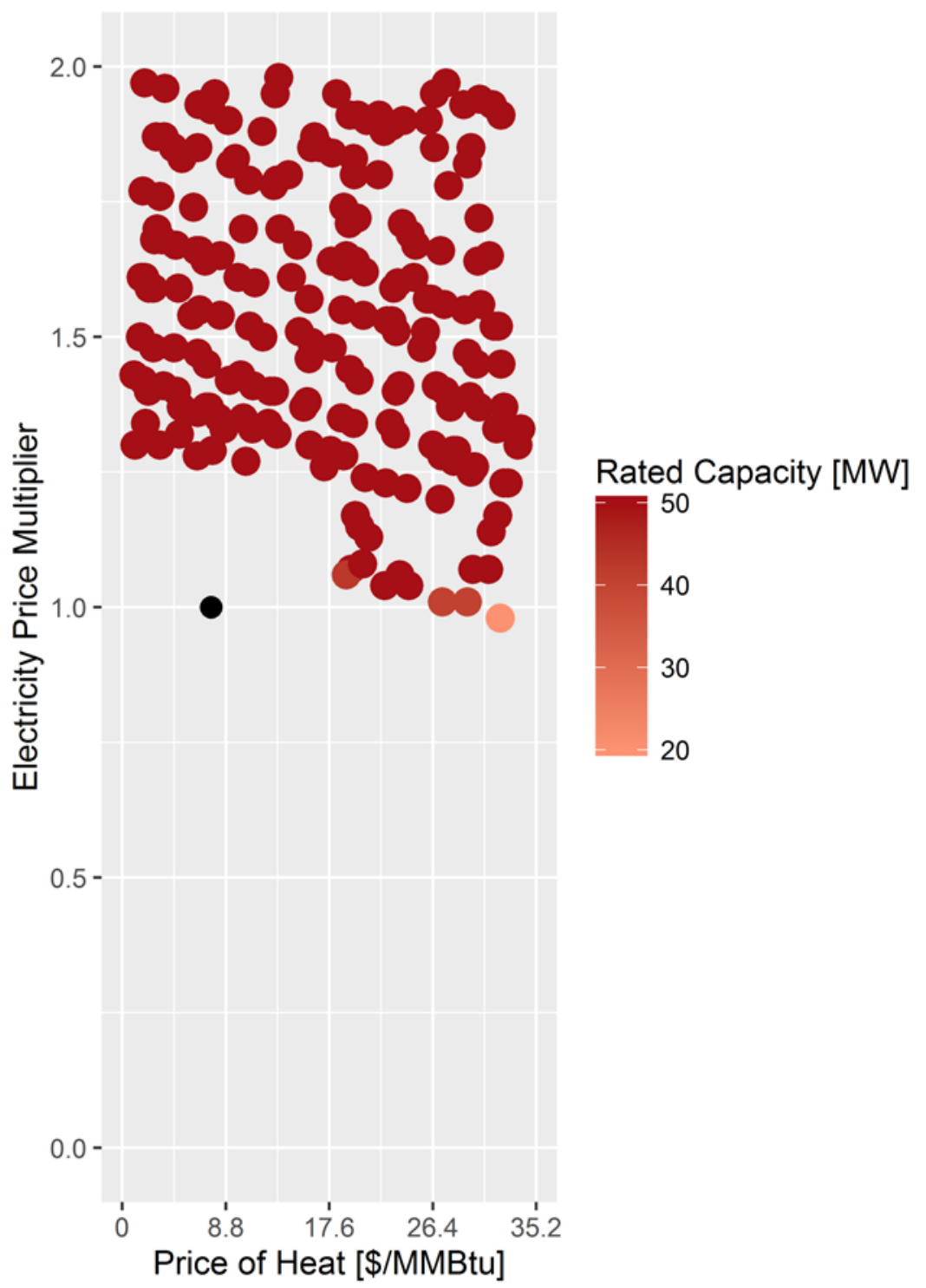

Figure 14. Optimal capacity of wind power plants for the Electric Thermal Storage Scenario at various heat prices and electricity price multipliers

Solid black dot at $\$ 7.70 / \mathrm{MMBtu}$ and 1.0 indicates reference case prices of heat and electricity

Figure 15 shows the optimal product mix based on each optimal configuration shown in Figure 11. Figure 16 indicates the capacity payment awarded. If the electricity price multiplier is above 1.22 and the thermal product's price is below $\$ 5.00 / \mathrm{MMBtu}$ (as shown by the black dots in Figure 15, the blue dots in the upper left of Figure 16, and the red and orange dots in Figure 11), the nuclear reactor with the thermal power cycle generates and sells electricity throughout the year and receives the capacity payment. In addition, the wind power plant generates electricity when the electricity price multiplier is greater than 1.25 .

At higher thermal product prices, the amount of electricity generated is reduced because only the wind power plant generates electricity (the middle orange dots on in the left graph in Figure 15). In those cases, the nuclear reactor exclusively generates heat for the industrial process and the 
optimal configuration does not include a thermal power cycle. The thermal power cycle is included in a few cases with thermal product prices between \$20.00/MMBtu and \$25.00/MMBtu with electricity price multipliers above 1.5 (pink dots in Figure 11) because the electricity price is high enough in those cases to receive the capacity payment (as shown in Figure 16) but the price of heat is not high enough for the value of the thermal product to overcome the value of electricity.

The difference between the gray dots and the black dots on the right side of Figure 15 is that the gray dots show where thermal product is produced only by the nuclear heat, and the black dots indicate where electricity is used to generate heat. The line differentiating them goes from the lower left to the upper right because the selection requires a tradeoff between electricity and heat prices. The line is not straight because wind generation allows for lower priced electricity generation if the value of the heat is high enough to use that electricity.
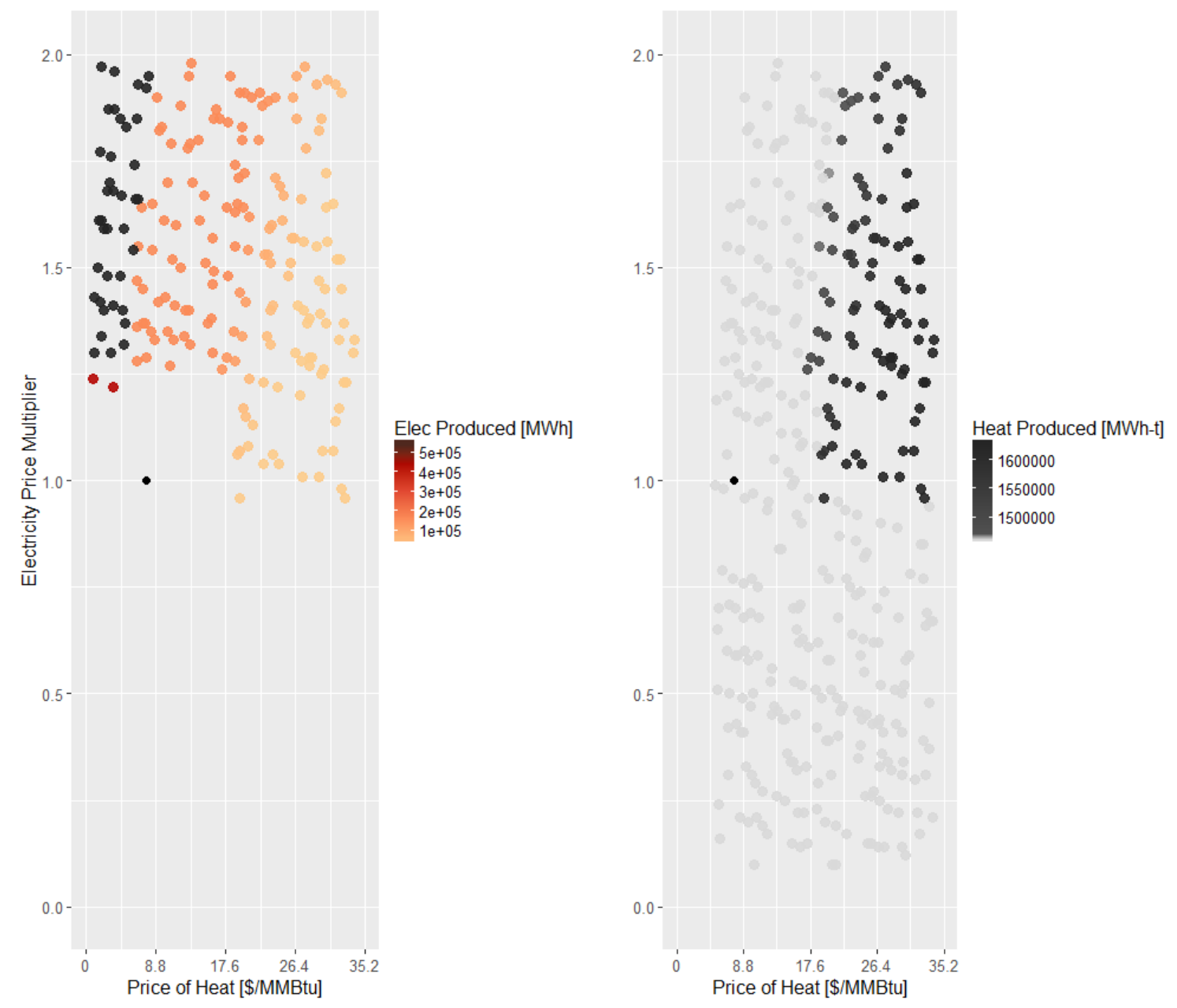

Figure 15. Optimal annual product generation for the Electric Thermal Storage Scenario at various heat prices and electricity price multipliers

Electricity is on the left with greater generation at the darker color. Heat is on the right. Electricity pricing based on $A E O$ reference case and $\$ 50 / \mathrm{kW}-\mathrm{yr}$ capacity payments.

Solid black dot at $\$ 7.70 / \mathrm{MMBtu}$ and 1.0 indicates reference case prices of heat and electricity. 


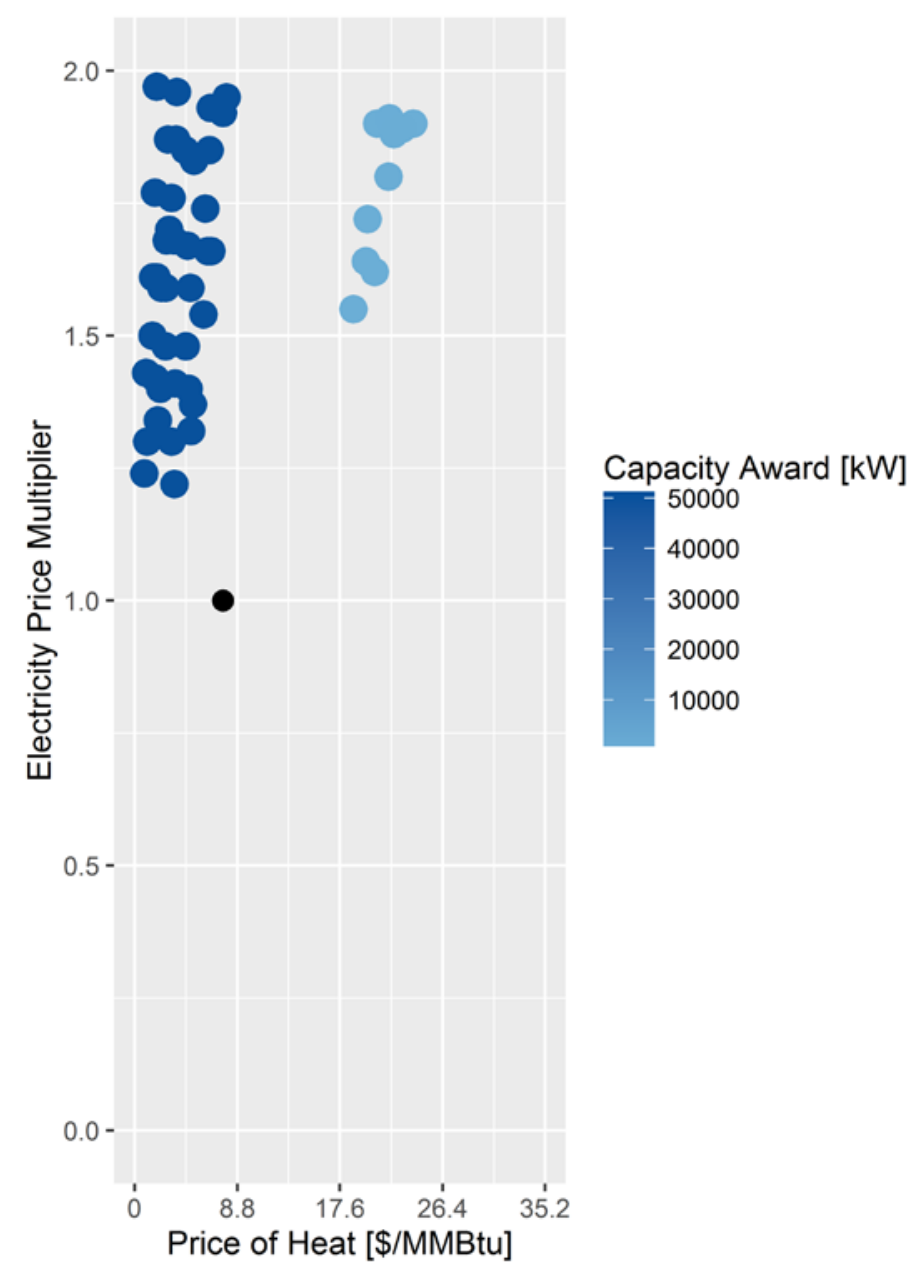

Figure 16. Optimal capacity payments awarded for the Electric Thermal Storage Scenario at various heat prices and electricity price multipliers

Solid black dot at $\$ 7.70 / \mathrm{MMBtu}$ and 1.0 indicates reference case prices of heat and electricity.

Figure 17 shows the NPVs for the optimal configurations as shown in Figure 11. Note that profitability increases more dramatically with rising heat prices than with rising electricity prices. 


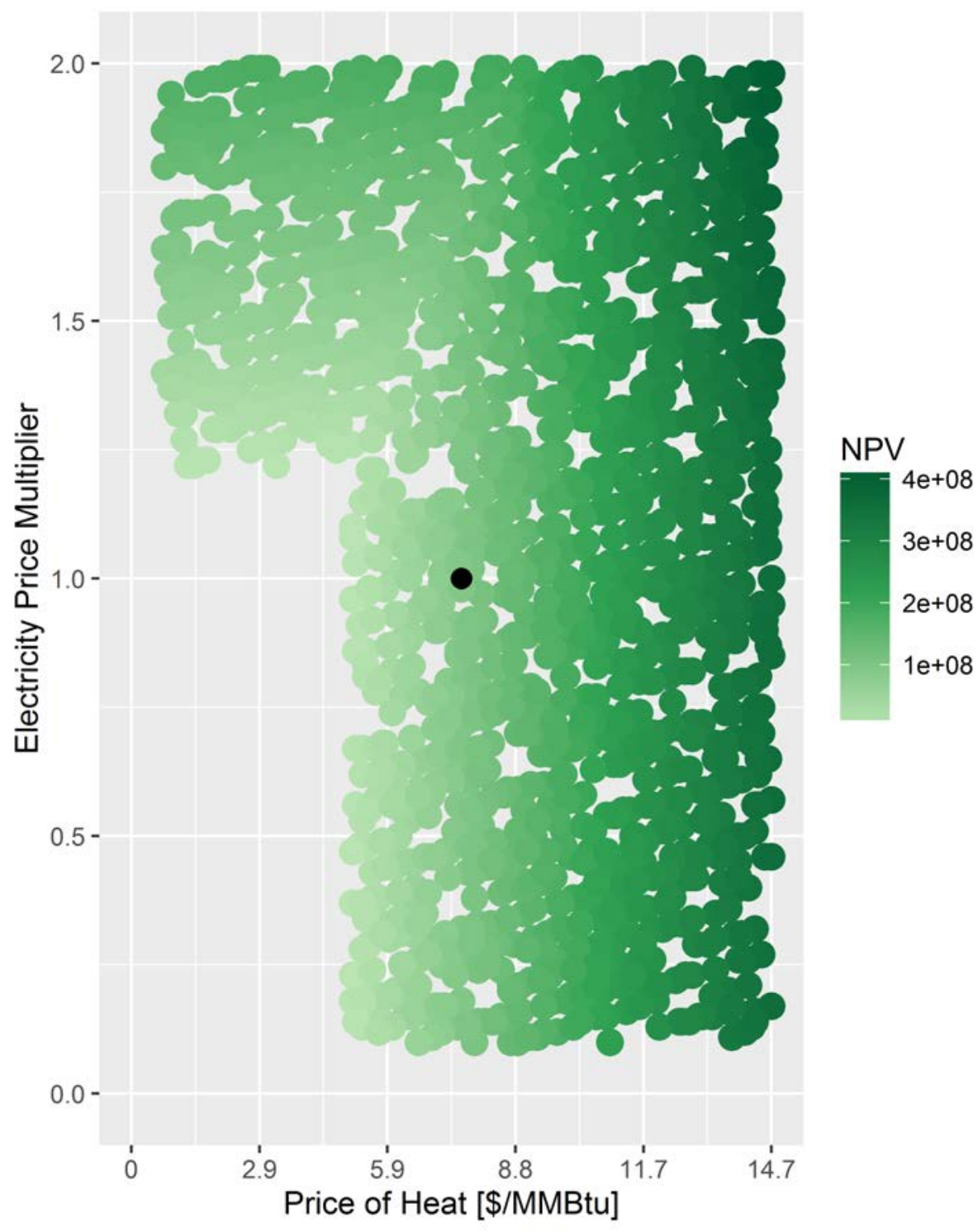

Figure 17. Electric Thermal Storage Scenario NPVs at various heat prices and electricity price multipliers

Electricity pricing based on AEO reference case and $\$ 50 / \mathrm{kW}$-yr capacity payments.

Darker shades indicate higher NPVs.

Solid black dot at $\$ 7.70 / \mathrm{MMBtu}$ and 1.0 indicates reference case prices of heat and electricity.

Table 11 provides the present values of all the annual revenues and expenses under the base case parameters for the optimal configuration (a nuclear reactor providing heat as a thermal product). For comparison, present values for three alternative configurations are also provided. Table 12 compares other financial parameters of the nuclear-only configuration and the alternatives.

When comparing Scenario 1 and Scenario 2 (the Electric Boiler Scenario) in these tables, one sees that adding a thermal power cycle to the nuclear reactor reduces the NPV in Scenario 2 
more than in Scenario 1. The reason is that we required heat production and sales to be constant in Scenario 2 but not in Scenario 1, so the thermal power cycle is used in Scenario 1 when the price of electricity is high and the N-R HES benefits from selling electricity. In Scenario 2, the thermal power cycle is not used at the base case conditions because the average value of heat is greater than the average value of electricity.

Like Scenario 1, adding wind generation without the electric thermal storage unit to the configuration with the nuclear reactor and the thermal power cycle impacts the NPV negatively because the value of wind electricity sold does not cover the capital and operating expenses of the wind power plant.

The economics of the full N-R HES are better than those for the configuration with the nuclear reactor, thermal power cycle, and wind power plant but not the electric thermal storage unit. The reason is that the electric thermal storage unit allows the N-R HES to use both wind-generated electricity and grid electricity to generate valuable heat when the price of electricity is low. 
Table 11. Electric Thermal Storage Scenario Present Values at Base Case Conditions for Four Configurations

Negative values indicate expenses and positive indicate income

\begin{tabular}{|c|c|c|c|c|}
\hline \multirow[t]{8}{*}{ Configuration } & $\begin{array}{l}\text { Nuclear } \\
\text { Reactor } \\
\text { (167 MWt) }\end{array}$ & $\begin{array}{l}\text { Nuclear } \\
\text { Reactor } \\
\text { (167 MWt) }\end{array}$ & $\begin{array}{l}\text { Nuclear } \\
\text { Reactor } \\
\text { (167 MWt) }\end{array}$ & $\begin{array}{l}\text { Nuclear } \\
\text { Reactor } \\
\text { (167 MWt) }\end{array}$ \\
\hline & & + & + & + \\
\hline & & $\begin{array}{l}\text { Thermal Power } \\
\text { Cycle (50 MWe) }\end{array}$ & $\begin{array}{l}\text { Thermal Power } \\
\text { Cycle (50 MWe) }\end{array}$ & $\begin{array}{l}\text { Thermal Power } \\
\text { Cycle (50 MWe) }\end{array}$ \\
\hline & & & + & + \\
\hline & & & $\begin{array}{l}\text { Wind Power } \\
\text { Plant } \\
\text { (50 MWe) }\end{array}$ & $\begin{array}{l}\text { Wind Power } \\
\text { Plant } \\
\text { (50 MWe) }\end{array}$ \\
\hline & & & & + \\
\hline & & & & $\begin{array}{l}\text { Electric } \\
\text { Thermal } \\
\text { Storage (50 } \\
\text { MWe) }\end{array}$ \\
\hline & $\begin{array}{l}\text { Present Value } \\
\text { (\$million) }\end{array}$ & $\begin{array}{l}\text { Present Value } \\
\text { (\$million) }\end{array}$ & $\begin{array}{l}\text { Present Value } \\
\text { (\$million) }\end{array}$ & $\begin{array}{l}\text { Present Value } \\
\text { (\$million) }\end{array}$ \\
\hline \multicolumn{5}{|l|}{ Nuclear Plant } \\
\hline Reactor Capex & $-\$ 186$ & $-\$ 186$ & $-\$ 186$ & $-\$ 186$ \\
\hline Nuclear Fixed O\&M & $-\$ 55$ & $-\$ 55$ & $-\$ 55$ & $-\$ 55$ \\
\hline \multicolumn{5}{|l|}{ Thermal Power Cycle } \\
\hline $\begin{array}{l}\text { Thermal Power Cycle } \\
\text { Capex }\end{array}$ & $\mathrm{N} / \mathrm{A}$ & $-\$ 65$ & $-\$ 65$ & $-\$ 65$ \\
\hline \multicolumn{5}{|l|}{ Wind Power Plant } \\
\hline Capex & $\mathrm{N} / \mathrm{A}$ & $\mathrm{N} / \mathrm{A}$ & $-\$ 84$ & $-\$ 84$ \\
\hline Fixed O\&M & $\mathrm{N} / \mathrm{A}$ & $\mathrm{N} / \mathrm{A}$ & $-\$ 27$ & $-\$ 27$ \\
\hline \multicolumn{5}{|c|}{ Electric Thermal Storage } \\
\hline Capex & $\$ 0$ & $\$ 0$ & $\$ 0$ & $-\$ 4$ \\
\hline \multicolumn{5}{|l|}{ Revenue } \\
\hline Purchased Electricity & $\$ 0$ & $\$ 0$ & $\$ 0$ & $-\$ 3$ \\
\hline Thermal Product Sales & $\$ 434$ & $\$ 434$ & $\$ 434$ & $\$ 434$ \\
\hline Capacity Payments & $\$ 0$ & $\$ 0$ & $\$ 0$ & $\$ 9$ \\
\hline Electricity Revenue & $\$ 0$ & $\$ 0$ & $\$ 95$ & $\$ 98$ \\
\hline Ancillary Services & $\$ 0$ & $\$ 3$ & $\$ 3$ & $\$ 7$ \\
\hline Taxes & $-\$ 99$ & $-\$ 89$ & $-\$ 89$ & $-\$ 94$ \\
\hline NPV & $\$ 94$ & $\$ 43$ & $\$ 26$ & $\$ 30$ \\
\hline
\end{tabular}


Table 12. Electric Thermal Storage Scenario Output Summary at Base Case Conditions for Four Configurations

\begin{tabular}{|c|c|c|c|c|}
\hline Configuration & $\begin{array}{l}\text { Nuclear } \\
\text { Reactor } \\
\text { (167 MWt) }\end{array}$ & 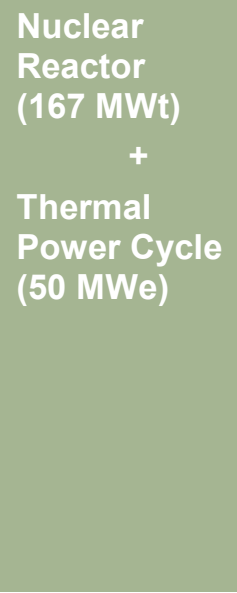 & 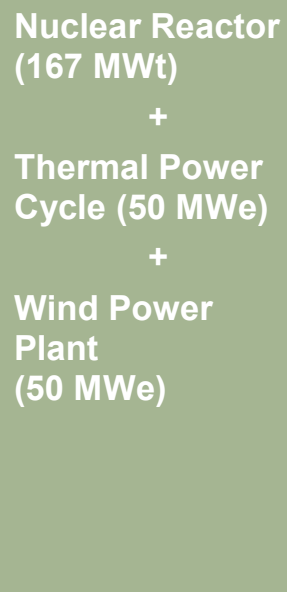 & 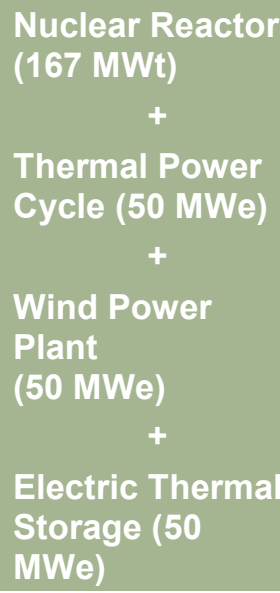 \\
\hline $\begin{array}{l}\text { Annual Electricity } \\
\text { Output (GWh) }\end{array}$ & 0 & 0 & 154 & 164 \\
\hline $\begin{array}{l}\text { Annual Thermal Energy } \\
\text { Produced (mmBtu) }\end{array}$ & $4,981,000$ & $4,981,000$ & $4,981,000$ & $4,982,000$ \\
\hline TCI (\$million) & $-\$ 186$ & $-\$ 251$ & $-\$ 336$ & $-\$ 339$ \\
\hline $\begin{array}{l}\text { NPV at } 10 \% \text { Discount } \\
\text { Rate (\$million) }\end{array}$ & $\$ 94.4$ & $\$ 43.3$ & $\$ 25.7$ & $\$ 30.1$ \\
\hline Payback Period (years) & 10.5 & 16.7 & 20.3 & 19.7 \\
\hline $\begin{array}{l}\text { IRR after } 25 \text { years of } \\
\text { operation }\end{array}$ & $5.8 \%$ & $2.1 \%$ & $1.0 \%$ & $1.1 \%$ \\
\hline NPV/TCI Ratio & 0.51 & 0.17 & 0.08 & 0.09 \\
\hline
\end{tabular}

Because the optimal configuration under the base case thermal product price and electricity price multiplier is a nuclear reactor generating heat for sales exclusively, the financial comparison between the nuclear configuration and one using natural gas is the same as shown in Table 9 ( Section 3.1.1), which discusses results for the Electric Boiler Scenario.

For Scenario 2, the full N-R HES (LW-SMR nuclear reactor-thermal power cycle-wind power plant-electric thermal storage unit) is not the economically optimal solution under the base case electricity and heat prices. Instead, the most profitable configuration is one that includes only a nuclear reactor providing heat. This option has an NPV that is $\$ 64.3$ million greater than that of the full N-R HES and a $0.51 \mathrm{NPV} / \mathrm{TCI}$ ratio, compared to the 0.09 of the full N-R HES.

From these results, we conclude that income of the full N-R HES configuration for this scenario exceeds the required cost of capital, but the configuration is not as profitable as the alternative configuration that produces the thermal product alone. 


\subsubsection{Potential to Reduce GHG Emissions and their Associated Costs}

Like Scenario 1 above, the optimal configuration for Scenario 2 under the base case thermal product price and electricity price multiplier is a nuclear reactor generating heat for sales exclusively. Thus, the comparison between the optimal configuration and a natural gas option including costs of carbon is the same as in Scenario 1. That comparison can be found in Table 10. Using natural gas-generated heat instead of nuclear-generated heat increases $\mathrm{CO}_{2}$ emissions by 281,000 metric tons annually and, at all costs of carbon, results in negative NPVs and NPV/TCI ratios.

\subsubsection{Potential to Support Resource Adequacy}

We tested the hypothesis that N-R HES Scenario 2 can support electricity resource adequacy while maximizing production of a more profitable industrial product with sufficient incentives (i.e., a capacity payment that is sufficiently high). In this scenario, as in Scenario 1, the optimal configuration at a capacity payment of $\$ 50 / \mathrm{kW}-\mathrm{yr}$ at base case prices only includes a nuclear reactor generating heat for sales. Because the optimal configuration does not include the thermal power cycle or wind generation, it does not support resource adequacy for the grid.

Increased capacity payments increase the incentive to build electricity generation. As shown in Figure 18, increased capacity payments result in lower hourly electricity prices necessary for optimal configurations to include thermal power cycles. Increasing the capacity payment from $\$ 50 / \mathrm{kW}$-yr to $\$ 100 / \mathrm{kW}$-yr has little effect unless the price of the thermal product is either below $\$ 5.00 / \mathrm{MMBtu}$ or above 1.25 when the price of heat is between $\$ 20.00 / \mathrm{MMBtu}$ and $\$ 25.00 / \mathrm{MMBtu}$ (pink dots in Figure 18). In the case where the price of the thermal product is below $\$ 5.00 / \mathrm{MMBtu}$, a lower electricity multiplier is necessary to build any configuration with a projected income that meets the required cost of capital. The configuration with the lowest required electricity multiplier sells both thermal energy and enough electricity to receive the capacity payment (most clear in Figure 19). As the increase in pink dots in Figure 18 shows, the range where coupling the nuclear reactor and thermal power cycle with the wind power plant to receive capacity payments is larger when the capacity payment is $\$ 100 / \mathrm{kW}$-yr than when it is $\$ 50 / \mathrm{kW}-\mathrm{yr}$.

The higher capacity payment of $\$ 150 / \mathrm{kW}$-yr further extends the range of pink dots where the coupled electricity generation by wind and nuclear power is more profitable than the configuration where the nuclear reactor produces only the thermal product and wind generates electricity (the light blue dots). In addition, the price range at which the configuration with the nuclear reactor and electric thermal storage subsystems (green dots) is optimal with capacity payments of $\$ 50 / \mathrm{kW}$-yr and $\$ 100 / \mathrm{kW}$-yr is replaced by an optimal configuration with the nuclear reactor, thermal power cycle, and electrical thermal storage unit when the capacity payment is $\$ 150 / \mathrm{kW}$-yr because including the electric thermal storage unit allows the N-R HES to receive the capacity payment. Figure 19 most clearly shows the impact of capacity payment prices on the range where the capacity payment is received.

Higher capacity payments lead to increased electricity generation during peak hours (i.e., those required to receive the capacity payment). Figure 20 shows the optimal annual electricity production under the three capacity payments. It also shows that at the high capacity payment of $\$ 150 / \mathrm{MW}$-yr the optimal configuration produces electricity for a small number of hours annually, even at low electricity prices (shown by the orange dots near the bottom of the plot on 
the right). The result indicates that this N-R HES can support grid resource adequacy as long as the capacity payment is sufficient.
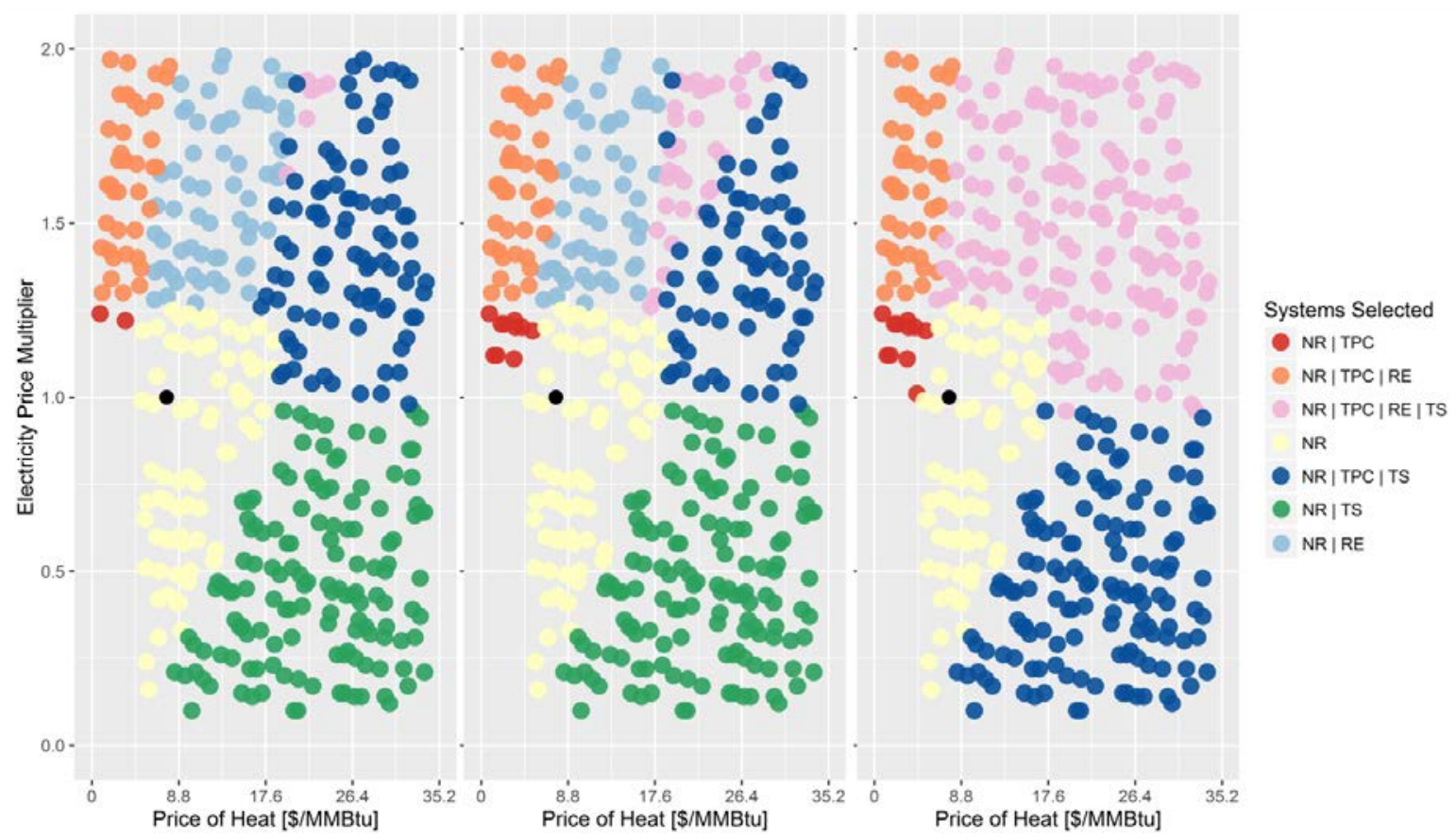

Figure 18. Optimal configurations for the Electric Thermal Storage Scenario at various heat prices and electricity price multipliers at three levels of capacity payments

\$50/kW-yr (left); \$100/kW-yr (middle); \$150/kW-yr (right)

NR: Nuclear reactor

$\mathrm{RE}$ : Renewable electricity generation

TPC: Thermal power cycle

TS: Thermal storage (the electric thermal storage unit)

Solid black dot at $\$ 7.70 / \mathrm{MMBtu}$ and 1.0 indicates reference case prices of heat and electricity. 


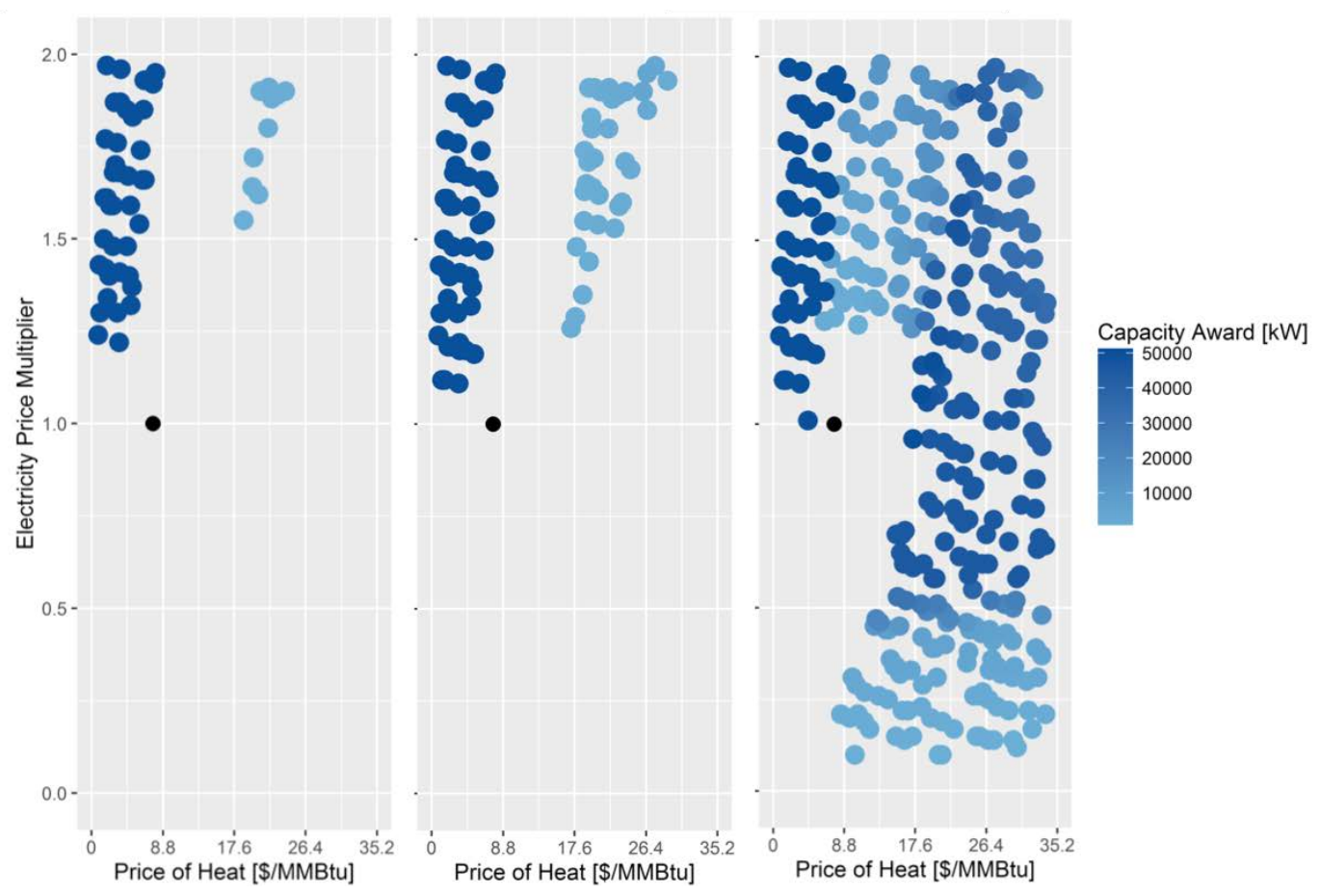

Figure 19. Optimal capacity payments awarded for the Electric Thermal Storage Scenario at various heat prices and electricity price multipliers at three levels of capacity payments

\$50/kW-yr (left); \$100/kW-yr (middle); \$150/kW-yr (right)

Solid black dot at $\$ 7.70 / \mathrm{MMBtu}$ and 1.0 indicates reference case prices of heat and electricity. 

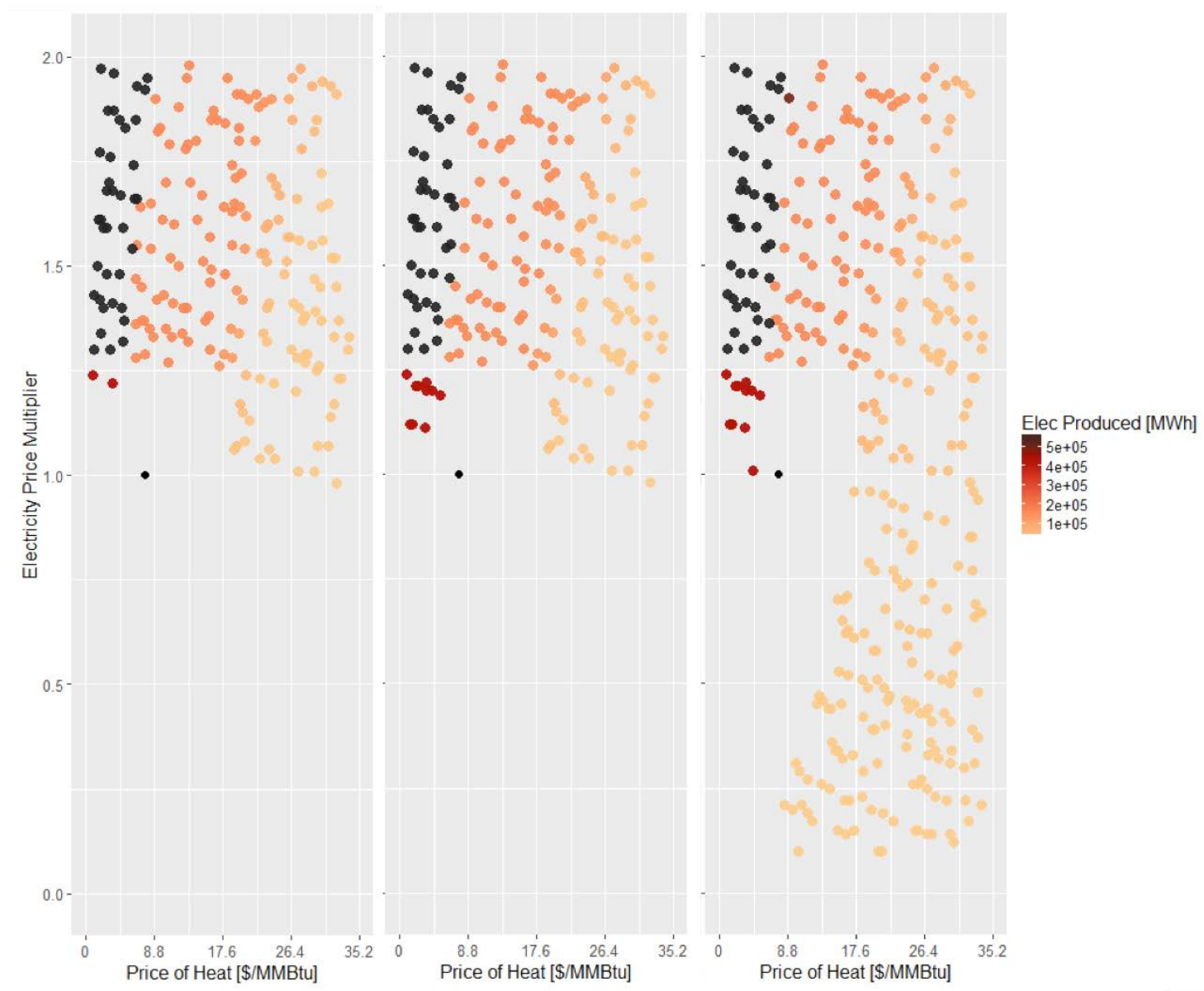

Figure 20. Optimal annual electricity production for Electric Thermal Storage Scenario at various heat prices and electricity price multipliers at three levels of capacity payments

\$50/kW-yr (left); \$100/kW-yr (middle); \$150/kW-yr (right)

Solid black dot at $\$ 7.70 / \mathrm{MMBtu}$ and 1.0 indicates reference case prices of heat and electricity.

\subsubsection{Potential for Flexibility to Increase Profitability}

We tested the hypothesis that, at some combinations of electricity and product prices, N-R HESs would be more profitable than uncoupled configurations because they can produce electricity when its price is high and the industrial thermal product when the price of electricity is low.

Based on this analysis, some configurations are more profitable because they can adjust their product to follow market prices. In Figure 20, that situation is most noticeable at the highest electricity price multiplier and thermal product prices between $\$ 8.00 / \mathrm{MMBtu}$ and $\$ 30.00 / \mathrm{MMBtu}$ (orange dots). In that range, heat is sold during some hours (orange dots) because it still has value even though the price of electricity is $\$ 0 / \mathrm{MWh}$ during those hours.

\subsubsection{Potential for Electricity-to-Heat Conversion to Increase Wind Capacity}

We tested the hypothesis that, at some combinations of electricity and thermal product prices, optimally configured N-R HESs include wind generation only because the wind-generated 
electricity is converted to heat. Thus, wind generation would be profitably built where otherwise it would not be.

Figure 11 shows that at thermal product prices below $\$ 18.00 / \mathrm{MMBtu}$, the wind power plant is only included in the optimal configuration if the electricity price multiplier is above 1.25 . When the thermal product price is above $\$ 18.00 / \mathrm{MMBtu}$, the wind power plant is included in the optimal configurations if the electricity price multiplier is above 0.95 . Those results indicate that the hypothesis is true as long as the price of the thermal product is high and the electricity price multiplier is not too low.

\subsection{Results for the Electric Boiler-Thermal Storage Scenario}

Scenario 3, the Electric Boiler-Thermal Storage Scenario, consists of five primary subsystems: (1) a nuclear reactor, (2) a thermal power cycle that can be associated with the nuclear reactor, (3) a wind power plant, (4) an electric boiler that uses electricity to produce steam, and (5) a thermal storage unit that can hold the thermal energy. We set the same maximum size for the nuclear reactor, the thermal power cycle, and the wind power plant to the same value - $50 \mathrm{MWe}$. The thermal power cycle efficiency of $30 \%$ implies a thermal capacity of $167 \mathrm{MWt}$ for the nuclear reactor. We set the maximum size of the electric boiler to $100 \mathrm{MWe}$ so it can both generate thermal energy for storage and sell heat as the thermal product.

In this scenario, the thermal product is generated by the nuclear reactor, generated by the electric boiler, and/or taken from the thermal storage unit during any given hour. The thermal product is held constant over all hours of the year. In other words, the customer(s) receive a consistent source of heat. Unlike in the Electric Boiler Scenario, the customers do not need to adapt to varying rates of thermal energy availability. The thermal storage unit has a constant charge and discharge rate of $0.2 \mathrm{~kW} / \mathrm{kWh}$ of storage.

As with the other scenarios, we used REopt to determine the optimal size of each subsystem and the energy flow on an hourly basis. It allows for energy to be split (i.e., some of the thermal energy from the nuclear reactor can be used for the industrial process and the remainder for electricity) during any hour if that provides the optimal solution.

\subsubsection{Potential Profitability}

We analyzed the potential profitability of the N-R HES with an electric boiler and thermal storage by varying the prices of the electricity and thermal products and using REopt to calculate the optimal subsystem combinations and internal dispatch, as discussed in Section 2.1. We varied the price of the thermal product from $\$ 0 / \mathrm{MMBtu}$ to $\$ 35.00 / \mathrm{MMBtu}$. The range was chosen to show the impacts of various prices. We varied the price of electricity using a multiplier that affected the electrical energy price for all 8,760 hours in the year. ${ }^{* *}$ In each case, the multiplier was randomly assigned a value between 0 and 2; thus, the electrical energy price in that case could be $\$ 0 / \mathrm{MWh}$ for every hour of the year, twice the electrical energy price developed for the reference case, or any other multiplied value between 0 and 2 . The electricity multiplier could be considered a combination of (1) the difference between marginal generation costs and market

\footnotetext{
** Prices of ancillary services (reserves, flex reserves, and regulation up and down) were not multiplied because a change in price has little effect on the operational selection and optimization.
} 
prices (due to bidding strategies) and (2) uncertainty in the natural gas price because natural gas is on the operating cost margin for the vast majority of the year. Unless stated otherwise, all other parameters remain at the reference values. Note that this analysis assumes perfect foresight of all expenses and product prices throughout the project life.

Figure 21 shows the optimal configuration selections for $\approx 500$ combinations of thermal product prices and electricity multipliers. These values were independently, randomly sampled from a uniform distribution across the ranges described above. The results of this analysis indicate that:

- If the electricity price multiplier is below 1.22 and the thermal product's price is below $\$ 5.00 / \mathrm{MMBtu}$, no configurations have incomes that meet the required cost of capital (i.e., the NPV is less than zero for all combinations).

- If the electricity price multiplier is between 1.22 and 1.25 and the price of the thermal product is below $\$ 5.00 / \mathrm{MMBtu}$ (as shown by the red dots), the LW-SMR with a thermal power cycle has a projected income that meets the required cost of capital and the configuration produces electricity when its price is above zero. During hours when the electricity price is $\$ 0 / \mathrm{kWh}$, the configuration produces and sells heat.

- If the electricity price multiplier is below 1.25 and the thermal product's price is either between $\$ 5.00 / \mathrm{MMBtu}$ and $\$ 18.00 / \mathrm{MMBtu}$ at an electricity multiplier of 1.25 , just above $\$ 5.00 / \mathrm{MMBtu}$ at an electricity multiplier of 0.2 , or to the left of the line between those two values (as shown by the yellow dots), the nuclear reactor generates and sells thermal energy exclusively (i.e., it does not generate any electricity).

- If the electricity price multiplier is below 0.6 and thermal product's price is above the line between $\$ 5.00 / \mathrm{MMBtu}$ with an electricity multiplier of 0.2 and \$15/MMBtu with an electricity multiplier of 0.6 (as shown by the gray dots), both the nuclear reactor and the electric boiler produce heat. The electric boiler is using grid electricity to generate the heat. Thermal storage is not selected in the optimal configuration because the price of electricity is low enough that the value of storage is insufficient to cover its costs.

- If the electricity price multiplier is between 0.6 and 0.95 and thermal product's price is above $\$ 15.00 / \mathrm{MMBtu}$ (as shown by the green dots), both the nuclear reactor and the electric boiler produce heat. The electric boiler is using grid electricity to generate the heat but it does not generate heat during all hours out of the year. Instead, optimal configuration includes the thermal storage unit so that the electric boiler does not need to produce heat during the hours with the highest price of electricity. Rather, the thermal product is taken from storage during those hours.

- If the electricity price multiplier is above 1.0 and the thermal product's price is above $\$ 15.00 / \mathrm{MMBtu}$, with that price increasing as the electricity price multiplier increases (as shown by the purple dots), then the nuclear reactor generates and sells thermal energy exclusively (i.e., it does not generate any electricity), the wind power plant generates electricity, and an electric boiler converts both wind and grid electricity to heat. The optimal configuration includes a thermal storage unit so that heat from wind and grid electricity can be stored during hours with low electricity prices and used during hours with high electricity prices. 
- A few cases near the left of the purple dots are indicated by pink dots. In those cases, the wind power plant generates electricity, an electric boiler converts both wind and grid electricity to heat, a thermal storage unit allows heat to be stored to maximize the ability to produce electricity, and the nuclear reactor primarily sells heat but can use a thermal power cycle to produce enough electricity to receive the capacity payments.

- If the electricity multiplier is above 1.25 , the thermal product's price is above $\$ 5.00 / \mathrm{MMBtu}$, and the prices of the thermal product and electricity are in the range indicated by the light blue dots, then the nuclear reactor generates and sells thermal energy exclusively (i.e., it does not generate any electricity) and a wind power plant generates and sells electricity to the grid exclusively. The value of electricity is too high for wind or grid electricity to be used to produce the thermal product but is not high enough for the nuclear-generated thermal energy to be used to generate electricity.

- If the electricity multiplier is above 1.25 , the thermal product's price is below \$5.00/MMBtu (as indicated by the orange dots), income from the LW-SMR with a thermal power cycle exceeds the required cost of capital, the configuration produces electricity when its price is above zero and a wind power plant generates and sells electricity exclusively.

The solid black dot indicates the reference case thermal energy product price (\$7.70/MMBtu) and the electricity price vector developed for this analysis (the multiplier is 1.0). To estimate the reference case thermal product price, we estimated the cost of a natural gas boiler to produce the thermal energy without a cost of carbon as discussed in Section 2.7 above. 


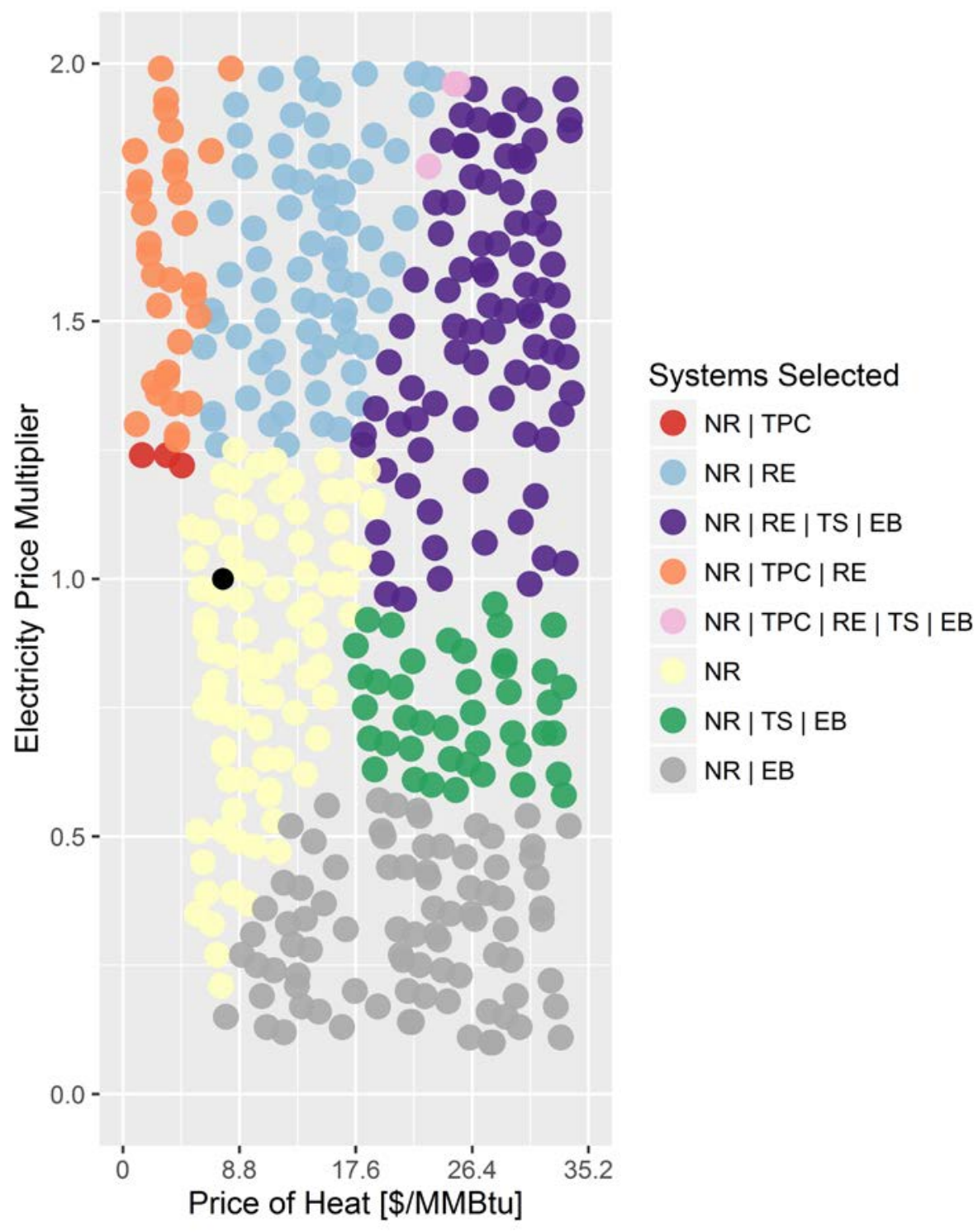

Figure 21. Optimal configurations for the Electric Boiler-Thermal Storage Scenario at various heat prices and electricity price multipliers

EB: Electric boiler

NR: Nuclear reactor

RE: Renewable electricity generation

TPC: Thermal power cycle

TS: Thermal storage

Solid black dot at $\$ 7.70 / \mathrm{MMBtu}$ and 1.0 indicates reference case prices of heat and electricity.

Figure 22 shows the optimal constant thermal product production rate from the N-R HES at various heat prices and electricity price multipliers. Note that the lower thermal energy production rate is the maximum generation from the nuclear reactor $(167 \mathrm{MWt})$ and the higher heat rate is that generation plus the maximum thermal rate available from the electric boiler (217 $\mathrm{MWt}$ ). In most cases, the heat generation is at one value or the other for all hours during the year 
depending upon the ratio of the average electricity price and thermal product price. At some points near the top of the interface, some thermal production is sacrificed (i.e., the thermal product generation rate is lower than $217 \mathrm{MWt}$ ) to receive capacity payments.

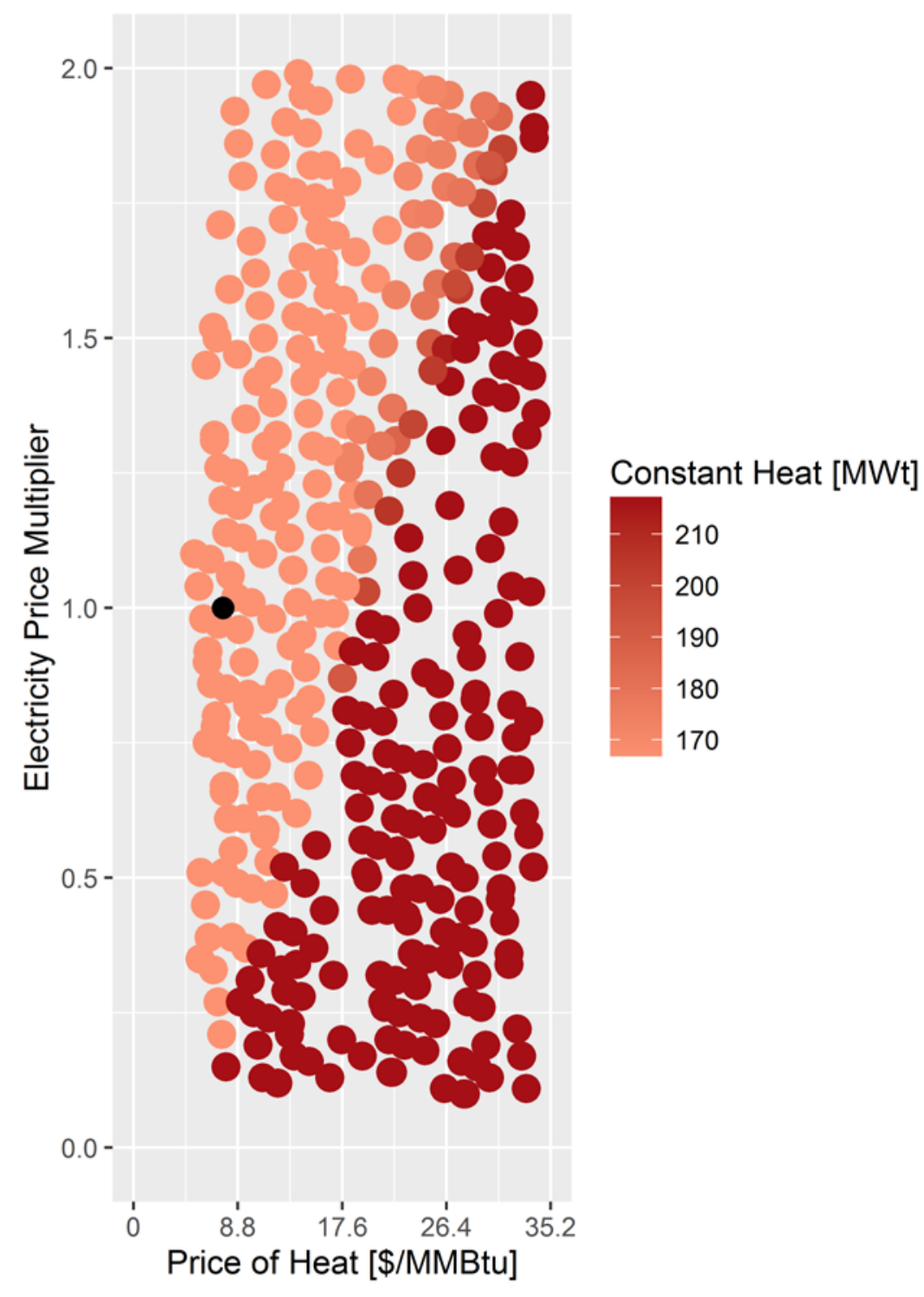

Figure 22. Optimal constant thermal product generation rate for the Electric Boiler-Thermal Storage Scenario at various heat prices and electricity price multipliers

Solid black dot at $\$ 7.70 / \mathrm{MMBtu}$ and 1.0 indicates reference case prices of heat and electricity.

Figure 23 shows the optimal thermal storage capacity in the N-R HES at various heat prices and electricity price multipliers. Note that thermal storage is only selected as a subsystem in the ideal systems shown by the green, purple, and pink dots in Figure 21. In most cases, the thermal storage capacity is $250 \mathrm{MWh}-\mathrm{t}$ because the storage unit is sized to enable storage of 50MWe during low cost electricity periods, as shown in Figure 22. 


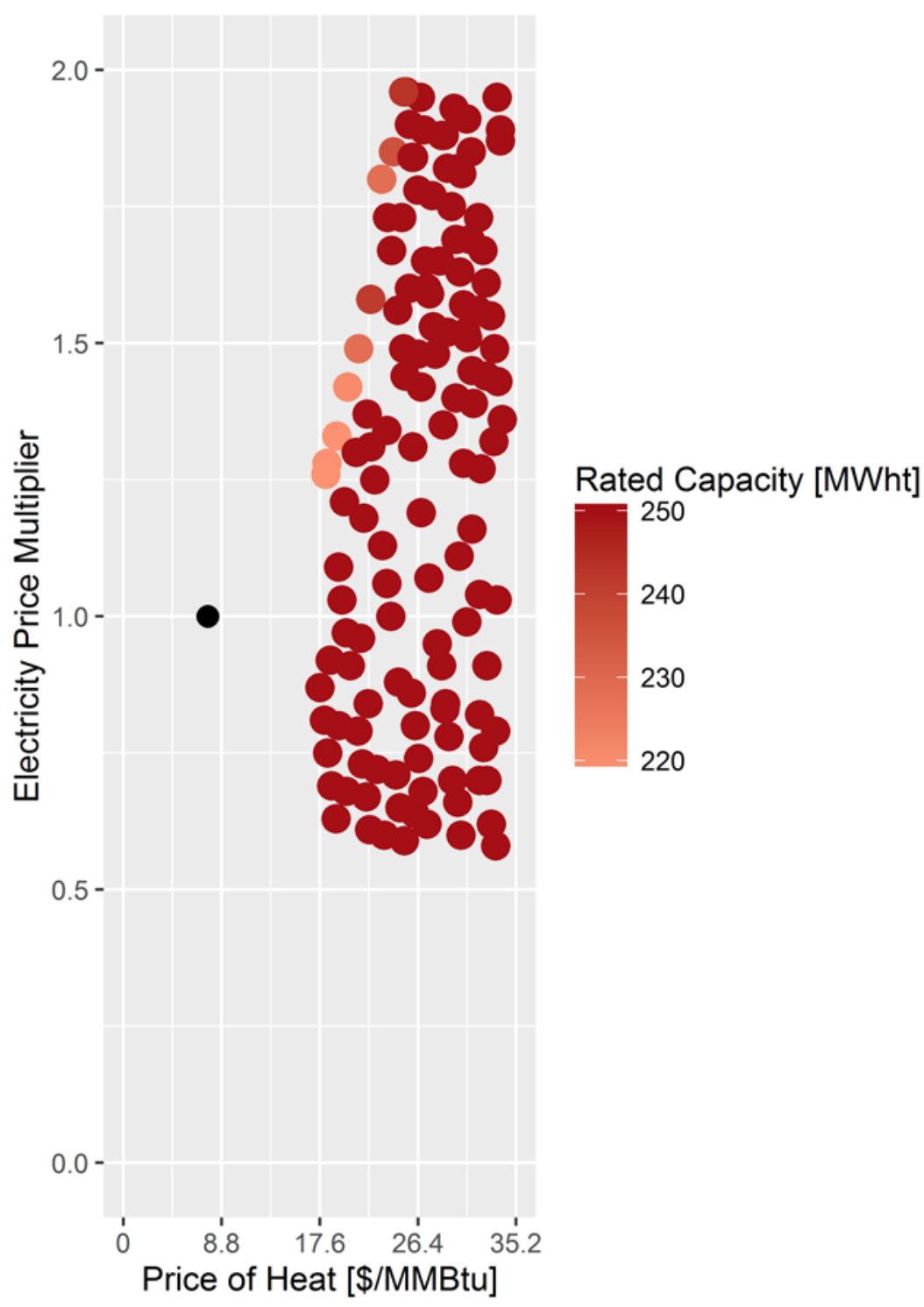

Figure 23. Optimal thermal storage capacity for the Electric Boiler-Thermal Storage Scenario at various heat prices and electricity price multipliers

Solid black dot at $\$ 7.70 / \mathrm{MMBtu}$ and 1.0 indicates reference case prices of heat and electricity.

Figure 24 shows the optimal capacity of the wind power plant for the configurations with wind power plants as shown in Figure 21 (the orange, light blue, pink, and purple dots). Note that in almost all cases, the wind power plant is at maximum capacity $(50 \mathrm{MW})$. The exception is the interface where the requirement for constant thermal generation impacts the size of the wind power plant. 


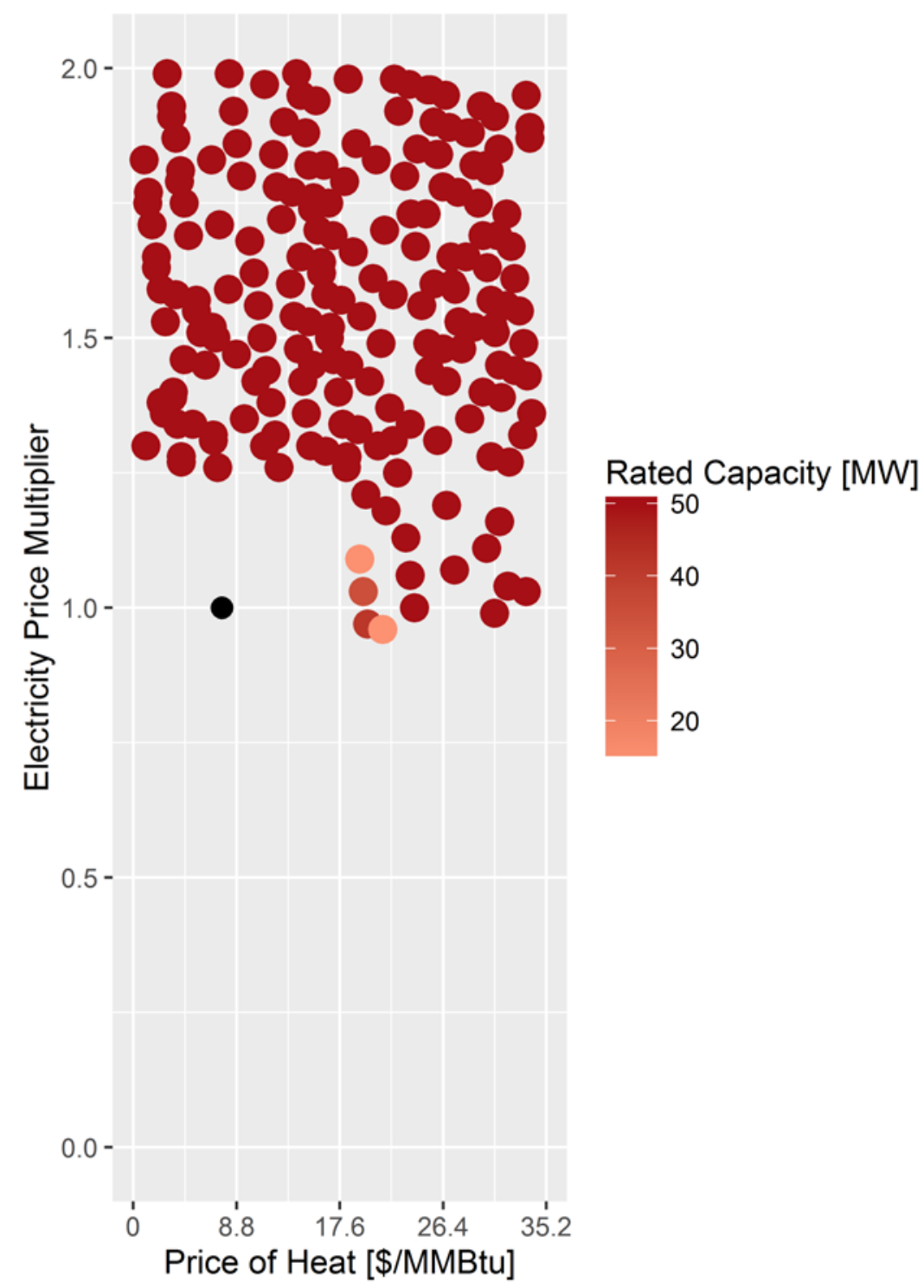

Figure 24. Optimal capacity of wind power plants for the Electric Boiler-Thermal Storage Scenario at various heat prices and electricity price multipliers

Solid black dot at $\$ 7.70 / \mathrm{MMBtu}$ and 1.0 indicates reference case prices of heat and electricity.

Figure 25 shows the optimal product mix based on each optimal configuration shown in Figure 21 , and Figure 26 indicates the capacity payment awarded. If the electricity price multiplier is above 1.22 and the thermal product's price is below \$5.00/MMBtu (as shown by the black dots in Figure 25, the blue dots in the upper left of Figure 26, and the red and orange dots in Figure 21 ), the nuclear reactor with the thermal power cycle generates and sells electricity throughout the year and receives the capacity payment. In addition, the wind power plant generates electricity when the electricity price multiplier is greater than 1.25.

At higher thermal product prices, the amount of electricity generated is lower because only the wind power plant is generating electricity (the middle orange dots on in the left graph in Figure 25). In those cases, the nuclear reactor is exclusively generating heat for the industrial process 
and a thermal power cycle is not included in the optimal configuration. The thermal power cycle is included in a few cases with thermal product prices between $\$ 20.00 / \mathrm{MMBtu}$ and $\$ 25.00 / \mathrm{MMBtu}$ with electricity price multipliers above 1.5 (pink dots in Figure 21) because the electricity price is high enough in those cases to receive the capacity payment (as shown in Figure 26). However, the price of heat is not high enough for the value of the thermal product to overcome the value of electricity.

The difference between the gray dots and the black dots on the right side of Figure 26 is that the gray dots show where thermal product is produced only by the nuclear heat and the black dots indicate where electricity is used to generate heat. The line differentiating them goes from the lower left to the upper right because the selection requires a tradeoff between electricity and heat prices. The line is not straight because wind generation allows for lower-priced electricity generation if the value of the heat is high enough to use that electricity.
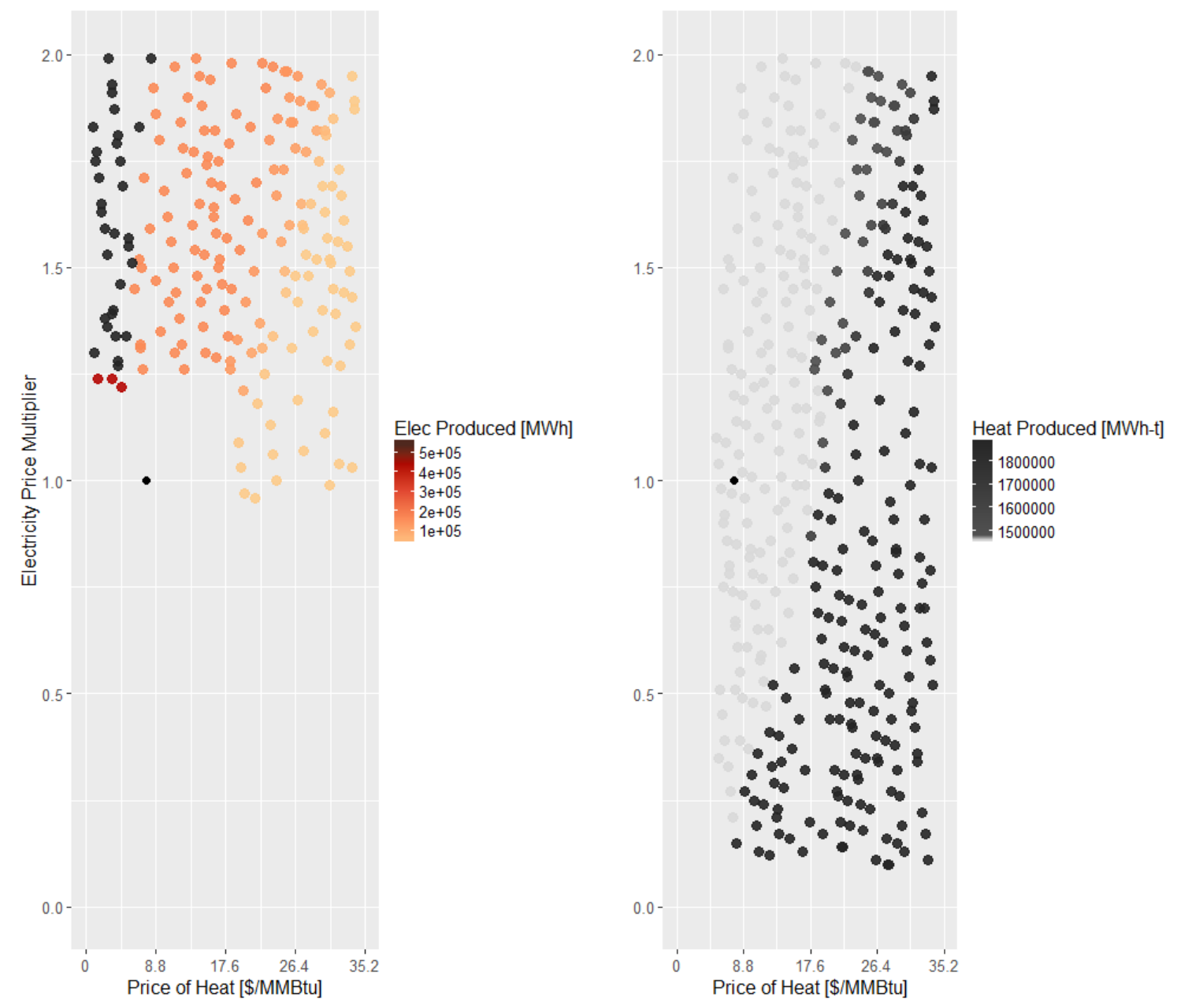

Figure 25. Optimal annual product generation for the Electric Boiler-Thermal Storage Scenario at various heat prices and electricity price multipliers

Electricity is on the left with greater generation at the darker color. Heat is on the right. Electricity pricing based on AEO reference case and $\$ 50 / \mathrm{kW}$-yr capacity payments.

Solid black dot at $\$ 7.70 / \mathrm{MMBtu}$ and 1.0 indicates reference case prices of heat and electricity. 


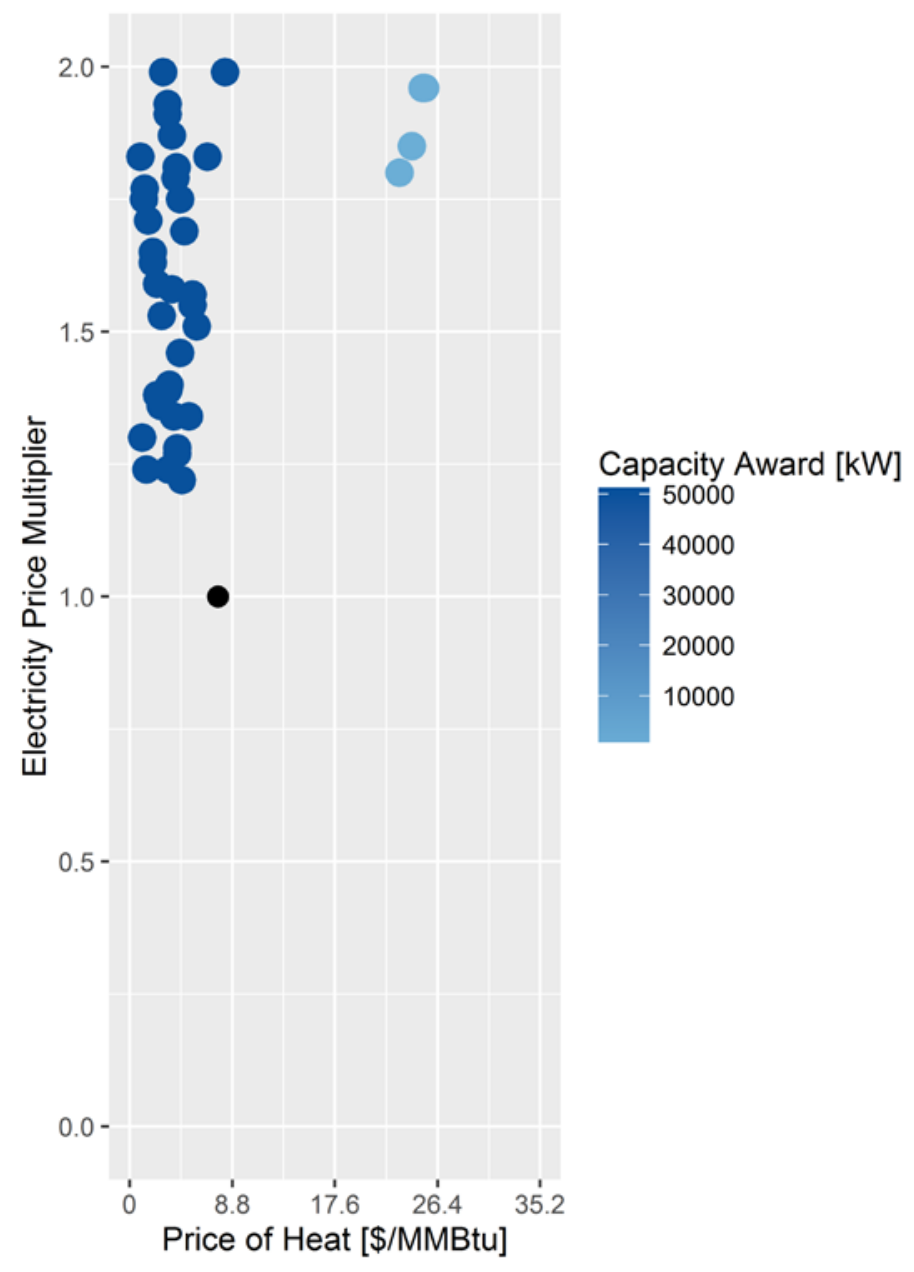

Figure 26. Optimal capacity payments awarded for the Electric Boiler-Thermal Storage Scenario at various heat prices and electricity price multipliers.

Solid black dot at $\$ 7.70 / \mathrm{MMBtu}$ and 1.0 indicates reference case prices of heat and electricity.

Figure 27 shows the NPVs for the optimal configurations as shown in Figure 21 above. Note that profitability increases more dramatically with rising heat prices than with rising electricity prices. 


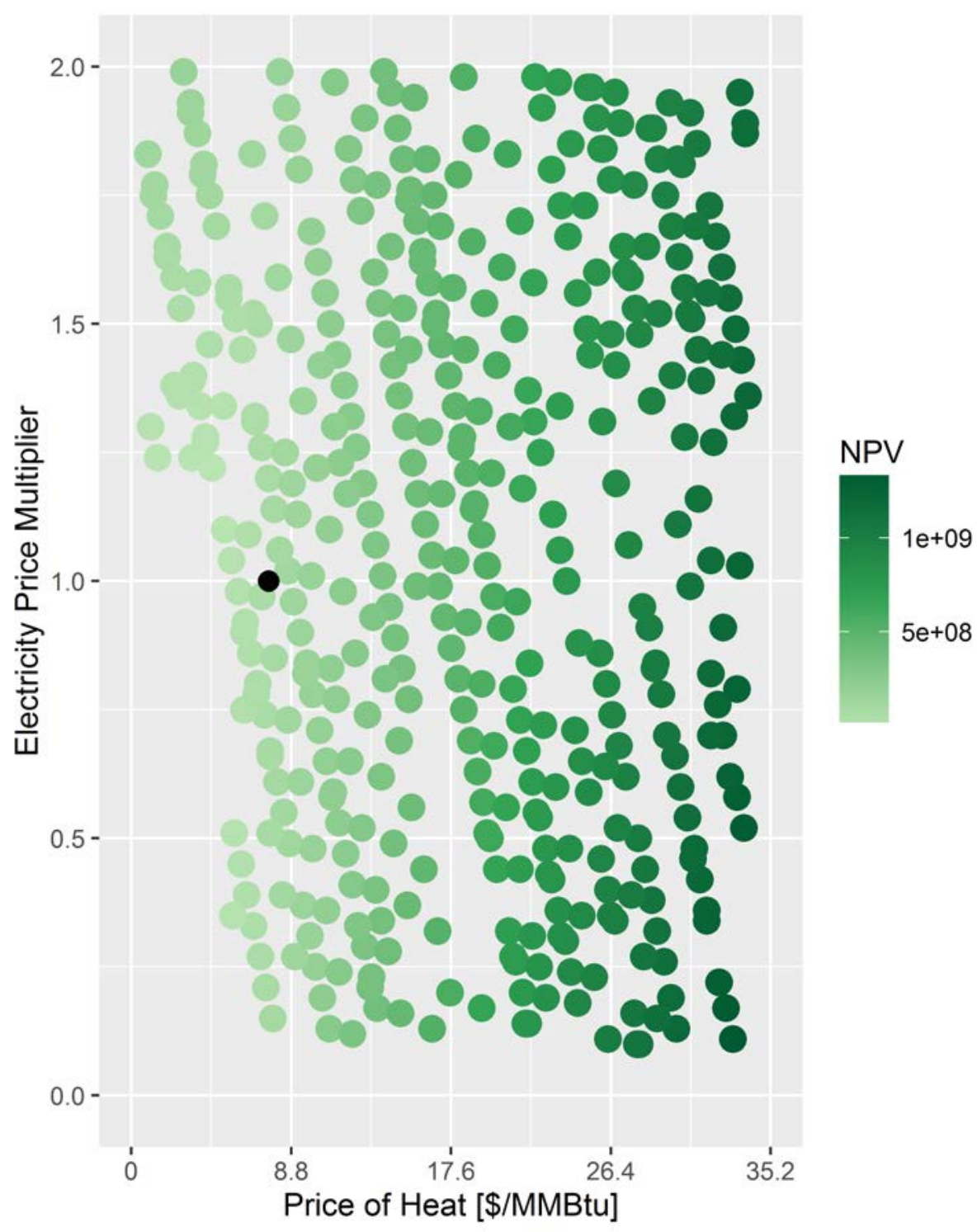

Figure 27. Electric Boiler-Thermal Storage Scenario NPVs at various heat prices and electricity price multipliers

Electricity pricing based on AEO reference case and $\$ 50 / \mathrm{kW}$-yr capacity payments.

Darker shades indicate higher NPVs.

Solid black dot at $\$ 7.70 / \mathrm{MMBtu}$ and 1.0 indicates reference case prices of heat and electricity.

Table 13 provides the present values of all the annual revenues and expenses under the base case parameters for the optimal configuration (a nuclear reactor providing heat as a thermal product). For comparison, present values for three alternative configurations are also provided. Table 14 compares other financial parameters of the nuclear-only configuration and the alternatives.

When comparing Scenario 2 and Scenario 3 in these tables, one sees that the configuration with the nuclear reactor, thermal power cycle, wind plant, and thermal storage unit has a slightly higher NPV than the comparable configuration in Scenario 2. The reason is that the thermal storage unit allows the nuclear reactor to generate and sell electricity when the price is high 
while still maintaining a constant production rate of the thermal product. However, the configurations without either a wind plant or thermal storage unit have a higher NPV than the configuration with them.

Adding an electric boiler for the full N-R HES configuration results in a further decrease in the NPV because the value of converting wind-generated and/or grid electricity is insufficient to cover the cost of the electric boiler in this case. Arbitrage is mostly gained by the ability to use the thermal power cycle only when the price of electricity is high. 
Table 13. Electric Boiler-Thermal Storage Scenario Present Values at Base Case Conditions for Four Configurations

Negative values indicate expenses and positive indicate income

\begin{tabular}{|c|c|c|c|c|}
\hline \multirow[t]{10}{*}{ Configuration } & $\begin{array}{l}\text { Nuclear } \\
\text { Reactor } \\
\text { (167 MWt) }\end{array}$ & $\begin{array}{l}\text { Nuclear } \\
\text { Reactor } \\
\text { (167 MWt) }\end{array}$ & $\begin{array}{l}\text { Nuclear } \\
\text { Reactor } \\
\text { (167 MWt) }\end{array}$ & $\begin{array}{l}\text { Nuclear } \\
\text { Reactor } \\
\text { (167 MWt) }\end{array}$ \\
\hline & & + & + & + \\
\hline & & $\begin{array}{l}\text { Thermal Power } \\
\text { Cycle (50 MWe) }\end{array}$ & $\begin{array}{l}\text { Thermal Power } \\
\text { Cycle ( } 50 \mathrm{MWe})\end{array}$ & $\begin{array}{l}\text { Thermal Power } \\
\text { Cycle (50 MWe) }\end{array}$ \\
\hline & & & + & + \\
\hline & & & $\begin{array}{l}\text { Wind Power } \\
\text { Plant } \\
\text { (50 MWe) }\end{array}$ & $\begin{array}{l}\text { Wind Power } \\
\text { Plant } \\
\text { (50 MWe) }\end{array}$ \\
\hline & & & + & + \\
\hline & & & $\begin{array}{l}\text { Thermal } \\
\text { Storage ( } 250 \\
\text { MWh) }\end{array}$ & $\begin{array}{l}\text { Thermal } \\
\text { Storage ( } 250 \\
\text { MWh) }\end{array}$ \\
\hline & & & & + \\
\hline & & & & $\begin{array}{l}\text { Electric Boiler } \\
(100 \mathrm{MWe})\end{array}$ \\
\hline & $\begin{array}{l}\text { Present Value } \\
\text { (\$million) }\end{array}$ & $\begin{array}{l}\text { Present Value } \\
\text { (\$million) }\end{array}$ & $\begin{array}{l}\text { Present Value } \\
\text { (\$million) }\end{array}$ & $\begin{array}{l}\text { Present Value } \\
\text { (\$million) }\end{array}$ \\
\hline \multicolumn{5}{|l|}{ Nuclear Plant } \\
\hline Reactor Capex & $-\$ 186$ & $-\$ 186$ & $-\$ 186$ & $-\$ 186$ \\
\hline Nuclear Fixed O\&M & $-\$ 55$ & $-\$ 55$ & $-\$ 55$ & $-\$ 55$ \\
\hline \multicolumn{5}{|l|}{ Thermal Power Cycle } \\
\hline $\begin{array}{l}\text { Thermal Power Cycle } \\
\text { Capex }\end{array}$ & $\mathrm{N} / \mathrm{A}$ & $-\$ 65$ & $-\$ 65$ & $-\$ 65$ \\
\hline \multicolumn{5}{|l|}{ Wind Power Plant } \\
\hline Capex & N/A & $\mathrm{N} / \mathrm{A}$ & $-\$ 84$ & $-\$ 84$ \\
\hline Fixed O\&M & N/A & $\mathrm{N} / \mathrm{A}$ & $-\$ 27$ & $-\$ 27$ \\
\hline \multicolumn{5}{|l|}{ Electric Boiler } \\
\hline Capex & $\mathrm{N} / \mathrm{A}$ & N/A & $\$ 0$ & $-\$ 8$ \\
\hline \multicolumn{5}{|l|}{ Thermal Storage } \\
\hline Capex & $\mathrm{N} / \mathrm{A}$ & $\mathrm{N} / \mathrm{A}$ & $-\$ 4$ & $-\$ 4$ \\
\hline \multicolumn{5}{|l|}{ Revenue } \\
\hline \multicolumn{5}{|l|}{ Purchased Electricity } \\
\hline Thermal Product Revenue & $\$ 434$ & $\$ 434$ & $\$ 429$ & $\$ 434$ \\
\hline Capacity Payments & $\$ 0$ & $\$ 0$ & $\$ 9$ & $\$ 9$ \\
\hline Electricity Revenue & $\$ 0$ & $\$ 0$ & $\$ 97$ & $\$ 92$ \\
\hline Ancillary Services & $\$ 0$ & $\$ 3$ & $\$ 4$ & $\$ 10$ \\
\hline
\end{tabular}




\begin{tabular}{|c|c|c|c|c|}
\hline \multirow[t]{10}{*}{ Configuration } & $\begin{array}{l}\text { Nuclear } \\
\text { Reactor } \\
\text { (167 MWt) }\end{array}$ & $\begin{array}{l}\text { Nuclear } \\
\text { Reactor } \\
\text { (167 MWt) }\end{array}$ & $\begin{array}{l}\text { Nuclear } \\
\text { Reactor } \\
\text { (167 MWt) }\end{array}$ & $\begin{array}{l}\text { Nuclear } \\
\text { Reactor } \\
\text { (167 MWt) }\end{array}$ \\
\hline & & + & + & + \\
\hline & & $\begin{array}{l}\text { Thermal Power } \\
\text { Cycle (50 MWe) }\end{array}$ & $\begin{array}{l}\text { Thermal Power } \\
\text { Cycle (50 MWe) }\end{array}$ & $\begin{array}{l}\text { Thermal Power } \\
\text { Cycle (50 MWe) }\end{array}$ \\
\hline & & & + & + \\
\hline & & & $\begin{array}{l}\text { Wind Power } \\
\text { Plant } \\
\text { (50 MWe) }\end{array}$ & $\begin{array}{l}\text { Wind Power } \\
\text { Plant } \\
\text { (50 MWe) }\end{array}$ \\
\hline & & & + & + \\
\hline & & & $\begin{array}{l}\text { Thermal } \\
\text { Storage ( } 250 \\
\text { MWh) }\end{array}$ & $\begin{array}{l}\text { Thermal } \\
\text { Storage ( } 250 \\
\text { MWh) }\end{array}$ \\
\hline & & & & + \\
\hline & & & & $\begin{array}{l}\text { Electric Boiler } \\
(100 \mathrm{MWe})\end{array}$ \\
\hline & $\begin{array}{l}\text { Present Value } \\
\text { (\$million) }\end{array}$ & $\begin{array}{l}\text { Present Value } \\
\text { (\$million) }\end{array}$ & $\begin{array}{l}\text { Present Value } \\
\text { (\$million) }\end{array}$ & $\begin{array}{l}\text { Present Value } \\
\text { (\$million) }\end{array}$ \\
\hline Taxes & $-\$ 99$ & $-\$ 89$ & $-\$ 92$ & $-\$ 94$ \\
\hline NPV & $\$ 94$ & $\$ 43$ & $\$ 27$ & $\$ 22$ \\
\hline
\end{tabular}


Table 14. Electric Boiler-Thermal Storage Scenario Output Summary at Base Case Conditions for Four Configurations

\begin{tabular}{|c|c|c|c|c|}
\hline \multirow[t]{9}{*}{ Configuration } & $\begin{array}{l}\text { Nuclear Reactor } \\
\text { (167 MWt) }\end{array}$ & $\begin{array}{l}\text { Nuclear Reactor } \\
\text { (167 MWt) }\end{array}$ & $\begin{array}{l}\text { Nuclear Reactor } \\
\text { (167 MWt) }\end{array}$ & $\begin{array}{l}\text { Nuclear Reactor } \\
\text { (167 MWt) }\end{array}$ \\
\hline & & + & + & + \\
\hline & & $\begin{array}{l}\text { Thermal Power } \\
\text { Cycle }(50 \mathrm{MWe})\end{array}$ & $\begin{array}{l}\text { Thermal Power } \\
\text { Cycle (50 MWe) }\end{array}$ & $\begin{array}{l}\text { Thermal Power } \\
\text { Cycle (50 MWe) }\end{array}$ \\
\hline & & & + & + \\
\hline & & & $\begin{array}{l}\text { Wind Power } \\
\text { Plant } \\
\text { (50 MWe) }\end{array}$ & $\begin{array}{l}\text { Wind Power } \\
\text { Plant } \\
\text { (50 MWe) }\end{array}$ \\
\hline & & & + & + \\
\hline & & & $\begin{array}{l}\text { Thermal Storage } \\
\text { (250 MWh) }\end{array}$ & $\begin{array}{l}\text { Electric Boiler } \\
(100 \mathrm{MWe})\end{array}$ \\
\hline & & & & + \\
\hline & & & & $\begin{array}{l}\text { Thermal Storage } \\
\text { (250 MWh) }\end{array}$ \\
\hline $\begin{array}{l}\text { Annual Electricity } \\
\text { Output (GWh) }\end{array}$ & 0 & 0 & 159 & 168 \\
\hline $\begin{array}{l}\text { Annual Thermal } \\
\text { Energy Produced } \\
\text { (mmBtu) }\end{array}$ & $4,980,000$ & $4,980,000$ & $4,930,000$ & $4,980,000$ \\
\hline TCI (\$million) & $-\$ 186$ & $-\$ 251$ & $-\$ 339$ & $-\$ 347$ \\
\hline $\begin{array}{l}\text { NPV at } 10 \% \text { Discount } \\
\text { Rate (\$million) }\end{array}$ & $\$ 94.4$ & $\$ 43.3$ & $\$ 26.9$ & $\$ 22.2$ \\
\hline $\begin{array}{l}\text { Payback Period } \\
\text { (years) }\end{array}$ & 10.5 & 16.7 & 20.1 & 20.9 \\
\hline $\begin{array}{l}\text { IRR after } 25 \text { years of } \\
\text { operation }\end{array}$ & $5.8 \%$ & $2.1 \%$ & $1.0 \%$ & $0.8 \%$ \\
\hline NPV/TCI Ratio & 0.51 & 0.17 & 0.08 & 0.06 \\
\hline
\end{tabular}

Because the optimal configuration under the base case thermal product price and electricity price multiplier is a nuclear reactor generating heat for sales exclusively, the financial comparison between the nuclear configuration and one using natural gas is the same as shown in Table 9 (in Section 3.1.1), which discusses results for the Electric Boiler Scenario.

For Scenario 3, the full N-R HES (LW-SMR nuclear reactor-thermal power cycle-wind power plant-electric boiler-thermal storage) is not the economically optimal solution under the base case electricity and heat prices. Instead, the most profitable configuration is one that includes only a nuclear reactor providing heat. This option has an NPV that is $\$ 72.2$ million greater than that of the full N-R HES and a 0.51 NPV/TCI ratio, compared to the 0.06 of the full N-R HES.

From these results, we conclude that the full N-R HES configuration for Scenario 3 has sufficient income to meet the required cost of capital, but it is not as profitable as the alternative configuration that produces the thermal product alone. 


\subsubsection{Potential to Reduce GHG Emissions and their Associated Costs}

Like the other scenarios above, the optimal configuration for Scenario 3 under the base case thermal product price and electricity price multiplier is a nuclear reactor generating heat for sales exclusively. Thus, the comparison between the optimal configuration and a natural gas option, including costs of carbon, is the same as in Scenarios 1 and 2. That comparison can be found in Table 10. Using natural gas-generated heat instead of nuclear-generated heat increases $\mathrm{CO}_{2}$ emissions by 281,000 metric tons annually and, at all costs of carbon, results in negative NPVs and NPV/TCI ratios.

\subsubsection{Potential to Support Resource Adequacy}

We tested the hypothesis that this N-R HES scenario can support electricity resource adequacy while maximizing production of a more profitable industrial product with sufficient incentives (i.e., a capacity payment that is sufficiently high). In this scenario, like the first two, the optimal configuration at a capacity payment of $\$ 50 / \mathrm{kW}-\mathrm{yr}$ at base case prices includes only a nuclear reactor generating heat for sales. Because the optimal configuration does not include the thermal power cycle or wind generation, it does not support resource adequacy for the grid.

Increased capacity payments increase the incentive to build electricity generation. As shown in Figure 28, increased capacity payments result in lower hourly electricity prices necessary for optimal configurations to include thermal power cycles. Increasing the capacity payment from $\$ 50 / \mathrm{kW}$-yr to $\$ 100 / \mathrm{kW}$-yr has little effect unless the price of the thermal product is either below $\$ 5.00 / \mathrm{MMBtu}$ or above 1.25 when the price of heat is between $\$ 20.00 / \mathrm{MMBtu}$ and $\$ 25.00 / \mathrm{MMBtu}$ (pink dots in Figure 28). In the case where the price of the thermal product is below $\$ 5.00 / \mathrm{MMBtu}$, a lower electricity multiplier is necessary to profitably build any configuration, and the configuration with the lowest required electricity multiplier sells both thermal energy and enough electricity to receive the capacity payment (most clear in Figure 29). As the increase in pink dots shows, the range where coupling the nuclear reactor and thermal power cycle with the wind power plant to receive capacity payments is larger when the capacity payment is $\$ 100 / \mathrm{kW}$-yr than when it is $\$ 50 / \mathrm{kW}$-yr.

The higher capacity payment of $\$ 150 / \mathrm{kW}$-yr further extends the range of pink dots where the coupled electricity generation by wind and nuclear power is more profitable than the configuration where the nuclear reactor produces only the thermal product and wind generates electricity. In addition, the price range at which the configuration with the nuclear reactor, electric boiler, and thermal storage configuration (green dots) is optimal with capacity payments of $\$ 50 / \mathrm{kW}$-yr and $\$ 100 / \mathrm{kW}-\mathrm{yr}$ is replaced by an optimal configuration with the nuclear reactor, thermal power cycle, and electrical thermal storage unit, at which the capacity payment is $\$ 150 / \mathrm{kW}$-yr because including the electric thermal storage unit, allows the N-R HES to receive the capacity payment. Figure 29 most clearly shows the impact of capacity payment prices on the range where the capacity payment is received.

Higher capacity payments lead to increased electricity generation during peak hours (i.e., those required to receive the capacity payment). Figure 30 shows the optimal annual electricity production under the three capacity payments. It shows that at higher capacity payments, electricity is generated up to the highest heat prices considered in the analysis. The result indicates that this N-R HES can support grid resource adequacy as long as the capacity payment is sufficient. 

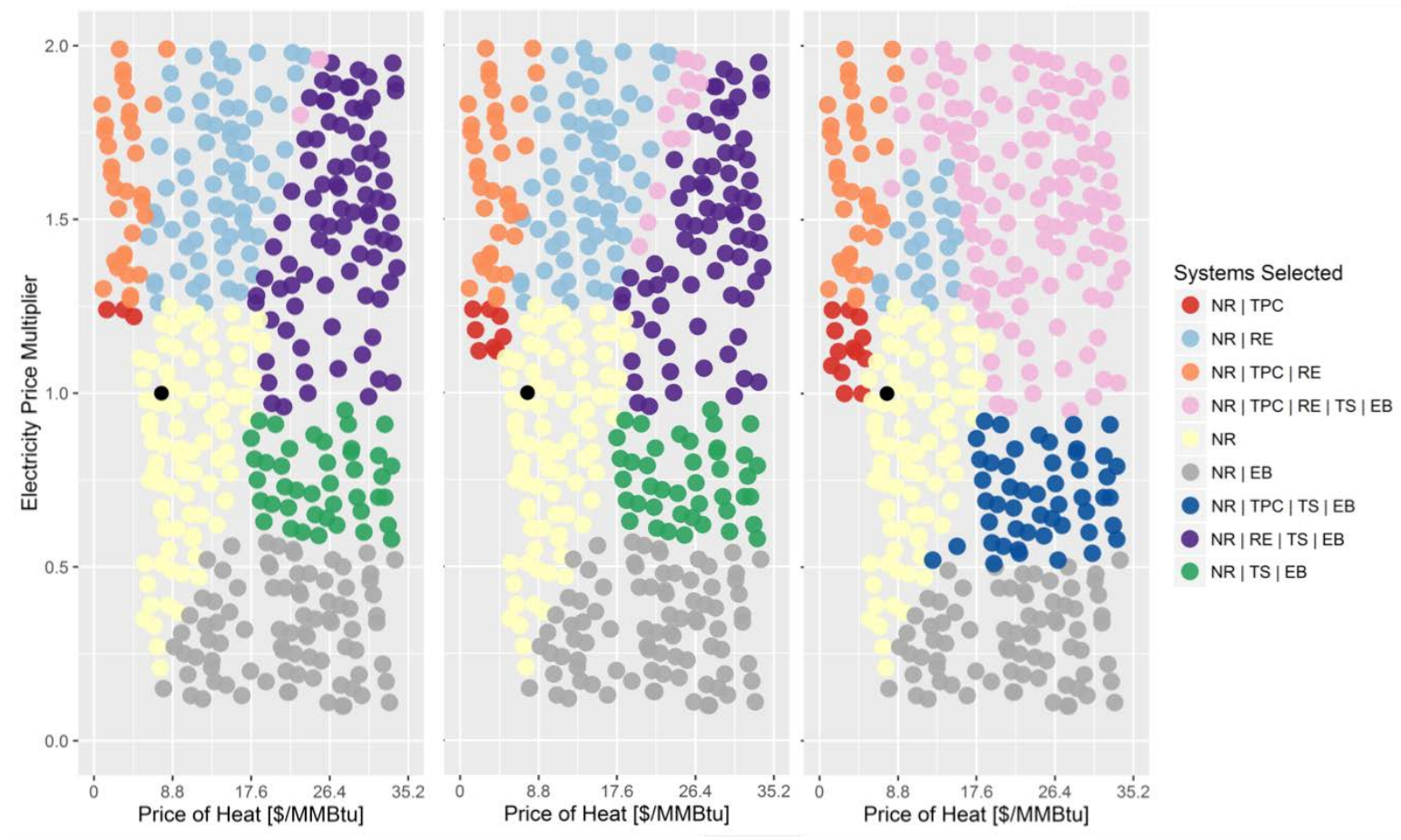

Figure 28. Optimal configurations for the Electric Boiler-Thermal Storage Scenario at various heat prices and electricity price multipliers at three levels of capacity payments

\$50/kW-yr (left); \$100/kW-yr (middle); \$150/kW-yr (right)

EB: Electric boiler

NR: Nuclear reactor

RE: Renewable electricity generation

TPC: Thermal power cycle

TS: Thermal storage

Solid black dot at $\$ 7.70 / \mathrm{MMBtu}$ and 1.0 indicates reference case prices of heat and electricity. 

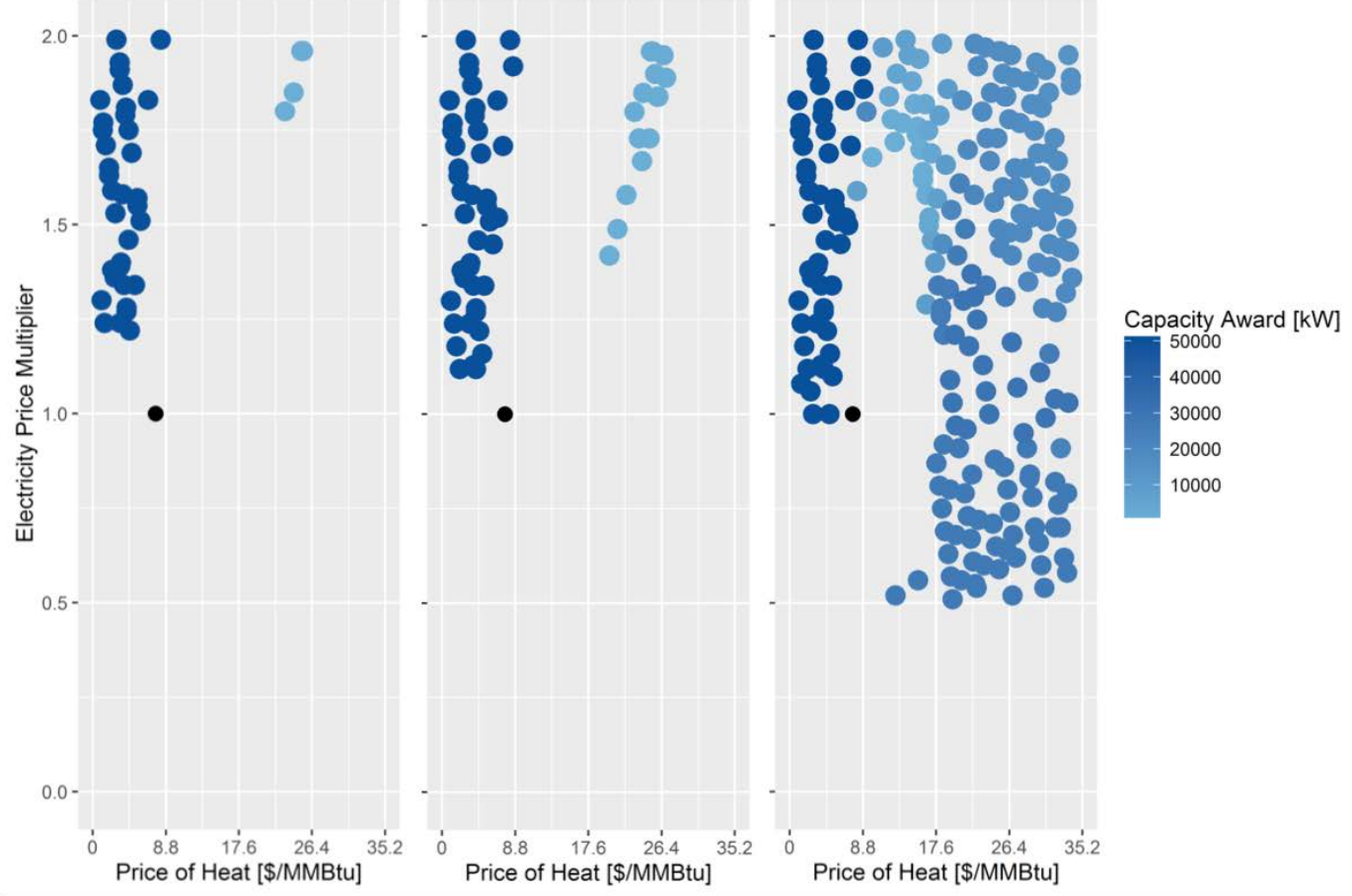

Figure 29. Optimal capacity payments awarded for the Electric Boiler-Thermal Storage Scenario at various heat prices and electricity price multipliers at three levels of capacity payments

\$50/kW-yr (left); \$100/kW-yr (middle); \$150/kW-yr (right)

Solid black dot at $\$ 7.70 / \mathrm{MMBtu}$ and 1.0 indicates reference case prices of heat and electricity. 

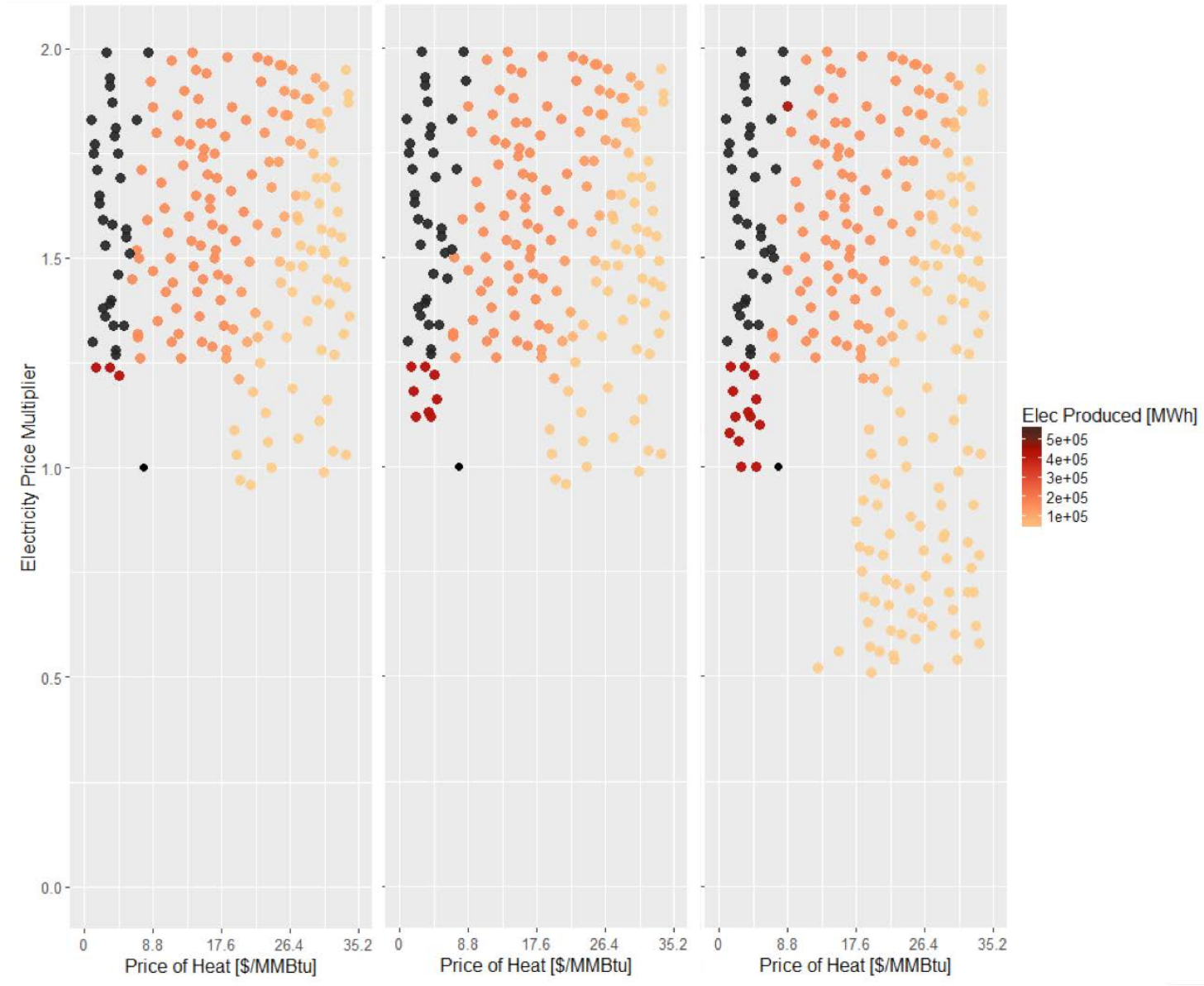

Figure 30. Optimal annual electricity production for Electric Boiler-Thermal Storage Scenario at various heat prices and electricity price multipliers at three levels of capacity payments

\$50/kW-yr (left); \$100/kW-yr (middle); \$150/kW-yr (right)

Solid black dot at $\$ 7.70 / \mathrm{MMBtu}$ and 1.0 indicates reference case prices of heat and electricity.

\subsubsection{Potential for Flexibility to Increase Profitability}

We tested the hypothesis that, at some combinations of electricity and product prices, N-R HESs would be more profitable than uncoupled configurations because they can produce electricity when its price is high and the industrial product when the price of electricity is low.

Based on this analysis, some configurations are more profitable because they can adjust their product to follow market prices. In Figure 30, that situation is most noticeable at the highest electricity price multiplier and thermal product prices between \$8.00/MMBtu and \$30/MMBtu (orange dots). In that range, heat is sold during some hours (orange dots) because it still has value even though the price of electricity is $\$ 0 / \mathrm{MWh}$ during those hours.

\subsubsection{Potential for Electricity-to-Heat Conversion to Increase Wind Capacity}

We tested the hypothesis that, at some combinations of electricity and thermal product prices, optimally configured N-R HESs include wind generation only because the wind-generated 
electricity is converted to heat. Thus, wind generation would be profitably built where otherwise it would not be.

Figure 21 shows that at thermal product prices below $\$ 15.00 / \mathrm{MMBtu}$, the wind power plant is only included in the optimal configuration if the electricity price multiplier is above 1.25 . When the thermal product price is above $\$ 18.00 / \mathrm{MMBtu}$, the wind power plant is included in the optimal configurations if the electricity price multiplier is above 1.0. If the thermal product price is between $\$ 15.00 / \mathrm{MMBtu}$ and $\$ 18.00 / \mathrm{MMBtu}$, the wind power plant is included when the price of the thermal product is high enough to warrant an electric boiler and thermal storage (as shown by the purple dots). Those results indicate that the hypothesis is true as long as the price of the thermal product is high and the electricity price multiplier is not too low. 


\section{Conclusions}

We analyzed the financial performances of three N-R HES scenarios. Each N-R HES has the potential to generate electricity for the grid and thermal energy for sale to an independent customer or set of customers (as might be in an industrial park). We modified the Texas N-R HES in Ruth et al. (2016) ${ }^{28}$ to create each of the three scenarios here by removing its industrial process and adding the ability to convert electricity into heat. In the first scenario analyzed, the heat flow varies from hour to hour. In the second and third scenarios, the heat flow remains constant to allow the heat consumers to operate at steady state. The first scenario (the Electric Boiler Scenario) includes an electric boiler so that wind-generated electricity can produce heat when the price of electricity is low. The second scenario (Electric Thermal Storage Scenario) also allows heat to be produced using electricity but it differs from the first scenario because the thermal energy can be stored and used as needed. The third scenario adds to the second scenario by allowing thermal storage from both the nuclear-generated thermal heat and wind-generated electricity.

We tested five hypotheses regarding the potential benefits of the N-R HES in each of the three scenarios:

1. The N-R HES configurations analyzed have the potential to be profitable to investors and are likely to be more profitable than uncoupled configurations.

2. Using nuclear-generated heat in an N-R HES can economically reduce GHG emissions from industry. If a cost of carbon is included in economic analyses, the N-R HES would have a lower cost than competing uncoupled natural gas configurations.

3. N-R HESs can support resource adequacy for the electricity grid while maximizing production of an alternative product (thermal energy) if the market structures incentivize that option.

4. N-R HESs would be more profitable than uncoupled configurations because they can produce electricity when its value is high and the thermal energy product when the value of electricity is low.

5. By enabling electricity conversion to heat within N-R HESs, additional wind generation is profitable because the electricity they generate can be converted to valuable heat when the electricity price is low.

For the base case analyses, the financial assumptions include $100 \%$ equity, a $10 \%$ nominal discount rate, a $3 \%$ inflation rate, and startup in 2035. Capital and operating cost estimates come from other published analyses and are very uncertain. The prices of electricity and the thermal product are also uncertain.

Our analysis partly supports hypothesis 1 . The full N-R HES configurations for all three scenarios are projected to have income that exceeds a 10\% nominal discount rate under the base case parameters; however, the configuration with the nuclear reactor generating and selling heat exclusively is more profitable than any other configuration at the base case parameters. Table 15 compares the net present value (NPV), internal rate of return (IRR) total capital investment (TCI), and profitability ratio (NPV/TCI) of all three full N-R HES configurations. The table also shows those financial results for a nuclear reactor generating heat for sale and a nuclear reactor 
with a thermal power cycle that can generate electricity when the value of electricity is greater than that of heat. Note that the production rate of the thermal product is allowed to vary in the nuclear reactor-thermal power cycle configuration as it does in Scenario 1. If the production rate were not allowed to vary the thermal power cycle would never be used, so the TCI would be the same as reported ( $\$ 251$ million) but the NPV would drop to $\$ 43.3$ million due to the lack of sales of electricity at high prices. The resulting NPV/TCI ratio would be 0.17 .

Both the projected IRR and the NPV/TCI profitability ratios of the nuclear reactor alone- $5.8 \%$ and 0.51 , respectively - are much higher than those of the three full N-R HES scenarios because the TCI of the nuclear reactor alone is much lower due to the simplicity of the configuration. In the systems analyzed here, the nuclear reactor alone would receive most of the potentially available income because the value of the thermal product is higher than that of the electricity product during most of the year. The reason is that the price of electricity is projected to be set by the marginal cost of either natural gas combined cycle generators or combustion turbines during most of the year, and the value of electricity at those prices is lower than that of the thermal product. The IRR and NPV/TCI ratios for Scenario 1 would be higher than those for the other two scenarios because Scenario 1 does not include additional costs necessary for the storage required to generate a constant thermal product. The flexibility to switch between heat and electricity without that requirement allows the configuration to maximize projected income without being constrained by the cost of additional storage. The NPV/TCI ratio of Scenario 2 is estimated to be greater than that for Scenario 3 because the electric thermal storage unit is less expensive than the combined electric boiler and thermal storage unit. 
Table 15. Financial Results of Three Full N-R HES Scenarios Compared to Nuclear-Heat Only Configuration and Flexible Nuclear Power Configuration

\begin{tabular}{|c|c|c|c|c|c|}
\hline Scenario & $\begin{array}{c}\text { Nuclear } \\
\text { Reactor Only }\end{array}$ & $\begin{array}{c}\text { Nuclear } \\
\text { Reactor with } \\
\text { Thermal } \\
\text { Power Cycle }\end{array}$ & $\begin{array}{c}\text { \#1 } \\
\text { Electric Boiler }\end{array}$ & $\begin{array}{c}\text { \#2 } \\
\text { Electric } \\
\text { Thermal } \\
\text { Storage }\end{array}$ & $\begin{array}{c}\text { \#3 } \\
\text { Electric } \\
\text { Boiler- } \\
\text { Thermal } \\
\text { Storage }\end{array}$ \\
\hline $\begin{array}{l}\text { Thermal } \\
\text { Production }\end{array}$ & Constant & Variable & Variable & Constant & Constant \\
\hline \multirow[t]{9}{*}{ Configuration } & $\begin{array}{l}\text { Nuclear } \\
\text { Reactor } \\
\text { (167 MWt) }\end{array}$ & $\begin{array}{l}\text { Nuclear } \\
\text { Reactor } \\
\text { (167 MWt) }\end{array}$ & $\begin{array}{l}\text { Nuclear } \\
\text { Reactor } \\
\text { (167 MWt) }\end{array}$ & $\begin{array}{l}\text { Nuclear } \\
\text { Reactor } \\
\text { (167 MWt) }\end{array}$ & $\begin{array}{l}\text { Nuclear } \\
\text { Reactor } \\
\text { (167 MWt) }\end{array}$ \\
\hline & & + & + & + & + \\
\hline & & $\begin{array}{c}\text { Thermal Power } \\
\text { Cycle (50 } \\
\text { MWe) }\end{array}$ & $\begin{array}{c}\text { Thermal Power } \\
\text { Cycle (50 } \\
\text { MWe) }\end{array}$ & $\begin{array}{c}\text { Thermal Power } \\
\text { Cycle (50 } \\
\text { MWe) }\end{array}$ & $\begin{array}{c}\text { Thermal Power } \\
\text { Cycle (50 } \\
\text { MWe) }\end{array}$ \\
\hline & & & + & + & + \\
\hline & & & $\begin{array}{c}\text { Wind Power } \\
\text { Plant } \\
(50 \mathrm{MWe})\end{array}$ & $\begin{array}{c}\text { Wind Power } \\
\text { Plant } \\
(50 \mathrm{MWe})\end{array}$ & $\begin{array}{c}\text { Wind Power } \\
\text { Plant } \\
(50 \mathrm{MWe})\end{array}$ \\
\hline & & & + & + & + \\
\hline & & & $\begin{array}{l}\text { Electric Boiler } \\
\text { (50 MWe) }\end{array}$ & $\begin{array}{l}\text { Electric } \\
\text { Thermal }\end{array}$ & $\begin{array}{c}\text { Electric Boiler } \\
(100 \mathrm{MWe})\end{array}$ \\
\hline & & & & Storage & + \\
\hline & & & & (50 MWe) & $\begin{array}{c}\text { Thermal } \\
\text { Storage (250 } \\
\text { MWh) }\end{array}$ \\
\hline NPV (\$million) & $\$ 94.4$ & $\$ 61.3$ & $\$ 43.3$ & $\$ 30.1$ & $\$ 22.2$ \\
\hline IRR & $5.8 \%$ & $2.9 \%$ & $1.6 \%$ & $1.1 \%$ & $0.8 \%$ \\
\hline TCI (\$million) & $\$ 186$ & $\$ 251$ & $\$ 340$ & $\$ 339$ & $\$ 347$ \\
\hline NPV/TCI Ratio & 0.51 & 0.24 & 0.13 & 0.09 & 0.06 \\
\hline
\end{tabular}

Our analysis partially supports hypothesis 2 . For all three scenarios, the optimal configuration is the nuclear reactor generating the thermal product exclusively. Using the nuclear reactor to produce that thermal energy would avoid the 281,000 metric tons $\mathrm{CO}_{2}$ annually that a natural gas boiler generating the same heat would emit. We set the thermal product price at $\$ 7.55 / \mathrm{MMBtu}$, which is the price of a competing thermal product that could be produced by a natural gas boiler that pays the $2015 \mathrm{AEO}$ reference case natural gas prices $^{29}$ but does not pay a cost of carbon that would have an NPV of $\$ 0$. At that thermal product price, the nuclear reactor has an NPV of $\$ 94.4$ million, so we project that the nuclear reactor would be more profitable than a natural gas boiler even without a cost of carbon. With a $\$ 20$ /metric ton carbon dioxide equivalent $\left(\mathrm{CO}_{2} \mathrm{e}\right)$ cost of carbon, the NPV for the natural gas boiler is negative at $-\$ 82$ million. A higher cost of carbon of $\$ 186 /$ metric ton $\mathrm{CO}_{2}$ e further decreases the NPV for the natural gas boiler to $-\$ 700$ million. With NPVs of \$43.3 million, \$30.1 million, and \$22.2 million, for the three full N-R 
HES configurations, respectively, all of the N-R HES scenarios are found to have a higher rate of return than a natural gas boiler at the base case prices.

Our analysis partially supports hypothesis 3. N-R HESs can support resource adequacy for the electricity grid while maximizing production of the thermal product if the market structures incentivize that option. Figure 31 shows the price ranges at which all three scenarios of the N-R HESs would optimally receive capacity payments of $\$ 50 / \mathrm{kW}-\mathrm{yr}$. The optimal configurations of all three scenarios would receive a capacity payment when the thermal power cycle is selected (i.e., at higher electricity prices) and the thermal product's price is below $\approx \$ 9.00 / \mathrm{MMBtu}$. Note that the $\mathrm{x}$-axis on Scenario 1 is different from the other two axes.

Scenarios 2 and 3 also receive capacity payments in a price range with a higher thermal product price. In those ranges, the combination of capacity payments and the value of electrical energy are sufficient to incentivize generation of electricity to support resource adequacy; however, the value of the thermal product is not so high that electricity would optimally be converted to heat.

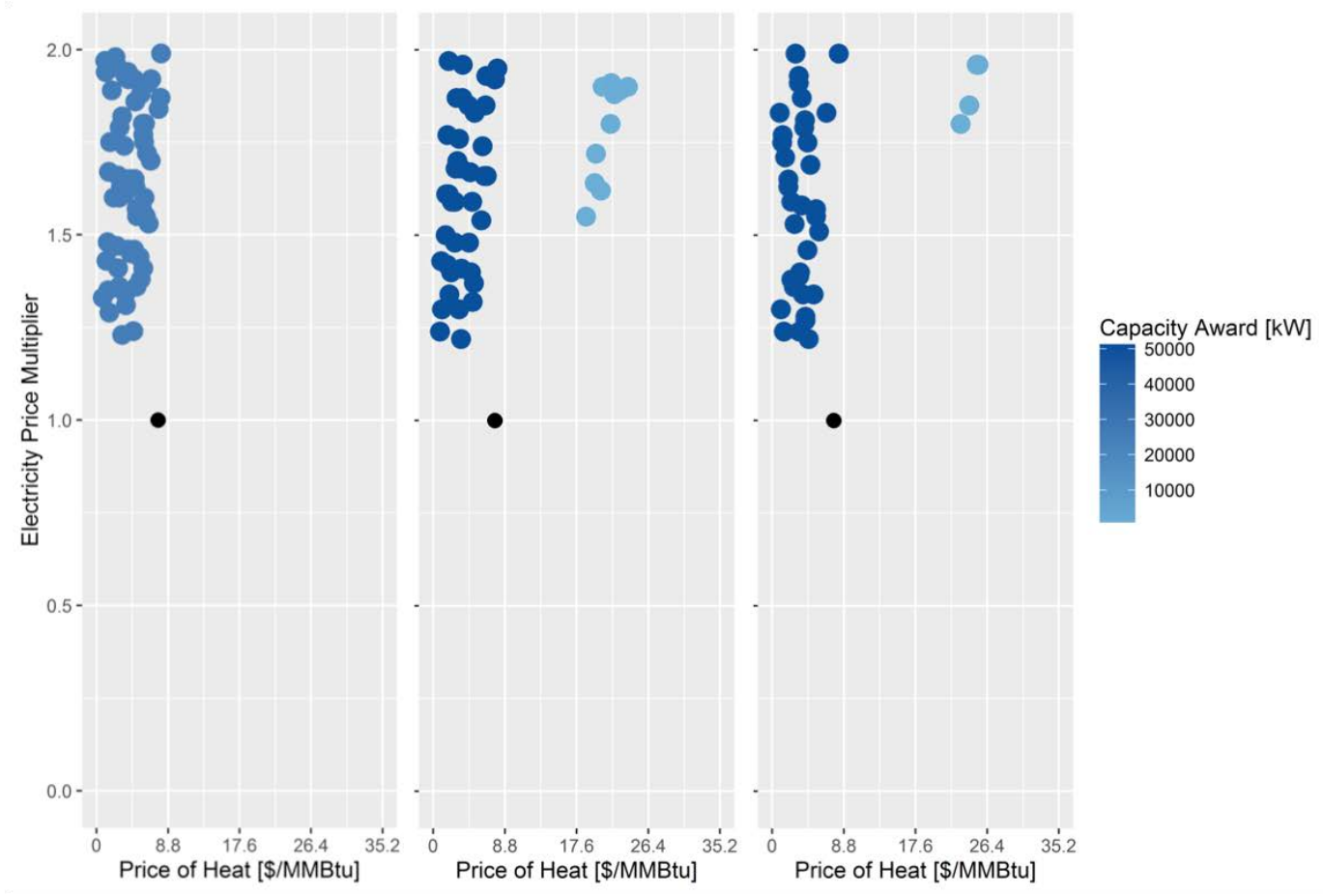

Figure 31. Optimal capacity payments awarded for the three scenarios at various heat prices and electricity price multipliers at $\$ 50 / \mathrm{kW}$-yr capacity payments

1 - Electric Boiler (left-with a different x-axis than the other two figures); 2 - Electric Thermal Storage (middle); 3 - Electric Boiler-Thermal Storage (right)

Solid black dot at $\$ 7.70 / \mathrm{MMBtu}$ and 1.0 indicates reference case prices of heat and electricity.

Our analysis partially supports hypothesis 4. N-R HESs would have a higher rate of return than uncoupled configurations because they can produce electricity when its price is high and the thermal energy product when the price of electricity is low. Figure 32 shows the annual electricity production for the optimal configuration and operations of all three scenarios at capacity payments of $\$ 50 / \mathrm{kW}$-yr. The orange dots indicate price ranges where the optimal configurations would sell both electricity and the thermal product over the course of the year 
depending upon the value of each in any given hour. Comparing Figure 32 to Figure 31 shows that electricity would be sold in price ranges larger than just where capacity payments are received; hence, in the price ranges where electricity is sold for some hours during the year, the N-R HES configurations would be more profitable than uncoupled configurations. Note that those price ranges do not include the base case electricity and thermal prices, so hypothesis 4 is not supported under those conditions.

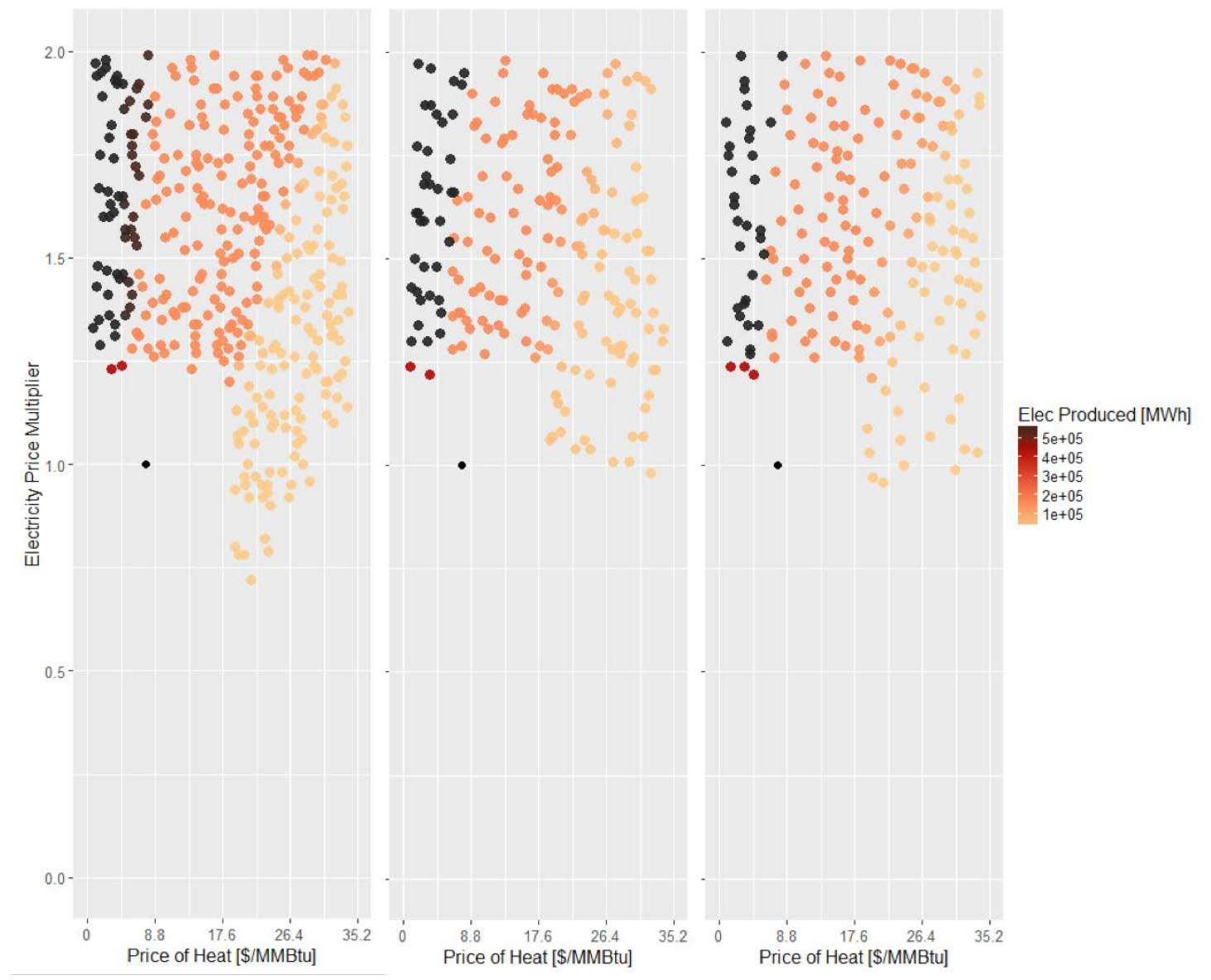

Figure 32. Optimal annual electricity production for the three scenarios at various heat prices and electricity price multipliers at $\$ 50 / \mathrm{kW}$-yr capacity payments

1 - Electric Boiler (left-with a different $x$-axis than the other two figures); 2 - Electric Thermal Storage (middle); 3 - Electric Boiler-Thermal Storage (right)

Solid black dot at $\$ 7.70 / \mathrm{MMBtu}$ and 1.0 indicates reference case prices of heat and electricity.

Our analysis partially supports hypothesis 5 . Additional wind generation would be profitable because the wind-generated electricity can be converted to valuable heat when the electricity price is low as long as the thermal product price is high and the annual average electricity price is not too low. In all three scenarios, the thermal product price had to be at least $\$ 15.00$ $\$ 19.00 /$ MMBtu before the optimal configurations included additional wind power plants at electricity costs below the costs at which wind power was profitable solely based on electric generation. Wind power appeared in the optimal configuration whenever the annual average electric price was more than $\sim 1.25$ times the projected annual average electricity price, yet under the high thermal product price referenced above, wind power would appear in the optimal 
solution at electric prices such that the annual average electricity price is as low as $0.95-1.0$ of the projected annual average electricity price. Thus, the hypothesis is supported in those ranges, but not when prices are closer to the reference prices for the thermal product.

This analysis shows that N-R HES configurations could be profitable, primarily because the projected cost of nuclear generation of heat is less than natural gas generation cost projections under the analysis assumptions. Nuclear generation of heat does not emit carbon dioxide so, with a cost of carbon, it would be more economical than natural gas generation. Even though nuclear generation of the thermal product exclusively is the optimal configuration at the base case electricity and thermal product prices, the benefits of the N-R HES's flexibility are apparent at higher electricity and thermal product prices. That flexibility allows the conceptual N-R HES to support resource adequacy on the grid if capacity payments are sufficient. Flexibility also allows the N-R HES to maximize profitability by switching between products depending upon the value of each product. 


\section{References}

${ }^{1}$ Energy Information Administration “2015 Annual Energy Outlook” DOE/EIA-0383(2015) (April 2015).

${ }^{2}$ Mark F. Ruth, Owen R. Zinaman, Mark Antkowiak, Richard D. Boardman, Robert S. Cherry, Morgan D. Bazilian, "Nuclear-renewable hybrid energy systems: Opportunities, interconnections, and needs," Energy Conversion and Management, Volume 78, February 2014, Pages 684-694, ISSN 0196-8904, http://dx.doi.org/10.1016/j.enconman.2013.11.030.

${ }^{3}$ Bragg-Sitton, et al. "Nuclear-Renewable Hybrid Energy Systems: 2016 Technology Development Program Plan,” Idaho National Laboratory Report INL/EXT-16-38165. (March 2016).

${ }^{4}$ M. Ruth, D. Cutler, F. Flores-Espino, G. Stark, T. Jenkin, T. Simpkins, J. Macknick. "The Economic Potential of Two Nuclear-Renewable Hybrid Energy Systems," NREL/TP-6A5066073 (2016).

${ }^{5}$ M. Ruth, D. Cutler, F. Flores-Espino, G. Stark, T. Jenkin, T. Simpkins, J. Macknick. "The Economic Potential of Two Nuclear-Renewable Hybrid Energy Systems," NREL/TP-6A5066073 (2016).

${ }^{6}$ M. Ruth, D. Cutler, F. Flores-Espino, G. Stark, T. Jenkin, T. Simpkins, J. Macknick. "The Economic Potential of Two Nuclear-Renewable Hybrid Energy Systems," NREL/TP-6A5066073 (2016).

${ }^{7}$ D.C. Stark, D. Curtis, R. Ibekwe, C. Forsberg. "Conceptual Design and Market Assessment of Firebrick Resistance Heated Energy Storage (FIRES) - Avoiding Wind and Solar Electricity Price Collapse to Improve Nuclear, Wind, and Solar Economics," International Congress on Advanced Nuclear Power Plants (ICAPP 2016) Paper 16622, San Francisco, California, April 17-20, 2016.

${ }^{8}$ M. Ruth, D. Cutler, F. Flores-Espino, G. Stark, T. Jenkin, T. Simpkins, J. Macknick. "The Economic Potential of Two Nuclear-Renewable Hybrid Energy Systems." NREL/TP-6A5066073 (2016).

${ }^{9}$ T. Simpkins, D. Cutler, K. Anderson, D. Olis, E. Elgqvist, M. Callahan, and A. Walker. "REopt: A Platform for Energy System Integration and Optimization," in Proc. $8^{\text {th }}$ International Conf. on Energy Sustainability, Boston, MA, 2014.

${ }^{10}$ M. Ruth, D. Cutler, F. Flores-Espino, G. Stark, T. Jenkin, T. Simpkins, J. Macknick. "The Economic Potential of Two Nuclear-Renewable Hybrid Energy Systems," NREL/TP-6A5066073 (2016).

${ }^{11}$ M. Ruth, D. Cutler, F. Flores-Espino, G. Stark, T. Jenkin, T. Simpkins, J. Macknick. "The Economic Potential of Two Nuclear-Renewable Hybrid Energy Systems," NREL/TP-6A5066073 (2016).

${ }^{12}$ Sullivan, Patrick, Cole, Wesley, Blair, Nate, Lantz, Eric, Krishnan, Venkat, Mai, Trieu, Mulcahy, David, and Porro, Gian.2015 Standard Scenarios Annual Report: U.S. Electric Sector Scenario Exploration (2015). http://www.nrel.gov/docs/fy15osti/64072.pdf

${ }^{13}$ U.S. Energy Information Administration. 2015 Annual Energy Outlook. DOE/EIA0383(2015). Washington, D.C.: U.S. Energy Information Administration, April. 
${ }^{14}$ Monitoring Analytics, LLC. (March 12, 2015) State of the Market Report for PJM 2014. http://www.monitoringanalytics.com/reports/PJM_State of the Market/2014/2014-som-pjmvolume2.pdf.

${ }^{15}$ Monitoring Analytics, LLC. (March 12, 2015) State of the Market Report for PJM 2014. http://www.monitoringanalytics.com/reports/PJM State of the Market/2014/2014-som-pjmvolume2.pdf.

${ }^{16}$ P. L. Joskow. "Capacity payments in imperfect electricity markets: Need and design," Utilities Policy 16, no. 3 (2008): 159-170.

${ }^{17}$ Monitoring Analytics, LLC. (March 10, 2016) State of the Market Report for PJM 2015. http://www.monitoringanalytics.com/reports/PJM_State of the Market/2015/2015-som-pjmvolume1.pdf.

${ }^{18}$ Annual Technology Baseline and Standard Scenarios. NREL. http://www.nrel.gov/analysis/data tech baseline.html.

${ }^{19}$ Annual Technology Baseline and Standard Scenarios. NREL. http://www.nrel.gov/analysis/data tech baseline.html.

${ }^{20} \mathrm{~S}$. Tegen, et al. 2011 Cost of Wind Energy Review. NREL/TP-5000-56266. March 2013. http://www.nrel.gov/docs/fy13osti/56266.pdf.

${ }^{21}$ H.J. Lang. "Cost Relationships in Preliminary Cost Estimates," Chem. Eng., 54(10), 117-121 (1947).

${ }^{22}$ D.C. Stark, D. Curtis, R. Ibekwe, C. Forsberg "Conceptual Design and Market Assessment of Firebrick Resistance Heated Energy Storage (FIRES) - Avoiding Wind and Solar Electricity Price Collapse to Improve Nuclear, Wind, and Solar Economics" International Congress on Advanced Nuclear Power Plants (ICAPP 2016) Paper 16622, San Francisco, California, April 17-20, 2016.

${ }^{23} \mathrm{http}$ //energy.gov/sites/prod/files/2014/08/f18/2014_SunShot Initiative Portfolio8.13.14.pdf.

${ }^{24}$ Energy Information Administration “2015 Annual Energy Outlook” DOE/EIA-0383(2015) (April 2015).

${ }^{25}$ M. Ruth, D. Cutler, F. Flores-Espino, G. Stark, T. Jenkin, T. Simpkins, J. Macknick "The Economic Potential of Two Nuclear-Renewable Hybrid Energy Systems" NREL/TP-6A5066073 (2016).

${ }^{26}$ MIT Energy Initiative "The Future of Natural Gas An Interdisciplinary MIT Study" (2011) Appendix 5. https://mitei.mit.edu/system/files/NaturalGas_Appendix5A.PDF

${ }^{27}$ Energy Information Administration "Frequently Asked Questions" (2016) https://www.eia.gov/tools/faqs/faq.cfm?id=73\&t=11 (accessed June 30, 2016).

${ }^{28}$ M. Ruth, D. Cutler, F. Flores-Espino, G. Stark, T. Jenkin, T. Simpkins, J. Macknick "The Economic Potential of Two Nuclear-Renewable Hybrid Energy Systems" NREL/TP-6A5066073 (2016).

${ }^{29}$ Energy Information Administration “2015 Annual Energy Outlook” DOE/EIA-0383(2015) (April 2015). 